UNIVERSIDAD NACIONAL DE LA PLATA

FACULTAD DE HUMANIDADES Y CIENCIAS DE LA EDUCACIÓN SECRETARÍA DE Posgrados

MAESTRÍA EN EDUCACIÓN

\title{
ELECCIONES DE LOS DOCENTES DE EDUCACIÓN FÍSICA DE ESCUELAS SECUNDARIAS FRENTE A LA OFERTA DE CAPACITACIÓN, EN LA PLATA (2007 - 2009)
}

Tesista: Guillermo Martín Almada

Director: Mg. Martín Roberto Legarralde 


\section{RESUMEN}

El tema de esta tesis son las elecciones que realizan los docentes de Educación Física de nivel secundario frente a la oferta de capacitación. Las preguntas que orientan esta tesis son: ¿Qué factores inciden en la elección de la oferta de capacitación que realizan los docentes? ¿Qué lugar ocupan estas elecciones de los docentes en el diseño de las políticas de capacitación? Para responder a estas preguntas se retoman las investigaciones que aportan datos y perspectivas sobre el peso de la normativa y el trabajo docente, y sobre la institucionalización de distintas modalidades de capacitación. Se aborda la elección de la capacitación desde la perspectiva de los actores, considerando la incidencia de sus contextos y la interacción con las culturas escolares en la que conviven y crean y desde la cual eligen opciones de capacitación. Para esto considero la perspectiva del saber docente y su desarrollo profesional en interacción con los aportes sobre la relación de los sujetos con el saber, reconociendo la implicancia de los sistemas de sentido que se construyen desde las características y la situación de quien elige.

La estrategia metodológica se centra en entrevistas a docentes de Educación Física, se complementa con entrevistas a responsables de la gestión de acciones de capacitación en el distrito de La Plata, y con el análisis de los documentos que regulan la capacitación en la provincia de Buenos Aires.

\section{Palabras Clave: FORMACIÓN DOCENTE, EDUCACIÓN FÍSICA, POLÍTICA EDUCATIVA.}

\section{Abstract}

The aim of this thesis is to analyze the choices made by Physical Education teachers at the secondary level in front of the training offer. The questions that guide this thesis are: What factors influence the choice of the training offer performing teachers? What is the place of these choices of teachers in the design of training policies? To answer these questions, this study takes data from other investigations about the normative and the teaching work, and from the institutionalization of different ways of training proposals. To analyze the choice made by teachers at the secondary level of the training offer, the approached of this thesis is from the perspective of the actors, considering the impact of their contexts and interaction with school cultures in which teachers live and from which they choose training options. For this, its consider the perspective of the teacher 
knowledge and professional development in interaction with the contributions on the relationship of individuals with the knowledge, recognizing the implication of meaning systems that are built from the social and educative characteristics of the teachers.

The methodological strategy focuses on interviews with Physical Education teachers, supplemented by interviews with managers of training activities in the district of La Plata, and the analysis of the official documents that regulates the training in the province of Buenos Aires.

Key Word: TEACHER EDUCATION, PHYSICAL EDUCATION, EDUCATION POLICY.

\section{RESUMO}

O tema desta tese são as eleições feitas pelos professores da Educação Física no nível secundário na frente da oferta formativa. As questões norteadoras desta tese são o que são os aspectos que influenciam a escolha da oferta formativa são? Qual o papel que estas eleições professorem na concepção de políticas de formação? Para responder a essas perguntas da pesquisa que fornece dado e perspectivas sobre o peso da regulamentação e do trabalho docente, bem como a institucionalização das diferentes modalidades de formação são retomadas.

A escolha do treinamento é abordada a partir da perspectiva dos atores, considerando o impacto de seus contextos e interação com a cultura escolar em que vivem e criar e da qual eles escolhem opções de treinamento. Para isso considerar o ponto de vista do conhecimento de professores e desenvolvimento profissional, em interação com as contribuições sobre a relação dos indivíduos com o conhecimento, reconhecendo as implicações de sistemas de significado que são construídos a partir das características e estado do seletor.

A estratégia metodológica centra-se em entrevistas com professores de Educação Física, complementados por entrevistas com responsáveis por gerenciar as atividades de formação no distrito de La Plata, e da análise dos documentos que regulam a treinamento na província de Buenos Aires.

Palavras-chave: FORMAÇÃO DE PROFESSORES, EDUCAÇÃO FÍSICA, A POLÍTICA DE EDUCAÇÃO. 


\section{Índice}

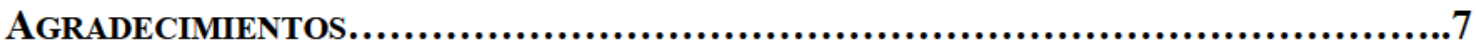

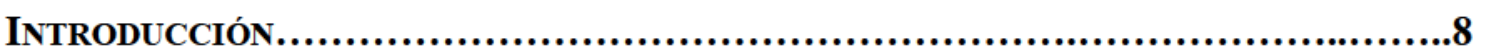

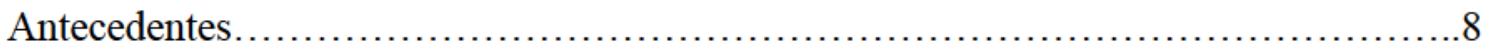

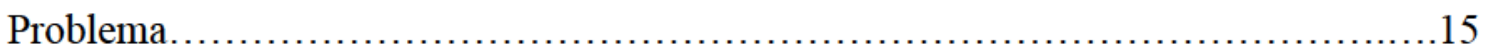

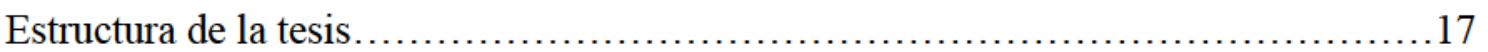

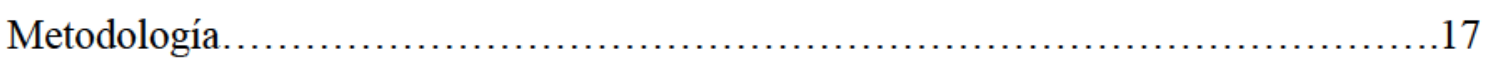

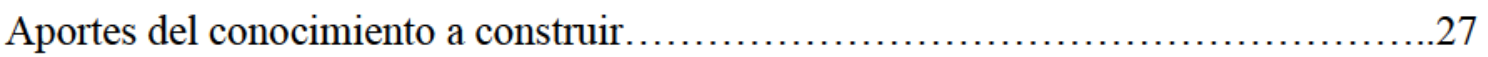

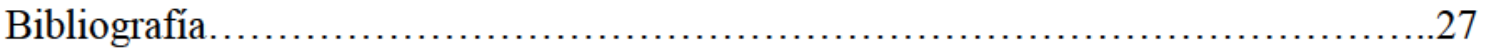

CAṔ́tulo I. Marco teórico conceptual........................................31

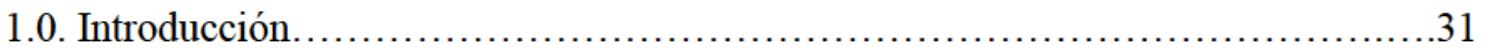

1.1. Los aportes del saber docente y el desarrollo profesional .......................31

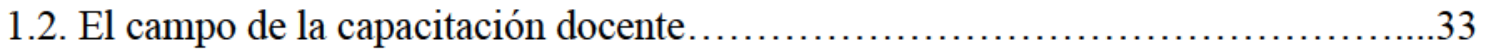

1.3. El habitus y la relación con el saber....................................... 36

1.4. Algunas consideraciones teóricas sobre las entrevistas........................... 38

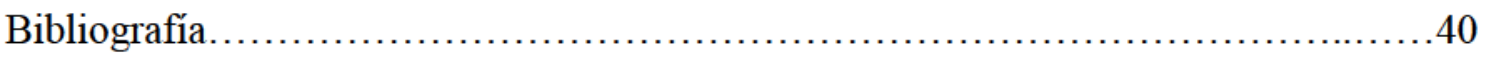

CAPítulo II. Algunas consideraciones sobre la capacitación docente. Viejos y nuevos condicionantes.............................................................

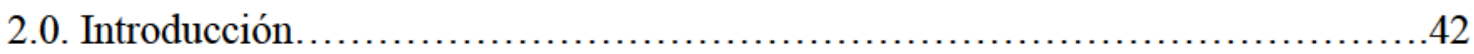

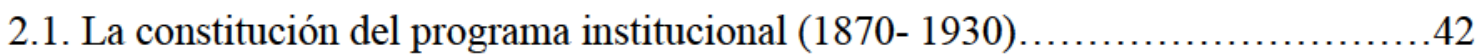

2.1.1. La capacitación en el momento de constitución del programa

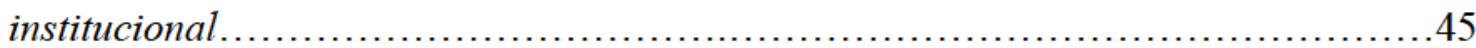

2.1.2. La formación docente en Educación Física en el momento de constitución del programa institucional ............................................................ 45

2.2. Aumento de la presencia de la disciplina Educación Física en el curriculum escolar

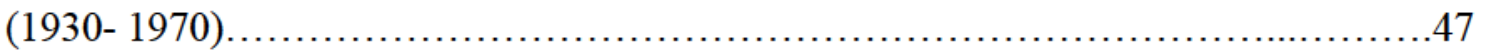

2.2.1. La expansión y fortalecimiento de la regulación del trabajo y la formación

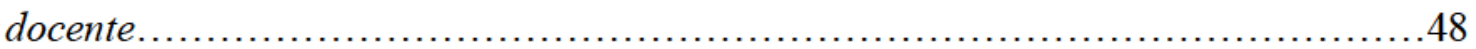

2.2.2. La capacitación y el surgimiento de los expertos ..............................49 
2.2.3. La profesionalización de la Educación Física en el nivel universitario....

2.3. Las desregulaciones del programa institucional en la lógica de reducción del Estado

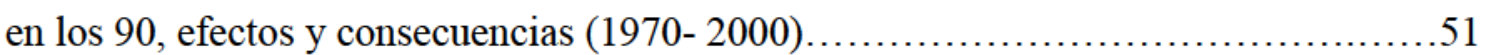

2.3.1. La estructura de la política de capacitación en la década de 1990, su

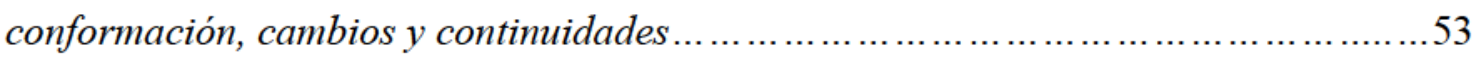

2.3.2. La lógica de la acreditación vs la lógica del puntaje ...............................54

2.3.3. De la vocación a la profesión. La reinterpretación del concepto de

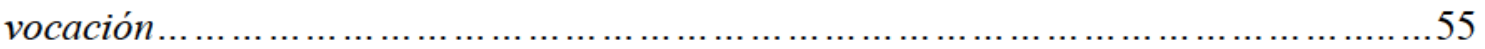

2.3.4. El "Congreso de Educación Física" como una particularidad en la oferta de

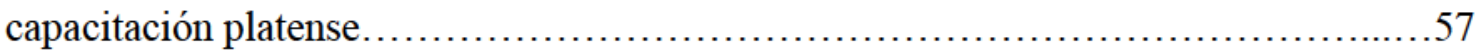

2.4.1. La Ley de Educación Nacional y los cambios y continuidades en la

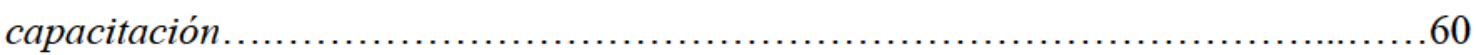

3.4.2. La implicancia en la provincia de Buenos Aires...............................61

2.4.3. Expansión, regulación y oficialización de la capacitación: su impacto en la

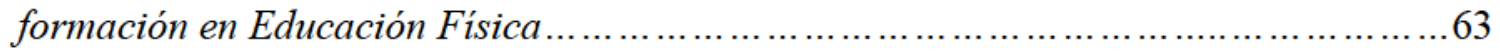

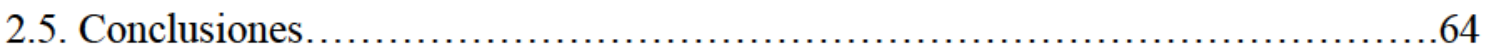

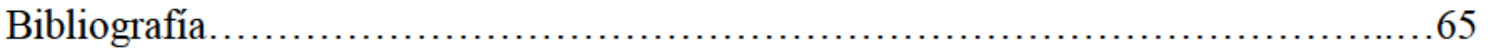

CApítulo 3. La elección de la oferta: múltiples intereses, posibilidades y

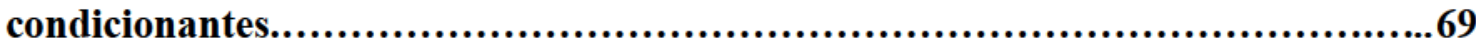

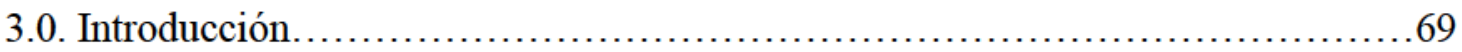

3.1. La elección frente a la tensión entre la necesidad de puntaje y la profesionalización. ...........................................................69

3.2. Las instituciones de formación de profesorado en La Plata y la selección de los

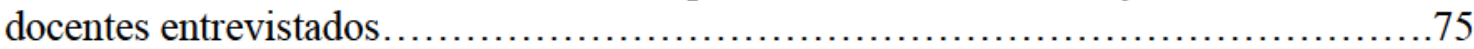

3.3. El rango del saber en el curriculum de la formación de profesorado, la vinculación con la práctica y la elección de la capacitación........................................ 76 3.3.1. La valoración de la formación inicial respecto a las necesidades de

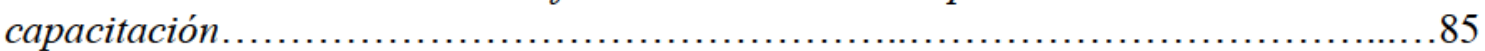
3.3.2. El vínculo entre vivencias deportivas y la elección de los contenidos para especializarse ................................................................ 87

3.4. La incidencia del formato de la oferta en la elección de la

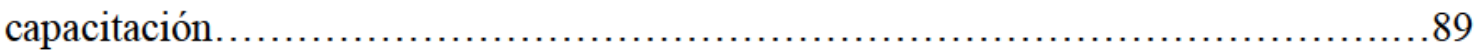

3.4.1. Los formatos y las posibilidades de capacitación ..............................90 3.4.2. Los cambios en los formatos de capacitación y las demandas de los docentes. 
3.4.3. La vinculación entre la capacitación y la carrera docente ¿desde qué oferentes?.

3.5. La incidencia del contenido y los oferentes.

3.5.1. El prestigio del oferente y su incidencia en la elección ...........................100

3.5.2. La difusión de la oferta, las fuentes de información............................100

3.5.3. La difusión de la oferta, las fuentes de información............................100

3.6. Las instituciones y el grupo de pares...................................... 102

3.6.1. El grupo de pares y su incidencia en la elección ...............................102

3.6.2. La institución escolar, el vínculo entre las instituciones y las posibilidades de capacitación de los docentes.................................................... 104

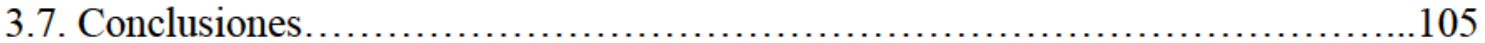

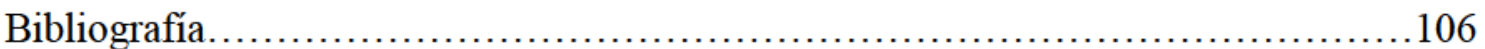

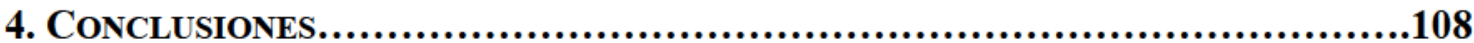

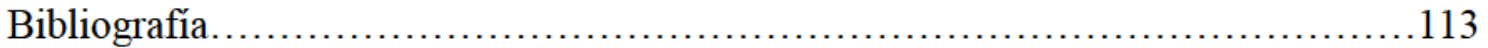




\section{Agradecimientos}

A mi mujer María Eugenia Vicente porque desde el amor me orientó, acompañó y participó en la elaboración de esta tesis y entre medio dio a luz a María Inés nuestra hija, ellas me dieron el impulso para poder terminar de una buena vez.

A mis padres que siempre me alentaron a estudiar

A Martín Legarralde, por todo lo que me enseñó, por la generosidad, el tiempo y el compromiso que puso en este trabajo.

A Alicia Inés Villa por su apoyo y orientación.

A quienes me leyeron, corrigieron y acompañaron a Leandro Stagno, María Angélica Cabello y Verónica Cheli.

A la Universidad Nacional de La Plata y al Programa de Formación de Recursos Humanos en Posgrado para docentes concursados de universidades públicas., dependiente de la Secretaría de Políticas Universitarias (SPU) del Ministerio de Educación de la Nación, por facilitarme las condiciones institucionales necesarias para llevar a cabo esta tesis y por la beca que me otorgaron para costear los costos de la Maestría.

A la Pontificia Universidad Católica de Río Grande do Sul por su disposición y recepción en el marco de la beca intercambio e investigación. 


\section{INTRODUCCIÓN}

El tema que abordo son las elecciones de la oferta de capacitación estatal y privada, efectuadas por los docentes de educación física del nivel secundario del sector estatal, en el distrito de La Plata entre el 2007 y 2009.

Entre esos años la Dirección General de Cultura y Educación (DGCyE) decidió priorizar la capacitación de oferta estatal. Esa priorización se expresó en un mayor puntaje $\mathrm{e}^{1}$ concedido a los cursos ofrecidos por el Estado provincial a través de los Centros de Capacitación, Información e Investigación Educativa (CIIE) ${ }^{2}$. Al respecto se analiza en qué medida el cambio en el puntaje incidió en la elección de los docentes y cómo impactó este cambio en las relaciones de los docentes con el saber.

La intención de esta tesis es producir conocimiento sobre el conjunto de los factores y situaciones que inciden en la relación de los docentes con la circulación del saber sobre la enseñanza, en la forma particular de acciones de capacitación. Para esto reúno datos que den cuenta de la intersección de distintos aspectos, entre los que se destacan: las

1 De acuerdo con el régimen laboral establecido por el Estatuto del Docente de la Provincia de Buenos Aires (Ley 10579), el puntaje es una unidad de medida para valorar títulos, antecedentes, certificaciones y otro tipo de actividades acreditadas por los docentes o aspirantes a la docencia.

El puntaje de los Listados Oficial, 108A, 108A in fine, 108B y 108B in fine y Emergencia se usa como orden de mérito para acceder a un cargo u horas en el sistema estatal. La persona que poseyera mayor puntaje tiene prioridad a tomar el cargo u horas que se ofrece en los Actos Públicos.

El artículo $\mathrm{N}^{\circ} 60$ del Estatuto del Docente indica que el valor final de puntaje de un docente, resulta una suma de varios valores, según los siguientes incisos:

Art. 60 Inciso Descripción Puntaje min/max A.VALOR DE TITULO 1 a 25 B. AÑO DE EGRESO 0,25 a 2,50 C. PROMEDIO DE TITULO 0 a 0,20 D. ANTIGÜEDAD EN LA RAMA 0 a 5 DESFAVORABILIDAD EN LA RAMA 0 a 2,50 E. ANTIGÜEDAD EN EL CARGO0 a 2,50 DESFAVORABILIDAD EN EL CARGO 0 a 1 F. CALIFICACIONES0 a 2 G. BONIFICANTES0 a 10 Se llama bonificantes al puntaje otorgado por los cursos de capacitación, $\mathrm{u}$ otros títulos. de más de $30 \mathrm{hs}$, u otros títulos.

2 Los CIIEs son instituciones que actúan como organismos descentralizados de la Dirección de Capacitación (actualmente se denomina "Dirección de Formación Docente Continua"), coordinan y desarrollan la oferta regional de formación docente continua en cada distrito.

La provincia de Buenos Aires, dividida en 25 regiones educativas, cuenta como planta de los CIIE con Equipos Técnicos Regionales (ETR) integrados por especialistas en las Disciplinas y Áreas Curriculares, en las Ciencias de la Educación y por Bibliotecarios, que capacitan en todas las áreas y en los niveles del Sistema Educativo, y dan -con un enfoque regional- respuesta a la formación docente continua.

Estos Equipos Regionales, junto con el Equipo Técnico Central, diseñan y ejecutan los proyectos de capacitación, teniendo en cuenta la política educativa y las prioridades y acuerdos que se realizan con los equipos de los distintos niveles de enseñanza. 
características de la estructura de capacitación provincial, la metodología y el contenido de las opciones elegidas, el momento del ciclo vital de los profesores, las características de su socialización laboral y las características de su formación inicial. Estos aspectos inciden en la relación particular de los sujetos con el saber y vinculan aspectos colectivos y generales de la capacitación con elementos particulares de la subjetividad de quienes eligen.

\section{Antecedentes}

Los trabajos que se presentan a continuación analizan la formación docente continua en la Argentina a través de las reformas de la década de 1990 para luego avanzar en una perspectiva más actual, advirtiendo las modificaciones sobre el lugar de los docentes y las escuelas en las propuestas y los sentidos que adquiere la capacitación.

Una posible entrada al tema es considerar los trabajos que analizan la construcción de sentidos de la capacitación. Si bien nos referimos a la elección de la oferta, en primera instancia hay que considerar que la capacitación no se restringe a ser solo un bien de consumo (Devalle de Rendo, 1997) sino que lo excede, como señala Cappellacci "Actualmente, los procesos de elección y definición de una carrera, un trabajo, un estilo de vida, tienen tal nivel de complejidad y dinamismo que no pueden realizarse de una vez y para siempre, en forma permanente se realizan elecciones que modifican la historia personal" (2008: 191). Para dar cuenta de los sentidos de la capacitación para los docentes es preciso hacer un recorrido para considerar los elementos que influyen en la elección de determinadas opciones de capacitación.

Al mismo tiempo hay que considerar los sentidos con los que se conciben las políticas de capacitación. Al respecto, Birgin se refiere a la "inflación" que las mismas poseen señalándolas como una solución mágica, así "el discurso sobre la formación docente (sobre todo la post inicial) la plantea como varita mágica que logrará resolver las cuestiones más simples y también las más dificiles a las que se encuentran afectadas la sociedad y las escuelas" (Birgin, 2012; 14)

La formación docente post inicial es parte de un complejo entramado de políticas docentes que incluyen la formación, la carrera, las condiciones laborales, la participación, entre otras, y se intersectan con políticas de Estado o empleo.

El trabajo de Serra "El campo de la capacitación docente" (2004) se apoya en la teoría de los campos de Bourdieu. Hace un corte transversal analizando la implementación de la Ley Federal de Educación (LFE) y el desarrollo de la Red Federal de Formación 
Docente Continua (RFFDC) planteando un nuevo mapa de la capacitación, considerando la noción de habitus para comprender la movilidad de los sujetos en el campo.

Instala el análisis de las posibilidades de profesionalización a través de las políticas de formación docente entre 1994 y 1999, teniendo en cuenta las características de esta política, las condiciones laborales sobre las que se implementó y las dinámicas de funcionamiento de las estructuras de capacitación vigentes. Sobre este último punto reconstruye la perspectiva de los docentes en relación a la capacitación. Serra sostiene que en el terreno de la formación docente el problema de la capacitación está asociado al desarrollo de dispositivos de intervención que mejoren la práctica docente. Respecto a la selección del dispositivo "curso" como formato hegemónico de la capacitación señala las limitaciones de este modelo de capacitación para el fortalecimiento de la formación docente y el mejoramiento de la enseñanza.

Dos elementos de análisis importantes presentes en muchos de los trabajos que abordan la capacitación docente en la Argentina son el trabajo y la carrera docente, poniendo el foco de análisis en ambos o mayormente en uno de ellos.

Los estudios que se refieren a la capacitación vinculada con el trabajo docente, en general hacen referencia a la elección de la profesión en un contexto de marcada desvalorización social y económica del trabajo docente. En esta línea se inscribe el Informe final del IIPE (2000) que se refiere las características actuales de la carrera docente como una "profesión de paso", que permite cubrir la necesidad de conseguir un empleo para dedicarse luego a otros estudios y no como una proyección laboral en si a la cual dedicarle un largo tiempo, algo que también señalan Diker y Terigi (1997) en $L a$ formación de maestros y profesores: hoja de ruta.

En esta línea también se encuentran los trabajos que dan cuenta de las condiciones de trabajo docente. El estudio de Poliak (2004) ofrece una mirada sobre los contextos de trabajo de la escuela pública remitiendo a la trama de la desigualdad educativa una variable contextual que tomo en cuenta en esta tesis.

Los estudios que hacen referencia a la carrera docente consideran la capacitación vinculándola con la normativa que la regula. La oferta de capacitación estuvo moldeada por la normativa respecto al valor de la certificación en lo referente a la carrera docente, y a los cambios que atañen a la política educativa. Por este motivo al hablar de capacitación es común encontrar que la mayoría de los trabajos consideran al Estatuto 
como una variable objetiva de gran peso (Serra, 2004; Birgin, 1999 y 2012; Davini, 1995; Diker y Terigi, 1997; Diker y Serra, 2008).

Tanto la carrera como el trabajo docente actúan como variables intervinientes en la formulación de una política pública de capacitación.

Imen (2002) afirma: "Múltiples declaraciones, documentos e informes oficiales reclaman la profesionalización docente, una meta compleja, en este sentido es preciso considerar los aspectos taxonómicos del término "profesionalización" y el de "formación docente continua" advirtiendo la dirección precarizadora de las políticas laborales en el campo educativo." Estos conceptos resultan relevantes para analizar la retórica de la política educativa.

La LFE, sancionada en abril de 1993, generó una estructura de capacitación desarrollada a través de la RFFDC que inscribió sus formulaciones explícitas en el marco de la profesionalización docente y en el de la formación docente continua. Los debates en torno a la profesionalización docente han superado varias instancias y visiones impulsadas desde la política educativa. Así, de acuerdo con Serra (2004), es posible diferenciar:

a. La visión de la docencia como una semi profesión, que toma como marco de referencia a las profesiones libres. Desde esta perspectiva el término "profesional" refiere a unas prácticas fundadas en una ideología legitimadora que reivindica para los profesionales un carácter elitista y la visión de la profesionalización como producto histórico social, que considera al concepto de profesión vinculada con la cuestión del poder relativo de los docentes frente a otros actores, considerando que el concepto de profesión no es neutro ni científico y que las profesiones son legitimadas en el contexto social en el que se desarrollan (Imbernón, 1994).

b. La profesionalización como desarrollo profesional se opone a la visión de la docencia como semi profesión. Busca definir la profesionalidad a partir de las características de la propia tarea docente, y es compatible con la segunda visión, considerando a la profesión como un proceso, como el desarrollo de una cultura profesional, que incluye las particularidades del trabajo docente y la multiplicidad de situaciones y actividades que comprometen diariamente a los docentes.

Diker y Terigi caracterizan la tarea docente como: "una tarea múltiple que rebasa la definición normativa de la docencia como enseñanza; que puede desempeñarse en una variedad de contextos (rural, urbano, urbano marginal, hospitales, prisiones, etc.), que 
está atravesada simultáneamente por múltiples dimensiones, lo cual crea condiciones de inmediatez para el accionar docente, y que está caracterizada por un alto grado de indeterminación, y por tanto de imprevisibilidad. (...) supone una implicación personal y un posicionamiento ético, en tanto una práctica que se realiza en relación a valores". (Diker y Terigi, 1997: 169). Desde esta perspectiva surge la necesidad de fortalecer la capacidad de los docentes para enfrentar su tarea cotidiana consecuentemente con el aprendizaje de sus alumnos.

El trabajo de Feldfeber "Profesionalización docente y reforma educativa en la Argentina" (2004) aborda el discurso de la reforma de 1993 poniendo énfasis en que la necesidad de profesionalizar a los docentes puede ser entendida como una política de regulación y control, que ha reducido las posibilidades de un ejercicio autónomo de la profesión. La reforma estuvo centrada en el cambio curricular, a través de la implantación de cambios diseñados por equipos técnicos, visualizando al colectivo docente como uno de los principales obstáculos del proceso reformista, por lo cual debían ser "reconvertidos".

El trabajo retoma la idea que desarrolla Popkewitz (1994) que considera que las ideas de cambio para la formación docente centradas en la noción de profesionalización constituyen nuevos mecanismos de control social, reforzando la individuación de los docentes como sujetos sociales, lo que asocia la capacitación con la noción de deber o mandato.

Si bien Feldfeber toma diversas fuentes para su marco teórico, en esta tesis me interesa retomar que el mismo se ubica en el marco de análisis de las políticas públicas, lo que implica la lucha por el sentido y la orientación de las políticas, el establecimiento de reglas y la distribución de los recursos, tanto desde su fase de formulación como implantación. Las políticas públicas refieren a procesos decisionales que tienen su centro en el espacio político del Estado (Tenti Fanfani, 1991).

La autora analiza las tensiones, articulaciones y contradicciones que se producen en el proceso de definición e implantación de las políticas de formación continua, y hace una interesante advertencia sobre los estudios que restringen el campo de la política educativa al concepto de actividad, que centran su atención en el conjunto de medidas a aplicar sin hacer referencias a las relaciones de poder y de lucha en el campo de la educación y los intereses ideológicos que orientan la política educativa. Estos estudios empobrecen el análisis y tienden a enmascarar la realidad. Una perspectiva más amplia de análisis de la política pública no se restringe a comprender la política de formación 
docente como una derivación mecánica de las demandas y las exigencias del contexto sino que debería advertir que las instituciones y los sujetos resignifican los programas de la política educativa en el ámbito de las prácticas.

Un trabajo que profundiza esta mirada y advierte sobre el lugar de los docentes frente a las reformas es el de Ziegler (2001). La autora analiza las resignificaciones que realizan los docentes a partir de la reforma curricular, visualizándolos como actores claves para vehiculizar las propuestas, pero considerando que estas no son traducidas de manera uniforme, sino que su interpretación y puesta en práctica se realiza a través de procesos mediados conflictivos e impredecibles.

Denota una brecha entre las formulaciones y las prácticas dando cuenta de la productividad de las reformas. Considera los desplazamientos en sus significados y advierte las contradicciones que se generan en las instancias de resignificación. Por esto señala que los principios de las reformas no se reproducen de manera lineal sino que hay un proceso de traducción en la recepción de los docentes y las escuelas. Este trabajo resulta interesante para esta tesis porque genera los siguientes interrogantes: ¿en qué medida estas resignificaciones han influenciado la organización de la oferta de capacitación?, y al mismo tiempo ¿cómo estas resignificaciones han influenciado la elección de la oferta de capacitación por parte de los docentes?

Los trabajos presentados aportan elementos para el análisis de las implicancias de la LFE sobre la formación continua en la Argentina. Para del recorte temporal seleccionado --los años 2007 a 2009-- cobran relevancia la Ley de Educación Nacional (2006) y la Ley Provincial de Educación (2007), las cuales modifican el contexto normativo formulado por la LFE. Al respecto, el trabajo de Diker y Serra (2008) presenta los cambios que implican estas reformas sobre la capacitación, en especial a través de la incorporación de los conceptos de "educación integral" y "desarrollo profesional". El trabajo analiza la estructura de capacitación nacional y marca continuidades y rupturas a partir de la creación del $\mathrm{INFD}^{3}$ respecto de su antecesora, la RFFDC. Cabe advertir que no existen trabajos que analicen sus consecuencias en términos de las políticas de formación docente.

3 Instituto Nacional de Formación Docente 
Para presentar los cambios en las orientaciones de los modelos de formación continua el trabajo de Finocchio y Legarralde "Modelos de formación continua en América Latina" (2006) advierte que en la región las reformas educativas tuvieron orientaciones similares, aunque estuvieron atravesadas por culturas políticas, institucionales e históricas específicas, lo que arroja como resultado configuraciones diferentes en las reformas de cada país.

Los autores plantean una distinción entre los modelos pensados desde la oferta respecto a los modelos surgidos desde la demanda. Es posible advertir que esta división fue dejando lugar a modelos que combinan ambas posiciones ya que si bien los contenidos pueden estar originados desde la oferta, pueden al mismo tiempo atender al carácter situado de las demandas. Lo cual implicó un cambio hacia nuevos modos en la forma de definir los contenidos y los dispositivos de la formación continua a partir de la construcción de problemas y la identificación y priorización de las necesidades de maestros y escuelas.

En los países en donde se han desarrollado los centros de maestros, como el caso mexicano, se presentan como una estrategia para evitar el divorcio entre lo que las administraciones ofertan para la formación y la propia demanda de los docentes. Tal fue el caso del ProNAP (Programa Nacional de Actualización Profesional) en México. El análisis de este programa es abordado en el trabajo de Finocchio "La Formación de Maestros Mexicanos en Clave ProNAP (1996 - 2006)". La autora reconoce que existe un claro rumbo trazado en el sistema de formación continua mexicano, que reconoce progresivamente a los docentes como actores y no exclusivamente como destinatarios de estas actividades.

En esta línea, Finocchio y Legarralde expresan: "se ha iniciado un movimiento y reconocimiento de buenas prácticas y experiencias educativas lo que ha dado lugar a una agenda más horizontal en la que los contenidos de la formación continua han sido reorientados para el intercambio de experiencias, la narración y la escritura de experiencias por los propios docentes" (Finocchio y Legarralde, 2006: 20).

En Argentina entre el 2000 y 2001 se dio inicio a una experiencia de escritura a cargo de los Centros de Actualización e Innovación Educativa (CAIE) ubicados en todo el país, dando cuenta de un redireccionamiento del formato tradicional de formación docente: el "curso". Los talleres generales de actualización en México, la red de maestros de Chile, la expedición pedagógica nacional en Colombia se alinean en este sentido de escucha a la voz de los docentes y ampliación de la oferta. 
Los trabajos de Finocchio y Legarralde (2006) y Finocchio (2006) marcan un antecedente respecto a lo que señala Vezub (2010) en relación a los cambios en las orientaciones de la agenda y los modelos de las políticas de formación docente continua en la región, que denotan un pasaje que va desde la centralización y la homogeneización de las propuestas de perfeccionamiento hacia una perspectiva más situada con la implementación de dispositivos de formación continua centrados en las escuelas que brinden la posibilidad de movilizar trayectorias docentes y permitan reformular las prácticas profesionales.

El relevamiento de estos estudios resulta útil para comprender algunas de las características del modelo de formación continua en nuestra región desde una perspectiva más amplia recobrando coordenadas y marcos de referencia que ayudan a encauzar este análisis.

Al volver sobre la pregunta que se hacen Devalle de Rendo y Vega (1997) “¿qué significa la capacitación como práctica?" es posible abrir otros interrogantes: ¿es una gestión administrativa, un mandato, un deber, o en verdad es una práctica, una necesidad para mejorar o facilitar la tarea docente? Es difícil pensar que la capacitación no responda a estas cuestiones afirmativamente. Es decir que es muchas cosas, porque se define y moldea desde distintos ángulos. Por eso el sentido de esta tesis es considerar qué elementos de estos interrogantes poseen mayor presencia en este campo específico.

\section{El problema}

Considerar la decisiones de los docentes que elijen opciones de capacitación implica pensar en la influencia de distintos aspectos: la estructura de la política de capacitación provincial, el valor del puntaje, el momento del ciclo vital de los profesores, los costos, la regulación de la carrera docente, el contenido y la metodología de la propuestas elegidas. Estos aspectos parecen influir de manera interdependiente en las elecciones.

A partir de la interdependencia de estos aspectos planteo la siguiente hipótesis: la elección individual de opciones de capacitación no se encuentra solo asociada a los contenidos que se vinculan con la práctica y con la incidencia que el puntaje tiene para la carrera docente, sino que están involucrados otros elementos vinculados con las características y la situación de quien elige. Desde esta perspectiva cobran peso en el análisis de la elección: el momento particular de la carrera docente, la biografía del docente, las características de su formación inicial, las particularidades de su 
socialización laboral y las características particulares del marco que plantea la política pública de capacitación de donde se elige.

Durante el período seleccionado (2007 a 2009) estos aspectos que parecen incidir de manera interdependiente, interactuaron con los cambios que a partir del 2008 se sucedieron en la valoración de puntaje que el estado provincial le asigna a la oferta pública frente a la generada por otros oferentes. También se relaciona con las variantes metodológicas de la oferta asociadas a la expansión de la educación superior, que en nuestro país resultó del crecimiento de las carreras de posgrado a partir de la década de 1990, lo que implicó también pensar el peso que adquiere la acreditación ${ }^{4}$ en la valoración del oferente al momento de la elección.

Así, las preguntas que orientan este trabajo son: ¿cuáles son los aspectos que inciden en la elección? ¿Qué lugar ocupan las decisiones de los docentes dentro de las actividades de capacitación? Y ¿Qué sentido/s tiene una acción de capacitación para quien la realiza?

El objetivo general es analizar los factores que inciden en la elección de la oferta de capacitación estatal y/o privada, que realizan los docentes de educación física pertenecientes al sector estatal, que se desempeñan en escuelas secundarias del distrito de La Plata. De éste se derivan los siguientes objetivos específicos:

- Analizar la incidencia de la antigüedad docente y el ciclo vital en la elección de la oferta de capacitación que realizan los docentes de educación física pertenecientes al sector público que se desempeñan en escuelas secundarias del distrito de La Plata, durante los años 2007 a 2009.

- Analizar la incidencia de la normativa sobre la carrera docente y el trabajo docente, en la elección de la oferta de capacitación pública o privada, en esos mismos docentes, -Analizar las características de la estructura de capacitación provincial y su incidencia en la valoración del oferente. Para ello, se considera la interacción entre: el puntaje, la cultura escolar y la acreditación del oferente en la elección de la oferta de capacitación que realizan estos docentes.

\footnotetext{
$4 \quad$ La acreditación refiere el reconocimiento formal que poseen las instituciones para ofrecer acciones de capacitación. Consejo Federal de Cultura y Educación, (1994), Documento A-9. "Creación de la Red Federal de Formación Docente Continua"
} 
-Analizar la incidencia de las características de la formación inicial desde la perspectiva de los modelos dominantes y emergentes y su incidencia en la elección de la oferta de capacitación.

- Analizar la incidencia de la práctica recurrente de determinados deportes en la elección de la oferta de capacitación pública o privada, en los docentes de educación física pertenecientes al sector público de escuelas secundarias del distrito de La Plata, durante los años 2007 a 2009.

\section{Estructura de la tesis}

La tesis está estructurada a partir de una introducción, tres capítulos y un cierre. La introducción refiriere a la presentación del tema y problema y a la estrategia de investigación empleada. El primer capítulo se aboca a la presentación del marco teórico y conceptual desde la cual se aborda el problema. El segundo capítulo --de carácter histórico-- analiza la organización del campo de la capacitación docente en la provincia de Buenos Aires, y en particular los cambios en la estructura de capacitación provincial desde el año 2008 apoyado en el análisis de documentos. El tercer capítulo se centra en el análisis de las entrevistas a partir de las categorías y el marco que se presentan en los capítulos anteriores. Por último el cierre presenta las conclusiones del trabajo y los interrogantes que se desprenden del mismo.

\section{Metodología}

La tesis se basa en una estrategia metodológica que constituye el "imaginario científico" (Becker, 2009) a través del cual se intenta responder al problema de investigación, sustentado en una serie de procedimientos, técnicas, hipótesis y teorías. Para ello, busca reconstruir las siguientes dimensiones del problema:

\section{- Las características del campo de la capacitación docente a lo largo de la historia} (1870 - 2009): el objetivo es entender cómo se conformó la estructura de la capacitación en la Argentina y en particular en la provincia de Buenos Aires.

La intención es analizar algunos cambios de las políticas de capacitación, implicados en procesos de reformas e innovaciones escolares considerando los viejos y nuevos condicionantes que influyen en las políticas de capitación. Tomo para la perspectiva de análisis los conceptos "programa institucional" (Dubet, 2004 y 2006), de "cultura escolar" (Viñao, 2002), "gramática escolar" (Tyack y Cuban, 1995) y aportes de otros 
autores que han abordado la temática de la capacitación, los sistemas de capacitación, el saber docente y las políticas educativas del período reciente.

- La estructura de la politica de capacitación: se realiza en esta tesis un trabajo con análisis de documentos, que en su mayoría proceden de la Dirección de Capacitación de la Provincia de Buenos Aires ${ }^{5}$. Estos documentos tienen una fuerte vinculación con el marco regulatorio de la carrera docente en lo que respecta a la normativa de formación docente, por lo cual se hace necesario el estudio del Estatuto del Docente de la Provincia de Buenos Aires ${ }^{6}$.

- Las características socio profesionales de los docentes de educación física que eligen los cursos de capacitación: de la escuela secundaria del sector público del distrito de La Plata. Para esto me apoyo en datos estadísticos extraídos del Censo Nacional de Docentes del año 2004, con la intención de precisar la cantidad de docentes que hay en el distrito, la edad, el nivel de formación, entre otras características.

- Los procesos internos vinculados a la elección de la oferta de capacitación: a través de entrevistas semi estructuradas a los docentes con preguntas sobre las siguientes dimensiones e indicadores: 


\begin{tabular}{|c|c|}
\hline Dimensiones & Indicadores \\
\hline Perfil del docente & $\begin{array}{l}\text { - Edad } \\
\text { - Antigüedad docente } \\
\text { - Antigüedad en el nivel } \\
\text { - Institución donde llevó a cabo su formación inicial. } \\
\text { - Años en los que llevó a cabo su formación inicial. } \\
\text { - Instituciones donde se desempeña actualmente } \\
\text { - Caracterización de los grupos de alumnos a su cargo. }\end{array}$ \\
\hline Capacitaciones realizadas & $\begin{array}{l}\text { - Cantidad } \\
\text { - Formato: curso o carrera } \\
\text { - Costos } \\
\text { - Concreción } \\
\text { - Carácter (presencial semi presencial o a distancia) } \\
\end{array}$ \\
\hline $\begin{array}{l}\text { Capacitaciones que realiza } \\
\text { actualmente }\end{array}$ & $\begin{array}{l}\text { - Cantidad } \\
\text { - Formato: curso o carrera } \\
\text { - Costos } \\
\text { - Carácter (presencial semi presencial o a distancia) }\end{array}$ \\
\hline $\begin{array}{l}\text { Motivos de la elección (de } \\
\text { las capacitaciones } \\
\text { realizó yue } \\
\text { realiza) }\end{array}$ & $\begin{array}{l}\text { - Elementos que influyen en la valoración de la oferta } \\
\text {-Vinculación de la capacitación con la carrera docente } \\
\text { (Puntaje) } \\
\text { - Cambios en la valoración de la oferta. } \\
\text { - Costos } \\
\text { - La antigüedad docente: } \\
\text { - La valoración de los contenidos de la oferta en relación a: } \\
\text { a) La historia personal relacionada a la práctica de actividades } \\
\text { corporales. } \\
\text { b) Formación inicial } \\
\text { c) Socialización laboral } \\
\text { (En colegas incluyo no solo a los docentes de educación física, } \\
\text { sino también al resto de los docentes y el personal directivo } \\
\text { de las escuelas) } \\
\text { - Características de los alumnos. }\end{array}$ \\
\hline Contenidos & $\begin{array}{l}\text { - Carácter del conocimiento: } \\
\text { - Referente a la enseñanza de la práctica, de actividades } \\
\text { deportivas (didáctica de algún deporte en particular) } \\
\text { - Vinculados a la actualización en el manejo del diseño } \\
\text { curricular. }\end{array}$ \\
\hline $\begin{array}{l}\text { El lugar del docente en las } \\
\text { actividades de capacitación }\end{array}$ & Participación en las actividades de capacitación \\
\hline Difusión de la oferta & $\begin{array}{l}\text { Fuentes de información de donde toma conocimiento de la } \\
\text { oferta: } \\
\text { - Institucional. } \\
\text { - Grupo de pares. } \\
\text { - Otros. } \\
\text { Frecuencia de la información: } \\
\text { - Cantidad y variedad. }\end{array}$ \\
\hline $\begin{array}{l}\text { Carácter público o privado } \\
\text { del oferente }\end{array}$ & Valoración del oferente \\
\hline
\end{tabular}




\section{Población y muestra:}

Población: profesores de educación secundaria, del sector público, del área educación física del distrito de La Plata.

\section{Los profesores de educación secundaria y su vínculo con la capacitación}

Los datos que dispongo para presentar a los docentes de escuela secundaria del sector público provienen en su mayoría del Censo Nacional Docente efectuado en el 2004 por la DINIECE. Si bien no es el período exacto ni se refirieren exclusivamente los docentes del distrito, es la fuente disponible de datos más aproximada. Sobre un total de 36.623 docentes del nivel medio/polimodal que se desempeñaron en la gestión estatal en la provincia de Buenos Aires en función frente a alumnos, es posible advertir que:

El 57,1\% asistieron a cursos de capacitación entre 1999 y 2004, es decir que aproximadamente 20.911 docentes estuvieron vinculados a los cursos de capacitación. Desde la perspectiva de la formación permanente, es necesario incluir la formación de grado y posgrado. Se advierte que el 19,1 \% cursa alguna carrera de nivel superior, de este porcentaje el 9,2 cursa exclusivamente en nivel superior universitario, el $6 \%$ cursa en el SNU (establecimientos educativos superiores no universitarios), el 3,4\% cursa posgrado y el $0,5 \%$ realiza combinaciones.

Respecto a la cantidad de establecimientos educativos en los cuales trabajan, el $27 \%$ de los docentes de escuela secundaria trabaja en más de tres establecimientos educativos. Es probable que esa cifra aumente para el caso de los profesores de educación física, ya que la materia está presente en los tres niveles inicial, primario y secundario lo cual implica una mayor cantidad y variedad de instituciones para el trabajo docente. En este punto cabe destacar que la capacitación asociada al puntaje aumenta las posibilidades que el docente tiene de concentrar sus horas de trabajo en una institución, ya que un mayor puntaje le permite elegir el destino de trabajo.

Respecto al tipo de designación, el 59,7\% tiene módulos exclusivamente. Cabe aclarar que existen dos formas de contabililizar las horas de trabajo de los docentes de educación física en la provincia: el módulo y la hora cátedra. El módulo equivale a una hora reloj y la hora cátedra a 40 minutos, el 26,2\% combina ambos modos de designación, lo que para el caso de educación física implica trabajar en distintos niveles de la enseñanza combinando el trabajo en los Centros de Educación Física (CEF) o en el nivel inicial con el trabajo en escuelas secundarias.

Respecto a la situación de revista, el $33,2 \%$ es titular exclusivamente, el $13,1 \%$ es interino provisional exclusivamente, el 9,8\% es suplente exclusivamente, el 10,6\% es 
titular e interino provisional, el 2,9 es titular y suplente. Por último existe un 20,8\% sin información. Cabe considerar que en muchos casos cuando los docentes titularizan ${ }^{7}$ no lo hacen por un cargo, lo que equivale a diez módulos de escuela secundaria, ya que eso implicaría una baja importante del puntaje afectando las posibilidades de acceso a horas suplentes y/o a otro cargo, puesto que a un docente que titulariza un cargo o su equivalente en horas cátedra ya sea en régimen estatal o privado se le deben descontar 10 puntos en el Listado Oficial en todas las ramas y cargos. Debido a esto, muchos docentes optan por titularizar 8 módulos, lo que constituye el límite de horas titulares sin pérdida de puntaje.

En el distrito de La Plata entre el 2007 y 2009 existían 72 ESB (Escuelas Secundarias Básicas), 37 escuelas medias, 6 técnicas, 1 Escuela agraria y 2 escuelas secundarias en cárceles. La división entre ESB y polimodal establecida por la Ley Federal de Educación de 1993, finalizó con La ley de Educación Nacional N²6.206 (2006) y su correlato en la Ley Provincial de Educación 13.688 (2007). En términos efectivos los últimos alumnos del polimodal egresaron en el 2010, y para el caso de las técnicas y de la escuela agraria en el 2011 ya que tenían un año más en su curricula.

Salvo uno, todos los docentes entrevistados trabajan en tres o más escuelas. La posibilidad de concentrar el trabajo en una institución está condicionada, porque si bien un cargo de profesor en escuela secundaria equivale a 10 módulos, estos a su vez se fragmentan en 5 puestos de trabajo, que se ofrecen en los actos públicos para su cobertura de manera fraccionada. Así cada docente de acuerdo a su puntaje en el listado puede tomar las horas que más se adecuen a sus tiempos y necesidades laborales. Por ello el puntaje y la capacitación asociada al puntaje adquiere sentido en la organización personal respecto a los tiempos y espacios de trabajo.

7 Cabe señalar que ser "titular" implica una serie de derechos entre los que se destacan los señalados en los siguientes incisos del artículo 7 del Estatuto (Ley 10579):

a) La estabilidad en el cargo, categoría, jerarquía y ubicación o destino.

c) El ascenso, la permuta y el traslado de acuerdo con las condiciones establecidas en el presente estatuto.

d) El progresivo acrecentamiento de horas-cátedra, hasta el máximo compatible.

e) El cambio de funciones en caso de disminución o pérdida de aptitudes psico-fisicas, cuando no se alcancen a cumplir los requisitos establecidos para la jubilación por incapacidad.

i) La concentración de tareas.

k) La consideración, por parte de las autoridades, de los problemas que afecten la unidad familiar.

ñ) La obtención de becas para su perfeccionamiento cultural y profesional y la consiguiente licencia si fuera necesario.

o) La participación en el gobierno escolar, integrando los distintos organismos de la Dirección General de Escuelas y Cultura, prevista en este estatuto y leyes pertinentes. 


\section{Los criterios para la selección de los docentes entrevistados}

Se realizaron entrevistas a docentes que se encontraban trabajando en escuelas secundarias en el periodo 2007-2009 recabando información sobre el vínculo que establecieron en ese momento con la oferta de capacitación y sobre la percepción actual de su vínculo con la capacitación. Para la selección de los docentes a entrevistar consideré dos criterios: la antigüedad docente y la formación de profesorado.

I - La antigüedad docente. Este criterio fue seleccionado en correspondencia con los datos que aportan las investigaciones del ciclo vital de los profesores (Sikes, 1985 citado en García, 1995) las cuales distinguen distintos periodos. De acuerdo con esto considero tres cortes:

Primer periodo de ingreso al trabajo docente: abarca los primeros años de trabajo desde el ingreso a las instituciones hasta los 5 años de antigüedad, y está asociado a las estrategias de supervivencia (García, 1995) para acceder al puesto de trabajo y generar estrategias que le permitan afianzarse en el mismo, en un proceso que implica interiorizarse sobre la regulación de la carrera docente. Respecto al trabajo docente, este periodo coincide con lo que algunos autores denominan " "shock de la realidad" que hace referencia al colapso de los ideales misioneros elaborados durante la etapa de formación de profesorado con la cruda y dura realidad de la vida cotidiana en clase" (Veenman, 1988; 61).

Generalmente comprende de los 23 a los 28 años de edad. Es una etapa de exploración de las posibilidades de la vida adulta e inicio de una estructura estable de vida. Durante este periodo los problemas de disciplina son los que más preocupan a los profesores debido a la construcción de su autoridad. La otra preocupación está centrada en el dominio de los contenidos. Además es la etapa de inicio en la socialización profesional lo que incluye la interacción con los colegas y el reconocimiento de las dinámicas institucionales (García, 1995).

Segundo periodo, periodo estabilización y reconocimiento de perspectivas: abarca desde los 5 hasta los 20 años de antigüedad. En este periodo los aspectos referentes al acceso y permanencia en el cargo estarían resueltos. El docente conoce las reglas burocráticas de sistema y tiene referencias más claras sobre las características de los distintos espacios de trabajo,. Así, al conocer las formas de movilidad laboral puede acceder a los puestos de trabajo frente a alumnos o no, que él elige. Hay un mayor 
conocimiento del oficio, lo que le permite acomodarse y anticipar muchas situaciones que probablemente le sucedan en su hacer diario.

De acuerdo con las investigaciones del ciclo vital de los profesores, pueden distinguirse dos fases dentro de este periodo:

a) Fase de transición: comprendida entre los 28 y 33 años de edad, aquí se diferencian dos grupos, los que buscan estabilizarse en el puesto de trabajo y los que están interesados en la búsqueda de un nuevo empleo. En esta fase los profesores están interesados en la enseñanza y el dominio del contenido (García, 1995).

b) Fase de afianzamiento: abarca de los 30 a los 40 años de edad, es un periodo de gran capacidad física e intelectual, lo que significa energía, implicación, ambición y confianza en sí mismos, es una fase de estabilización y normalización en la cual los profesores tratan de ser más competentes y a veces procuran la promoción (García, 1995).

Tercer periodo, de posible cambio de funciones: abarca desde los 20 años de antigüedad en adelante. Aquí habría dos grupos de docentes: aquellos que se encuentran a gusto trabajando frente a alumnos, y un grupo importante, formado por quienes están cansados de trabajar a cargo de grupos e intentan pasar a otra función dentro del sistema educativo (por ejemplo, cargos directivos, secretarios).

Este dato se advierte en las entrevistas a los encargados de gestionar capacitación en el distrito:

"Existen dos bloques de profesores para poder pensar cuales son los aspectos que inciden en la elección de la capacitación así: existe un grupo de profesores grandes de varios años de antigüedad que están tranquilos en el puesto de trabajo a los que no les interesa hacer curso, que lo dicen que no les interesa, dentro de este grupo están también a los que les interesa capacitarse pero es porque quieren acceder a otro tipo de cargos dentro del sistema educativo, en este caso la capacitación está vinculada a un intento de ascenso de jerarquía. Y después está el que empieza en la docencia ese el gran grueso." (Capacitadora del CIIE La Plata e Inspectora de Educación Física)

"En media muchos docentes de educación física particularmente buscan actividades de capacitación vinculadas a los concursos para los cargos jerárquicos. Es gente con varios de antigüedad es gente que tiene en general más de 40 años." (Responsable de la Secretaría de Cultura del SUTEBA) 
II -La Formación inicial de profesorado: si bien pueden distinguirse dos tipos de formación, la universitaria y la superior no universitaria, en La Plata la mayoría de los docentes de educación física egresó de la carrera de Profesorado en Educación Física de la Facultad de Humanidades y Ciencias de la Educación de la Universidad Nacional de La Plata (FaHCE-UNLP), por lo cual lo que voy a tomar es el año de egreso para indagar la valoración respecto a los modelos de gestión curricular ${ }^{8}$ de la institución y los modelos de gestión pedagógica ${ }^{9}$ de las asignaturas.

\section{Referencias de los profesores entrevistados:}

-Profesor A: varón, 4 años de antigüedad en la docencia, 27 años de edad, trabaja en once escuelas públicas, egresado de la UNLP-FaHCE en 2006, estudió posgrado en rehabilitación (UCA) y estudia Medicina (UBA), realiza y realizó cursos de capacitación pagos por el puntaje.

-Profesor B: varón, 11 años de antigüedad en la docencia, 38 años de edad, trabaja en tres escuelas públicas, estudió en la UNLP y egresó en el año 1999. Es guardavidas de la Cruz Roja, y realizó cursos de capacitación pagos por puntaje.

-Profesor C: mujer, 16 años de antigüedad en la docencia, 40 años de edad, trabaja en cinco escuelas, cuatro públicas y una privada, egresó en el año 1989 de la UNLP FaHCE. Realizó un posgrado en rehabilitación en la Facultad de Medicina de la UNLP y Cursa la Maestría en Educación Corporal en la UNLP.

-Profesor D: varón, 27 años de antigüedad en la docencia, 50 años de edad, trabaja en una escuela pública y tiene horas afectadas a la Dirección de Deportes coordinando el área de Vóley. Es egresado en 1983 de la UNLP, especialista en Vóley.

$8 \quad$ Entendido como el tipo de trayectoria de aprendizaje que las instituciones ofrecen al alumno en forma explícita a través de la malla curricular y de la definición de los trayectos por los que el alumno debería transitar desde que ingresa hasta que se titula, lo cual implica una trayectoria específica de formación y supuestamente un tipo especifico de competencias en el alumno. (Gómez, 2006, 2007)

Refiere a la totalidad de dispositivos que los docentes utilizan en el dictado de las asignaturas, tales como flexibilidad de los contenidos, técnicas de enseñanza, procesos de planeamiento, competencias que esperan de los alumnos, formas de comunicación, relación de las cátedras con soportes bibliográficos, formas de evaluación intercátedra, articulación entre cátedras (Gómez, 2006, 2007). 
-Profesor E: varón, 27 años de antigüedad en la docencia, edad 50 años, docente en 8 escuelas en los distritos de La Plata y Ensenada, egresado 1983 UNLP, capacitador de la Dirección Provincial de Deportes con especialidad en handball.

-Profesor F: varón, 34 años de antigüedad en la docencia, edad 59 años, egresó del Instituto Nacional de Educación Física Romero Brest en 1976, Trabaja en la misma escuela pública desde el año 1976.

\section{Referentes de la capacitación en el distrito de La Plata, entrevistados:}

-Referente I: Inspectora de educación secundaria y capacitadora del CIIE La Plata para el área. 2010.

-Referente II: Responsable de la Secretaría de Cultura del SUTEBA. 2010.

-Referente III: Responsable de Extensión y capacitación de la FaHCE de la UNLP. 2010

-Referente IV: Asesora pedagógica de la Dirección de Educación Física, y coordinadora de los equipos técnico profesionales de capacitación del área en educación física en la provincia. 2010.

-Referente V: Director del instituto educativo CESALP. 2011

\section{Instrumentos de recolección de datos:}

Para la recolección de datos se emplearon dos tipos de fuentes:

1) documentales y

2) orales (entrevistas). 
Fuentes de datos y estrategia de análisis:

\begin{tabular}{|c|c|c|c|}
\hline \multicolumn{2}{|l|}{ Fuentes: } & $\begin{array}{l}\text { Información que } \\
\text { brindan }\end{array}$ & $\begin{array}{ll}\begin{array}{l}\text { Estrategia } \\
\text { análisis }\end{array} & \text { de }\end{array}$ \\
\hline \multirow{2}{*}{ 造 } & Textos académicos & $\begin{array}{l}\text { Datos históricos } \\
\text { sobre la estructura } \\
\text { de la capacitación } \\
\text { en Argentina y en la } \\
\text { provincia de } \\
\text { Buenos Aires }\end{array}$ & $\begin{array}{l}\text { Análisis de } \\
\text { contenido: Cuándo, } \\
\text { dónde, quienes } \\
\text { hicieron el campo } \\
\text { de la capacitación, y } \\
\text { de cómo se } \\
\text { estructura. }\end{array}$ \\
\hline & $\begin{array}{l}\text { Normativas, } \\
\text { estatutos y censos } \\
\text { docentes. }\end{array}$ & $\begin{array}{l}\text { Datos sobre la } \\
\text { regulación } \\
\text { institucional del } \\
\text { trabajo y la carrera } \\
\text { docente. }\end{array}$ & $\begin{array}{l}\text { Análisis de } \\
\text { contenido: } \\
\text { resoluciones, } \\
\text { licencias, } \\
\text { presentismos, } \\
\text { salario, cantidad de } \\
\text { docentes, cantidad } \\
\text { de puestos de } \\
\text { trabajo. }\end{array}$ \\
\hline \multirow{2}{*}{$\frac{\mathscr{d}}{\sigma}$} & $\begin{array}{l}\text { Entrevistas semi } \\
\text { estructuradas a } \\
\text { referentes de la } \\
\text { capacitación. }\end{array}$ & $\begin{array}{l}\text { Datos sobre la } \\
\text { organización de la } \\
\text { oferta de } \\
\text { capacitación. }\end{array}$ & $\begin{array}{l}\text { Análisis de } \\
\text { contenido del relato: } \\
\text { perfil del } \\
\text { destinatario, la } \\
\text { metodología, las } \\
\text { demandas de } \\
\text { formación, } \\
\text { contenidos, } \\
\text { comunicación entre } \\
\text { institución y } \\
\text { docentes, la } \\
\text { comunicación entre } \\
\text { los oferentes. }\end{array}$ \\
\hline & $\begin{array}{l}\text { Entrevistas semi } \\
\text { estructuradas a los } \\
\text { docentes que eligen } \\
\text { las capacitaciones }\end{array}$ & $\begin{array}{l}\text { Datos sobre } \\
\text { trayectorias socio } \\
\text { laborales de los } \\
\text { docentes. }\end{array}$ & $\begin{array}{l}\text { Análisis de } \\
\text { contenido del relato: } \\
\text { períodos en sus } \\
\text { trayectorias: } \\
\text { formación inicial, } \\
\text { antigüedad docente, } \\
\text { ingreso al trabajo } \\
\text { docente, } \\
\text { estabilización y } \\
\text { reconocimiento, } \\
\text { cambio de } \\
\text { funciones }\end{array}$ \\
\hline
\end{tabular}




\section{Aportes del conocimiento a construir:}

La intención de esta tesis es ampliar el conocimiento respecto al campo de la capacitación, a partir de analizar la interacción entre la estructura de la capacitación, las características de la oferta y los intereses de los actores, para aportar elementos que contribuyan a comprender cómo se estructura la relación con el saber en este campo. El sentido potencial de la tesis apunta al mejoramiento de las propuestas de capacitación en el área específica de los docentes de secundaria de educación física del distrito de La Plata.

\section{Bibliografía}

Becker, H. (2009). Trucos del oficio: cómo conducir su investigación en Ciencias Sociales. Buenos Aires: Siglo XXI Editores.

Birgin, A. (1999). El trabajo de enseñar. Entre la vocación y el mercado: las nuevas reglas del juego. Buenos Aires. Editorial Troquel S. A.

Birgin, A. (2012). "Introducción. La formación ¿Una varita mágica?”, en A. Birgin (Comp.) Más allá de la capacitación: debates acerca de la formación de los docentes en ejercicio. Buenos Aires. Paidós, p. 13 - 27.

Cappellacci, I. (2008). "Orientación para los estudios postobligatorios y el mundo del trabajo", en: Krichesky M. (Coord.) Proyectos de orientación y tutoría. Enfoques y proyectos para el cambio en la escuela. Buenos Aires: Paidós, p. 191 - 236.

Davini, M.C., (1995). La formación docente en cuestión: política y pedagogía. Paidós, Buenos Aires.

Devalle de Rendo, A. y Vega, V. (1997). "La capacitación docente. Otro bien de consumo", en Novedades Educativas, $\mathrm{n}^{\circ} 76$, p. $44-45$.

Diker, G. (2005). "Los sentidos del cambio en educación”, en Frigerio, G. y Diker, G. (Comps.) Educar: ese acto político. Buenos Aires: Del Estante Editorial, p. 127 - 138.

Diker, G. y Serra, J. C. (2008). La cuestión docente. Argentina: las políticas de capacitación docente. Buenos Aires: Fundación Laboratorio de Políticas Públicas.

Diker, G. y Terigi, F. (1997). La formación de maestros y profesores: hoja de ruta. Buenos Aires: Paidós.

Dubet, F. (2004). “¿Mutaciones institucionales y/o neoliberalismo?”, en: Tenti Fanfani, E. (Org.) Gobernabilidad de los sistemas educativos en América Latina. Buenos Aires: IIPE - UNESCO, p. 15 - 44. 
Dubet, F. (2006). El declive de la institución. Profesiones, sujetos e individuos en la Modernidad. Barcelona: Gedisa.

Fedlfeber, M. (2004). Profesionalización docente y reforma educativa en Argentina. Buenos Aires: FLACSO.

Finocchio, S. (2006). La formación de maestros mexicanos en clave ProNap (1996 2006). México: Centro de Estudios en Políticas Públicas.

Finocchio, S. Legarralde, M. (2006). Modelos de formación en América Latina. Buenos Aires: Centro de Estudios en Políticas Públicas.

García, M. (1995). Formação de Professores- Para uma mudança educativa. Portugal: Porto Editora.

Gómez R. H. (2006). “ ¿Cómo se enseña a los que enseñan? Perfil dominante y perfil emergente en la formación docente en la Educación física Hispanoamericana”, en: Actas del Congreso Repensar la Educación Física. Córdoba: IPEF.

Gómez, R. H. (2007). Perfil dominante y perfil emergente en la formación docente en Educación Física, en: Actas del Congreso Internacional de Educación Física - IPEF. Córdoba: UNC.

Ibernón, F., (1994). La formación y el desarrollo profesional de profesorado. Hacia una nueva cultura profesional. Barcelona: Editorial Grao.

IIPE (2000). "Los docentes y los desafíos de la profesionalización”. Informe Final. Buenos Aires.

Imen, P. (2006). "Trabajo docente debates sobre la autonomía laboral y la democratización de la cultura", en: Fedlfeber, M. y Andrade Oliveira, D. (Comps.) Políticas educativas y trabajo docente. Nuevas regulaciones ¿nuevos sujetos? Buenos Aires: Noveduc, p. $239-262$.

Poliak, N. (2004). "Reconfiguraciones recientes en la educación media: escuelas y profesores en una geografía fragmentada", en: Tiramonti, G. (Comp.) La trama de la desigualdad educativa. Mutaciones recientes en la escuela media. Buenos Aires: Manantial, p. 147 - 191.

Popkewitz, T., (1994). Sociología politica de las reformas educativas. Madrid: Fundación Paideia - Ediciones Morata.

Serra, J. C. (2004). El campo de la capacitación docente. Políticas y tensiones en el desarrollo profesional. Buenos Aires: FLACSO - Miño y Dávila.

Tyack, D. y Tobin J. (1995). En busca de la utopía. Un siglo de reformas de las escuelas públicas. México: Fondo de Cultura Económica. 
Veenman, S. (1988). "El proceso de llegar a ser profesor: un análisis de la formación inicial" en Villa A., (Coord.) Perspectivas y problemas de la función docente. Madrid: Narcea, p. $39-68$.

Vezub, L. F. (2010). El desarrollo profesional docente centrado en la escuela: concepciones, políticas y experiencias. - $\mathrm{1}^{\mathrm{a}} \mathrm{ed}-\mathrm{Buenos}$ Aires: IIPE - Unesco.

Viñao, A. (2002). Sistemas educativos, culturas escolares y reformas. Continuidades y cambios. Madrid: Morata.

Ziegler, S. (2001). De las políticas curriculares a las resignificaciones de los docentes. Buenos Aires: FLACSO.

\section{Fuentes:}

Censo Nacional de Docentes 2004, DiNIECE.

Consejo Federal de Cultura y Educación (1994). Documento A-9: "Creación de la Red Federal de Formación Docente Continua"

Dirección General de Cultura y Educación de la Provincia de Buenos Aires, Resolución No3817/07 del 2007.

Estatuto del Docente de la Provincia de Buenos Aires.

Ministerio de Cultura y Educación, Secretaría de Programación y Evaluación Educativa, Resolución 193/96. 


\section{CAPÍtulo I}

\section{Marco teórico conceptual}

\subsection{Introducción}

La intención de este capítulo es presentar el marco conceptual a partir del cual analizo la elección de la oferta de capacitación estatal y privada efectuada por los docentes del área de educación física del nivel secundaria del sector estatal, en el distrito de La Plata durante el 2007 a 2009. La perspectiva aborda la elección de la capacitación desde la particularidad de los actores, considerando la incidencia de sus contextos y la interacción con la cultura escolar en la que conviven y crean y desde la cual eligen (o no) opciones de capacitación.

Para esto, a través del concepto de desarrollo profesional, formación docente continua y socialización profesional (Davini, 1995) introduzco los aportes de la teoría del saber docente y su desarrollo profesional que plantea Tardif (2004).

Luego describo las características de la dinámica del campo de la capacitación (Serra, 2004) para sumar conceptos que permitan analizar cómo se trazan las estrategias de formación docente.

Retomo la noción de habitus de Bourdieu (1997), para introducir la tensión entre lo singular y lo colectivo.

En esta tensión cobran valor para el análisis los aportes de Charlot (2000) sobre la relación de los sujetos con el saber y desde las características y la situación socio educativa de quien elige, atendiendo a las dimensiones identitaria y epistemológica.

Por último presento algunas consideraciones teóricas utilizadas en el abordaje del trabajo de campo, específicamente en las entrevistas, que se desprenden de la teoría de la acción de Lahire, que implican empezar a vincular las dimensiones presentes en el análisis de la relación con el saber de Charlot (2000) con elementos de la teoría del saber docente de Tardif (2004).

\section{Los aportes del saber docente y el desarrollo profesional}

Desde la perspectiva del desarrollo profesional se define a la profesionalidad a partir de las características de la propia tarea docente. Esta perspectiva considera a la profesión 
como un proceso, como el desarrollo de una cultura profesional que incluye las particularidades del trabajo docente y la multiplicidad de situaciones y actividades que comprometen diariamente a los docentes (Serra, 2004). Este proceso se lleva a cabo a través de la formación docente continua en la cual pueden distinguirse distintas fases o etapas en la socialización profesional que, como advierte Serra, "involucran tanto acciones formativas intencionales, como aquellos procesos no intencionales que influyen en la formación docente".

Las fases que se pueden indicar son las siguientes:

- La primera fase es la de la experiencia como alumnos antes de ser profesores.

- La segunda fase abarca la formación inicial como docentes.

- La tercera fase es de iniciación en la iniciación de la vida profesional en los centros escolares.

- La cuarta fase de formación permanente incluye todas las actividades planificadas por las instituciones o por los propios docentes para propiciar el desarrollo profesional y el perfeccionamiento de la enseñanza.

Si bien esta tesis se centra en las elecciones de los docentes respecto de la oferta de capacitación en la última etapa, el concepto de formación docente continua brinda la posibilidad de indagar sobre la incidencia de las etapas anteriores en la elección de la capacitación. Conceptos como "capacitación", "perfeccionamiento", “actualización", “especialización” tienen un marco de origen político e histórico diferente. Sin embargo, en el contexto de esta tesis se emplearán sin acentuar esas diferencias, salvo que se indique.

En relación con las políticas de capacitación en la Argentina, los agentes que participan de ella son: los ministerios de educación nacional y provinciales, los oferentes de capacitación de distinta procedencia (entre los que se cuentan instituciones académicas de gestión estatal y privada, instituciones de formación docente, sindicatos, editoriales, etc.) y los propios docentes. Para cada uno de ellos la capacitación reviste intereses y significados diferentes.

Para caracterizar los intereses y significados que adquieren para los docentes, Davini define a la socialización profesional como el "proceso de largo alcance que implica la incorporación explícita e implícita de formas de pensamiento, valoración y actuación en distintos ámbitos sociales". (1995: 111) Las cuales van a contribuir a la formación de un tipo de saber particular, el saber docente, que de acuerdo con Tardif puede definirse "como un saber plural formado por una amalgama, más o menos coherente, de saberes 
oriundos de la formación profesional y de saberes disciplinares y experienciales" (29; 2004)

Tardif señala que "el saber profesional se conforma partir de la confluencia de varias fuentes de saberes provenientes de la historia de la vida individual, de la sociedad, de la institución escolar, de los lugares de formación, etc" (49; 2004)

Tardif advierte que el saber docente es un saber desvalorizado, frente al campo intelectual y de recontextualización oficial, "los saberes de la formación profesional, los saberes curriculares y los saberes curriculares de los profesores parecen siempre ser más o menos de segunda mano (...) la función docente se define en relación a los saberes, pero parece incapaz de definir un saber producido y controlado por los que la ejercen" $(31 ; 2004)$

\subsection{La dinámica del campo de la capacitación docente (ilusio, habitus y capital)}

La teoría de los campos de Pierre Bourdieu brinda categorías que permiten entender la complejidad de relaciones entre los distintos agentes que conforman la política pública de capacitación, y en ese marco, analizar la elección de la oferta de capacitación. Para esto Serra (2004) aporta elementos para entender la política de formación docente continua $^{10}$. Desde esta perspectiva la política de capacitación docente puede ser entendida como un campo de interés para los diferentes agentes. El concepto de "campo" puede pensarse como el espacio de posiciones articulado por relaciones o conflictos (Serra, 2004). Partiendo de esta noción de campo a continuación se presentan distintos conceptos que servirán para analizar la elección.

El campo orienta las estrategias mediante las cuales los ocupantes de distintas posiciones intentan individual o colectivamente salvaguardar o mejorar su posición en el campo, e imponer el principio de jerarquización que les es favorable. Es decir las estrategias de los agentes dependen de su posición en el campo (dominación, subordinación, homología) relacionada con la distribución de un capital específico, así como la percepción que tienen del campo desde su punto de vista particular, el cual depende también de la posición que ocupan dentro del campo (Bourdieu y Wacquant, 1995)

10 Los aportes de Serra (2004) refieren al análisis del periodo1994 y 1999, se advierte que el planteo sigue siendo actual y adecuado a los fines de este análisis, ya que si consideramos la estructura de la política de capacitación en argentina y la influencia del estatuto del docente en la configuración de la capacitación, no se perciben cambios relevantes 
La ilusio $^{11}$ se refiere al hecho de estar involucrado en el juego y por el juego, aceptando las reglas, advirtiendo que las apuestas son importantes y dignas de ser emprendidas. En este sentido, la adquisición de puntaje a través de la participación en actividades de capacitación podría ser una consecuencia de aceptar las reglas de juego previstas en el Estatuto Docente para regular la carrera docente, ya que determina la estabilidad y el acceso a los cargos.

Más allá de las posiciones que cada agente ocupe, para que el campo se construya es necesario que los agentes posean un habitus, el cual se configura en una relación de condicionamiento con el campo. Así el campo estructura el habitus y el habitus contribuye a construir el campo.

El habitus es el concepto que articula lo individual y lo social, las estructuras internas de la subjetividad y las estructuras objetivas que constituyen el ambiente, es decir las llamadas condiciones materiales de existencia.

"Es un sistema socialmente construido de disposiciones estructuradas y estructurantes adquirido mediante la práctica y orientado hacia fines prácticos" (Bourdieu y Wacquant, 1995: 83). En el habitus se inscriben la multiplicidad de sentidos que tiene la capacitación configurando un sentido particular para el agente.

Es un sistema de disposiciones para actuar, percibir, sentir y pensar de cierta manera, interiorizadas e incorporadas por los individuos a lo largo de su historia, en esta particularidad del habitus es donde es posible pensar que reside la matriz identitaria del saber, a partir de la cual es posible la singularidad y la relación particular con el saber.

El habitus se manifiesta por el sentido práctico, es decir por la actitud para moverse y orientarse en la situación en la que está implicado, esto sin recurrir a la reflexión consciente por medio de las disposiciones adquiridas que funcionan como automatismos (Serra, 2004).

Desde esta conceptualización es posible definir un campo de la educación y diversos subcampos, uno de ellos es el campo intelectual que refiere a las posiciones que surgen de la producción del discurso educativo y sus prácticas. Este campo "es una fuente en la generación de posiciones en la teoría, investigación y práctica educativa y en la definición parcial de los discursos y practicas pedagógicas que circulan en el sistema educativo" (Diaz, 1995: 339).

\footnotetext{
$11 \quad$ Concepto que Bourdieu utiliza para escapar al reduccionismo economicista que implica la
} noción de interés. 
La reproducción de este discurso se da en el campo pedagógico el cual estructura y es estructurado por las prácticas pedagógicas, que considera las relaciones sociales de los sujetos en la escuela. Es importante advertir que "en general el campo intelectual de la educación mantiene una relación hegemónica con el campo pedagógico, dado que actúa como su frente critico e ideológico" (Serra, 2004: 29).

$\mathrm{Al}$ mismo tiempo en la relación entre el campo intelectual y el campo pedagógico existe un campo de recontextualización oficial, el cual es reglado directamente por el Estado, políticamente a través de la legislación y administrativamente a través de los servicios civiles.

Así, las agencias de recontextualización del Estado producen legislaciones específicas, las cuales se constituyen en el aparato discursivo legal, el cual junto a los textos administrativos mantienen el control legal y político sobre sus agentes, agencias, prácticas y discursos requeridos para la reproducción de la cultura de la escuela y la producción de formas específicas de experiencia (Diaz, 1995).

De acuerdo a esta división de los campos, Serra (2004) define al campo de la capacitación como un subcampo dentro de la recontextualización oficial, dado que los discursos y las prácticas que se asocian a la capacitación articulan producciones del campo intelectual de la educación, nacional e internacional, con sus respectivas recontextualizaciones nacionales e internacionales, que constituyen una forma particular de entender la capacitación en la Argentina.

Es importante advertir que además del campo de recontextualización oficial existe el campo de recontextualización pedagógica, con relativa autonomía respecto a la autoridad política y del control del Estado (Serra, 2004), donde entran en juego las decisiones del hacer pedagógico de los profesores que pueden o no alinearse con los lineamientos oficiales.

Para los propios docentes, en tanto actores de este campo, revisten intereses específicos y particulares que implican una relación específica con el saber, dado que dependiendo de su posición en el campo y del tipo y cantidad de capital que posean, disponen de diferentes maneras de apropiarse de los diferentes recursos: económicos, políticos y simbólicos involucrados.

Lo que los sujetos invierten para moverse en el campo es el capital, entendido como energía social acumulada. Las estrategias que los docentes generan individual o colectivamente para moverse en el campo, están condicionadas por la disposición de determinado tipo de capital en relación a un habitus y una ilusio que las orientan. En 
términos de Bourdieu es posible identificar tres clases de capital, a las que es preciso añadir el capital simbólico (Bourdieu y Wacquant, 1995) que es la modalidad adoptada por cada una de ellas a partir de un sobreañadido de prestigio, legitimidad, autoridad y principios de distinción (Serra, 2004).

El capital económico: acumulado de manera objetiva en mercancías o dinero, es transferible y no está ligado al cuerpo de las personas.

El capital social: que "es la suma de los recursos actuales o potenciales correspondientes a un individuo o grupo, en virtud de que éstos poseen una red duradera de relaciones, conocimientos y reconocimientos mutuos más o menos institucionalizados" (Bourdieu y Wacquant, 1995: 82)

El capital cultural que puede existir en tres estados:

Objetivado: bajo la forma de bienes culturales, cuadros, libros, etc.

Institucionalizado: bajo la forma de objetivación reconocida institucionalmente (Bourdieu, 1979), por ejemplo mediante certificaciones o titulaciones.

Incorporado: bajo la forma de disposiciones duraderas del organismo. Está ligado al cuerpo y se realiza personalmente, no puede ser delegado y su transmisión no puede hacerse por donación, compra o intercambio sino que debe ser adquirido y muere con el portador. Se destaca por su modo disimulado de adquisición que lo hace aparecer como una adquisición propia o innata, por lo cual está predispuesto a funcionar como capital simbólico.

Al mismo tiempo está ligado al capital económico, porque se necesitan recursos para tener tiempo libre y destinarlo a la incorporación de este tipo de capital.

La elección de la capacitación, implica acción en torno a una estrategia donde se invierten distintas formas de capital disponible para consolidar o modificar la posición en el campo.

En el capítulo 2 se analiza la incidencia del capital simbólico en el diseño la de política pública de capacitación en relación a la lógica del puntaje de la versus la lógica acreditación, en la que se advierte el peso de la certificación de la capacitación.

En el capítulo 3 se visualiza la incidencia de los distintos tipos de capital invertidos en las estrategias individuales.

\subsection{El habitus y la relación con el saber}

Hasta aquí se presentó el campo de la capacitación docente para comprender la dinámica de la capacitación docente en la Argentina y en especial en la provincia de 
Buenos Aires. En adelante voy a centrarme en el docente, retomando la noción de habitus para pensar la tensión entre lo colectivo y lo singular en relación a su incidencia en la relación con el saber en el marco de la elección de la oferta de capacitación.

Curcuf (2005) señala que en su libro "Architecture gothique et pensé scolastique" Pierre Bourdieu planteaba ambiciones pero también tensiones vinculadas a la noción de habitus: "“oponer la individualidad y la colectividad para salvaguardar mejor los derechos de la individualidad creadora y los misterios de la creación singular es privarse de descubrir la colectividad en el corazón mismo de la individualidad bajo la forma la cultura" (142)... Se advierte aquí una vacilación entre dos caminos: $1^{\circ}$ aquel que sigue la mayor parte de sus contemporáneos y que toma el partido de lo colectivo contra lo singular ilusorio, y $2^{\circ}$ el llamado a una nueva alianza entre la individualidad y lo colectivo" (Curcuf, 2005: 121)

Charlot se ubica dentro de esta nueva alianza entre lo individual y lo colectivo y aporta elementos útiles para el análisis que aquí se plantea. Analiza la relación con el saber y advierte que aunque Bourdieu introduce un lugar para lo psíquico a través del habitus que es un conjunto de disposiciones psíquicas, pero es un psiquismo pensado en referencia al sujeto, "es un psiquismo de posición" (Charlot, 2000). En relación a esto retoma a Dubet (1996) quien va a definir al psiquismo en términos de interiorización de lo social, considerando la psiquis de cada sujeto.

Charlot retoma este planteo para pensar la acción del individuo en y sobre el mundo. Desde esta perspectiva analiza la relación con el saber y advierte que no hay saber sin relación con el saber. Esto implica que no hay saber sino es organizado de acuerdo a relaciones internas y producido en una confrontación interpersonal. En este sentido, el saber implica al sujeto, a la actividad del sujeto, a la relación del sujeto con él mismo y a la relación del sujeto con los otros (Charlot, 2000).

Así para entender al sujeto del saber es preciso entender que la relación con el saber no es neutral, por lo cual hay otras dimensiones del sujeto, más allá de su posición, que precisan ser consideradas, como la ideología, el deseo de poder, la dominación simbólica, las pasiones, el inconsciente.

El saber no es neutral, hay un rango epistemológico en la percepción del mismo que incide en la valoración subjetiva que el individuo haga de él, que sin dudas debe ser advertido en el análisis de la elección de la oferta de capacitación. En el capítulo 3 se analiza la valoración individual de las distintas fuentes que conforman el saber docente y su incidencia en la elección de la capacitación. 
Charlot (2000) advierte que no hay saber ni sujetos del saber solos, el saber es en relación. Esto implica que el saber adquiere sentido en diferentes sistemas de sentido, y permite pensar que la elección de la oferta de capacitación va a estar condicionada por diferentes dimensiones del individuo, no solo por su posición en el campo, es decir que además de las normas que regulan la carrera y el trabajo docente, otros factores como su formación inicial, su trayectoria como alumno, la edad, el sexo, la trama vincular y otros aspectos de su historia personal podrían ejercer incidencia en la creación de los sistemas de sentido, lo cual permite advertir múltiples sentidos en la elección de la capacitación. Pensar la particularidad de los sistemas de sentido, que se construyen en la relación con el saber en las experiencias de capacitación, implica también pensar que la metodología desde donde son abordadas y las características de quienes las dictan. Marcan formas de aprender en relación con el saber, las cuales exceden al contenido y pueden o no entrar en contradicción con aspectos relativos a la autopercepción docente. Esto implica preguntarse: ¿Quién soy yo para los otros y para mi mismo? ¿Qué soy capaz de aprender y que no? Preguntas que pueden operar en la desvalorización o en la jerarquización del saber docente.

Charlot (2000) trabaja la relación con el saber como una cuestión identitaria, en las que advierte una relación epistémica y una relación identitaria, las cuales implican que aprender tiene sentido en referencia a la historia del sujeto, a sus expectativas, a sus referencias, a su concepción de vida, y a sus relaciones con los otros, a la imagen que tiene de sí y a la que quiere dar a los demás (Charlot, 2000)

Además de la dimensión epistémica e identitaria, es importante considerar la dimensión social que contribuye a darle a ambas una forma particular ya que como señala el autor: "o sujeito não tem, por um lado, uma identidade, por outro, um ser social: esses aspectos são inseparáveis" (Charlot, 2000: 73). No obstante, que la relación social con el saber sea social no quiere decir que debe ser puesta en correspondencia con la posición social (Charlot, 2000).

Para el análisis de esta relación con el saber en el capítulo 3 se presenta el análisis de las entrevistas a los referentes de la capacitación del distrito y a docentes, y se busca indagar en la mirada y el interés de los docentes sobre las opciones de capacitación.

\subsection{Algunas consideraciones teóricas sobre las entrevistas}

Parto del análisis que realiza Lahire (2006) de lo que llama una "teoría de la acción", teoría práctica del conocimiento y la reflexividad, que está básicamente centrada en el 
límite entre lo que los actores hacen, saben y dicen que saben. Tiene como objetivo conocer las prácticas y los saberes efectivos de los actores a partir de la frecuente no conciencia de lo que somos, hacemos y sabemos, lo que evidencia un desfasaje entre lo que los actores saben y hacen y lo que dicen que saben y hacen ${ }^{12}$.

El autor advierte que entre las prácticas y los discursos sobre las prácticas suele haber contradicciones. Así al pensar la elección de la oferta de capacitación desde las dimensiones identitaria, epistémica y social que intervienen la relación con el saber Charlot (2000) sostiene que éstas podrían presentarse a través de una manera no legítima de decirse, corriendo el riesgo de silenciar o menoscabar argumentos de importancia.

Esta advertencia implica reflexionar sobre los marcos y los medios propuestos a los entrevistados.

Considerar los aportes de "la teoría de la acción" de Lahire (2006) atendiendo al desfasaje entre lo que los actores saben y hacen y lo que dicen que saben y hacen, también permite sumar al marco teórico algunas reflexiones de Tardif, y Gauthier (2005) sobre las exigencias de racionalidad que define al saber docente.

Estos autores advierten que no existe una única definición de saber y que la definición que propone es solo una de las definiciones posibles.

Su definición va a ser necesariamente de uso restrictivo porque va a reflexionar sobre una parte del saber "el saber de los maestros" partiendo de determinadas concepciones del saber que va a ajustar a las exigencias de racionalidad.

Así proponen tres concepciones de saber:

a) El sujeto y la representación: aquí lo importante es la certeza subjetiva propia de saber a la que puede arribarse, ya sea por una intuición intelectual que conduzca a la verdad, o por una forma de representación que resulte de una cadena de razonamientos. Por lo tanto señala "la subjetividad es considerada aquí el lugar del saber" (323: 2005)

b) El juicio y el discurso asertivo: aquí el saber es el juicio verdadero, el discurso que afirma con razón alguna cosa acerca de otra.

c) El argumento y la discusión: aquí el saber es la actividad discursiva que intenta validad una proposición o acción, con la ayuda de argumentos, operaciones lingüísticas y discursivas.

$12 \quad$ Este desfasaje está vinculado a la acción de los sujetos frente al determinismo y a su posibilidad de administrar de manera conciente y racional sus propias disposiciones (Bourdieu y Wacquant 1995) 
Lo importante de estas tres concepciones del saber es que tienen en común vincular la naturaleza del saber con alguna exigencia de racionalidad. De acuerdo a esto "saber hacer una cosa de forma racional es ser capaz de responder a preguntas como: ¿por qué usted dice esto? ¿por qué hace aquello?” (328; 2005). De modo que desde este abordaje, solo podrá llamarse saber, a los pensamientos, las ideas, los juicios y las argumentos que respondan a ciertas exigencias de racionalidad.

Lo valioso de esta perspectiva de análisis sobre el saber docente es que aporta elementos para estudiar la elección que los docentes realizan frente a la oferta de capacitación, porque conforma una visión de la investigación que implica observar a los actores, hablar con ellos e indagarlos sobre los saberes en que se apoyan para actuar, y a través de los cuales argumentan sus elecciones.

La idea de las exigencias de racionalidad que proponen Tardif y Gauthier: "no remite a un actor hiperracional, cuya acción y discurso derivan de un conocimiento completo de la situación, al contrario, creemos que estas exigencias se deben a una racionalidad fuertemente marcada por el saber social, saber (en) común y compartido por una comunidad de actores, saber práctico que responde a varias "lógicas de comunicación" y está enraizado en razones, motivos e interpretaciones que apelan a varios tipos de juicio" (2005; 333)

Lahire (2006) ayuda a pensar el abordaje metodológico de las exigencias de racionalidad que proponen Tardif y Gauthier (2005) para la definición y el análisis del saber docente desde una perspectiva que permite indagar e integrar las dimensiones identitaria, epistemológica y social que Charlot (2000) considera en la relación con el saber.

En síntesis, esta tesis se propone analizar las elecciones de los docentes respecto de la oferta de capacitación haciendo uso de los conceptos de la teoría de los campos de Pierre Bourdieu. En términos metodológicos, el análisis está atravesado por las advertencias que provienen del reconocimiento de la naturaleza del saber docente. En los próximos capítulos se desarrollan estas categorías en el análisis del material empírico.

\section{Bibliografía}

Bourdieu, P. (1997). Razones Prácticas. Barcelona: Editorial Anagrama. 
Bourdieu, P. (1979). "Los tres estados del capital cultural", en Actes de la Recherche en Sciences Sociales $N^{\circ} 30$. Trducción por Emilio Tenti.

Bourdieu, P. y Wacquant, L. (1995). Respuestas: por una Antropología Reflexiva. México: Grijalbo.

Charlot, B. (2000). Da relação com o saber: elementos para uma teoria. Porto Alegre: Artes Médicas Sul.

Corcuff, P. (2005). "Lo colectivo en el desafío de lo singular: partiendo del habitus" en: Lahire, B. (Dir.) El trabajo sociológico de Pierre Bourdieu: deudas y críticas. Buenos Aires: Siglo XXI Editores, p. $113-142$.

Davini, M.C. (1995). La formación docente en cuestión: política y pedagogía. Buenos Aires: Paidós.

Díaz, M. (1995). “Aproximaciones al campo intelectual de la educación”, en Larrosa, J. (Ed.) Escuela, poder y subjetivación. Madrid: Ediciones La Piqueta, p. 333 - 361.

Lahire, B. (2006). A cultura dos indivíduos. Porto Alegre: Artmed.

Lahire, B. (2006). "Lógicas prácticas: el hacer y el decir sobre el hacer", en: Lahire, B. El espíritu sociológico. Buenos Aires: Manantial, p. 137 - 155.

Serra, J. C. (2004). El campo de la capacitación docente. Políticas y tensiones en el desarrollo profesional. Buenos Aires: FLACSO - Miño y Dávila.

Tardif, M. y Gauthier, C. (2005). "El maestro como "actor racional": racionalidad, conocimiento, juicio", en: Léopold, P. (Coord.) La formación profesional del maestro: estrategias y competencias. España: Fondo de Cultura Económica, p. 309 354.

Tardif, M. (2004). Los saberes del docente y su desarrollo profesional. Madrid: Narcea. 


\section{CAPítulo II}

\section{Algunas consideraciones sobre la capacitación docente Viejos y nuevos condicionantes}

\subsection{Introducción}

La intención de este capítulo es analizar las condiciones para la elección de la oferta de capacitación estatal y privada efectuada por los docentes del área de Educación Física del nivel secundaria del sector estatal, en el distrito de La Plata durante el 2007-2009, partiendo de la conformación del programa institucional como una matriz del discurso pedagógico moderno, para luego centrarme en el análisis del surgimiento y desarrollo de la disciplina Educación Física en la Argentina y su correlato en las políticas de capacitación y formación docente.

Desde esta perspectiva cobran relevancia procesos de reformas e innovaciones escolares considerando los viejos y nuevos condicionantes que influyen en las políticas de capacitación. Para la perspectiva de análisis retomo los conceptos de "programa institucional" (Dubet; 2004, 2006), de "cultura escolar" (Viñao, 2002) y de "gramática escolar" (Tyack y Cuban, 1995). En el análisis que planteo se presta particular atención a las disputas y transformaciones sobre el sentido de la profesionalización en el marco de la retórica de las reformas (Southwell, 2008, 2009, 2011) y a la constitución de la profesionalización docente en la Educación Física.

\subsection{La constitución del programa institucional (1870- 1930)}

El desarrollo del Estado generó la rápida expansión de una red burocrática que implicó la especialización para el desempeño de la tarea docente y la certificación para el monopolio de esa especialización. La conjunción de estos elementos llevó a que en la producción de la fuerza de trabajo docente se fuese configurando un conjunto de prácticas específicas que definieron qué es ser un docente. En este momento la vocación definió al trabajo docente y la profesionalización quedaba subordinada al saber técnico subsidiario de esa vocación (Alliaud, 1993).

El proceso de burocratización del Estado, junto a la expansión del sistema educativo fueron moldeando la normativa respecto a la conformación de una profesión que en sus 
límites y autonomía debía ser regulada, sobre todo considerando al Estado como el responsable de la educación y, al mismo tiempo, como empleador de la fuerza de trabajo docente. Se constituye lo que Dubet define como programa institucional: " $l a$ ampliación de la empresa escuela en la formación de los individuos, la modernidad del siglo XIX y la primera mitad del siglo XX asumió una forma escolar, un modelo de socialización que yo caracterizo como un programa institucional. La palabra programa debe ser entendida en un sentido informático, el de una estructura estable de información pero cuyos contenidos pueden variar de manera infinita" (Dubet, 2006: 17). De acuerdo con Dubet este programa puede ser definido por cuatro grandes características:

a) Valores y principios fuera del mundo, al respecto señala "la escuela siempre está ubicada bajo la empresa de un modelo cultural "fuera del mundo, como una ciudad ideal. Es evidente que la iglesia es la madre de este programa en la medida que ella quiso fabricar cristianos alejados de la cultura profana" (Dubet, 2006: 17)

b) La vocación, lo que implica que los profesionales de la educación deben ser definidos por su vocación más que por su oficio.

c) La escuela es un santuario, en la medida que se identifica con los principios "fuera del mundo", debe estar protegida de los desordenes y pasiones que suceden en el contexto social.

d) La socialización también es una subjetivación: el programa institucional descansa en la noción de que el sometimiento a la disciplina escolar engendra autonomía y libertad en los sujetos, alimentado la creencia pedagógica según la cual la libertad individual nace del sometimiento a la figura de lo universal.

El programa constituido de este modo consolida la autoridad docente que se basa en valores y principios indiscutibles. Al mismo tiempo la escuela posee la capacidad de externalizar sus problemas considerando que las dificultades provienen del medio ambiente, de modo que las dificultades en su funcionamiento no orientan la crítica hacia ella misma sino hacia la sociedad, y por último en la medida en que se apoya en las 
vocaciones, la institución escolar puede ser una organización relativamente simple basada en un orden mecánico (Dubet, 2006).

Al mismo tiempo que se consolida el programa institucional moderno en la Argentina, en un contexto marcado por la inmigración y de preocupación por el estado sanitario de la población, se produjo la conformación de la Educación Física como disciplina escolar. Esta va a reunir saberes de tres campos que se articulan, negocian y se enfrentan: el campo cultural de las actividades físicas y deportivas constituido por actores de variada procedencia (militares, esgrimistas, deportistas y gimnastas), el campo de las ciencias biológicas, sociales y de la salud integrado aunque no exclusivamente por médicos higienistas, y el campo pedagógico constituido por los pedagogos y maestros el cual delimita y ordena los discursos que pretenden entrar a la escuela desde otros ámbitos (Aisenstein, 2003).

Desde los preceptos homogeneizadores del discurso pedagógico moderno la Educación Física va a contribuir al moldeado del cuerpo del hombre argentino y a la "mejora de la raza”. En síntesis se conforma como una disciplina que apunta a la educación integral: intelectual, moral y física (Aisenstein, 1999).

Aisenstein (1998) señala que es el Dr. Romero Brest quien crea el "Sistema Argentino de Educación Física" a través del cual vierte las principales ideas del modelo "fundacional hegemónico" que legitima a la Educación Física el cual se caracteriza por una perspectiva metódica, continua y racional orientada hacia cuatro efectos: 1) Higiénico; 2) Estético; 3) Económico y 4) Moral. Fundamenta la necesidad del cambio educativo, para producir cierto cambio social --mejora del pueblo y la raza-- ubicando así a la Educación Física entre las disciplinas pedagógicas de la modernidad. También explica que la condición pedagógica de la clase debe estar garantizada por la disciplina del trabajo, entendida como disciplina razonada acorde a la conformación de un país republicano, y no como obediencia de tipo militar.

Con Romero Brest, la discusión didáctica se sintetiza en el debate entre la Educación Física racional fundamentada en las ciencias positivas, la anatomía y la fisiología versus la gimnasia empírica. Es el anclaje científico que la Educación Física halla en las ciencias naturales lo que le permite en aquel momento fundamentar su razón de ser en la escuela (Aisenstein, 1999).

De acuerdo a las características del modelo fundacional, las demandas de profesionalización para quienes se ubiquen al frente de las clases de Educación Física no se distancian de las que se les exigen al resto de los docentes. Estará asociada a "el 
lugar del que sabe, del que vigila, del que es capaz de contribuir a la producción de saberes en la institución escolar de una manera correcta" (Southwell, 2009: 117).

\subsubsection{La capacitación en el momento de constitución del programa institucional}

Desde fines del siglo XIX, en los inicios del sistema educativo argentino, la capacitación es una dinámica incorporada tanto al trabajo como a la carrera docente. Como señala Birgin (1999), históricamente entre las iniciativas que conformaron la oferta de capacitación se encontraban: las conferencias pedagógicas referentes a cuestiones prácticas y doctrinales, la concurrencia a institutos Superiores de Pedagogía, los debates en revistas pedagógicas (Pineau, 2012). Asimismo los inspectores eran otra vía de capacitación legitimando su cargo con la difusión de un saber experto (Dussel, 1995), así como también los grupos de docentes que se autogestionaban espacios de actualización motivados por sus propios intereses para abordar problemáticas específicas.

En este marco el Estado se afianza como responsable de impulsar y regular la política pública referente a la capacitación. En este momento surgen y se consolidan aspectos del programa institucional, que junto a los sentidos de cultura y gramática de la escolaridad ${ }^{13}$ sirven para pensar los cambios y regularidades frente a las reformas. En el marco del programa institucional, la necesidad de un saber técnico en la formación docente y en la capacitación, fue moldeando una gramática de la escolaridad, que vincula la capacitación con la obtención de "recetas" de enseñanza provenientes del saber experto. Pero al mismo tiempo es posible pensar que la cultura escolar posibilitó la reinterpretación de los contenidos de la capacitación por parte de los docentes, y la búsqueda de contenidos a través de acciones autogestionadas de capacitación acorde a sus propios intereses.

\subsubsection{La formación docente en Educación Física en el momento de constitución del} programa institucional

En los años posteriores a la Ley de Educación Común (Ley 1420) aprobada en 1884 "la Gimnástica es abordada por maestros o por algunos profesores extranjeros y el objetivo principal es el desarrollo muscular" (Aisenstein, 1999: 149). Los programas

\footnotetext{
13 La gramática escolar hace alusión a aspectos estrictamente instruccionales -y mantiene una preocupación por la permanencia frente a las reformas-, mientras que la cultura escolar es una categoría más amplia, que aborda otros aspectos más allá de los relativos a la enseñanza -recuperando una preocupación por el cambio no tan presente en la idea de gramática escolar
} 
contienen ejercicios gimnásticos, que buscan uniformidad, con muchas ejercitaciones rígidas tomadas del orden castrense (Saraví Riviere, 1999).

Esto se explica a partir de dos cuestiones: en primer lugar no existe aún un espacio destinado a la formación docente sistemática en Educación Física, ya que recién en 1901 se inician los cursos temporarios de ejercicios para maestros, y en segundo lugar cobra relevancia la llegada de los ofíciales del ejército a las escuelas. A partir de 1895 se decreta la obligatoriedad de la enseñanza militar en todos los institutos de educación secundaria y normal y se prescribe que en colegios y escuelas de las provincias se den clases de gimnasia e instrucción militar (Aisenstein; 1999).

En los antecedentes de la formación docente sistemática hay que señalar que por una decisión ministerial, el decreto del 8 de octubre de 1901 crea el Primer Curso de Educación Física de Vacaciones, que debía comenzar a funcionar desde el 20 de diciembre de 1901 hasta el 20 de febrero de 1902, bajo la Dirección del Dr. Romero Brest. A este curso fueron invitados quienes tenían a su cargo los ejercicios físicos en los establecimientos nacionales de educación secundaria, normal y especial, los maestros y maestras de grado de las escuelas anexas a las Normales y los alumnosmaestros de escuelas Normales, desde $4^{\circ}$ año inclusive en adelante.

En 1906, luego de 5 cursos temporarios impartidos, fueron declarados permanentes. El 1 de febrero del mismo año se cambia el nombre a Curso Normal de Educación Física y este hecho se considera como la fecha de fundación del Instituto Nacional de Educación Física. Aunque en realidad no es hasta 1909 cuando el Ministro Rómulo Naón por decreto la declara Escuela Normal de Educación Física, y recién en 1912 es elevada a Instituto Superior de Educación Física. Todo esto bajo la dirección del Dr. Romero Brest.

La formación docente en Educación Física adquiere carácter institucional definido a partir la creación del Instituto Nacional de Educación Física en 1906. Al respecto Scharagrodsky señala "El Sistema Argentino de Educación Física se implementó durante las tres primeras décadas y media del siglo XX en las escuelas argentinas, siendo en Instituto Nacional de Educación Física de Buenos Aires el centro de difusión neutral y, a la vez, soporte de principios y presupuestos" (Scharagrodsky, 2011: 55).

En términos generales cabe advertir que, como tantas otras profesiones, los profesores de Educación Física se forman en circuitos educativos diferenciados donde conviven regímenes y jurisdicciones diferentes con objetivos y alcances diferentes. Así en sus 
inicios la formación docente sistemática estuvo hegemonizada por los Institutos Nacionales y Provinciales de Educación Física (Villa, 1997).

\subsection{Aumento en presencia de la disciplina Educación Física en el curriculum escolar (1930- 1970).}

En este período merece especial consideración la experiencia desarrollada durante el gobierno de Manuel Fresco en la provincia de Buenos Aires (1936-1940). Bejar advierte que aunque el gobierno de Fresco coincide con los rótulos de "fascista", "conservador fraudulento", "nacionalista de derecha", es importante señalar que "no ignoró los desafios de su tiempo, provocó realineamientos políticos significativos y articuló prácticas y concepciones políticas que alcanzarían una prolongada inserción en la sociedad argentina" (Béjar, 1992: 85). En este sentido, aunque se resignificó la matriz militar de la Educación Física escolar, lo que motivó el declive y la jubilación compulsiva de la figura de Romero Brest (Scharagrodsky, 2011), la valoración del desarrollo físico como la expresión de la vitalidad de una sociedad y una raza, como exaltación del valor a la patria y sus tradiciones y como factor cohesionador de la sociedad, dieron un nuevo impulso la Educación Física como asignatura.

En el marco de las políticas educativas, en 1936 el Poder Ejecutivo provincial dispuso por decreto la creación de la primera Dirección de Educación Física y Cultura del país (Scharagrodsky, 2011). La intención era que su presencia se haga sentir más allá del ámbito escolar y llegase a la población en general. Se encargó de "la organización de reuniones deportivas y recreativas en estadios locales, como una forma de acercar a los padres y a los hijos al deporte. Además la Dirección debía brindar su colaboración a la escuela en el terreno de la asistencia social y de la difusión cultural, organizando los comedores escolares y la distribución de ropas y útiles, y la programación de actos y conferencias de interés para la comunidad. Por último, y dado que se le confirió la misión de incentivar el sentimiento nacional, se abocó a la preparación de la escenografía de los actos escolares. Los imponentes desfiles organizados por la dirección estuvieron presentes en las principales conmemoraciones históricas, y fueron exaltados en el discurso oficial como una magnifica demostración del orden y la disciplina que tanto anhelaba el gobierno" (Béjar, 1992: 97)

Al interior de las escuelas, la Dirección de Educación Física y Cultura propuso la práctica de gimnasia diaria, deporte y tiro una vez por semana, aunque esto no se hizo efectivo por la escasez de recursos humanos y materiales. 
A través del gobierno de Fresco se revalorizó el peso y el papel de la Educación Física escolar. Esta orientación no se abandonó sino que se potenció a través de los sucesivos gobiernos.

En el marco de la evolución de la asignatura cabe destacar que el gobierno justicialista en sus dos primeros mandatos constitucionales (1946-1952 y 1952-1955) ubicó al deporte en un lugar predominante de su gestión a partir de varios aspectos: incorporó a la actividad a miles de jóvenes; fomentó la creación y desarrollo de instituciones deportivas; organizó competiciones nacionales e internacionales. El deporte se consolidó como un instrumento de producción de sentido: de imaginarios, símbolos y héroes de un nosotros "nacional y popular" (Massarino, 2002). Las clases de Educación Física para el nivel medio pasaron a tener de una a dos horas semanales. En este contexto tanto la asignatura como el trabajo del profesor de Educación Física adquieren mayor presencia la escuela.

\subsubsection{La expansión y fortalecimiento de la regulación del trabajo y la formación} docente

A fines de la década de 1950 se produce una verdadera conjunción de la regulación sobre distintos aspectos: la formación docente, la certificación de títulos, el ascenso en la carrera y la capacitación.

Las características y ventajas del programa institucional se consolidan con una mayor presencia del Estado que queda plasmada con la sanción del Estatuto del Docente. Al respecto, la heterogeneidad de opciones de capacitación presentes en los orígenes del sistema educativo argentino, sufrió una fuerte transformación con el desarrollo y la consolidación de una normativa específica respecto a la carrera docente. El "Estatuto del personal docente de la Nación", sancionado en 1958, les daba a los docentes un tratamiento específico, que los diferenciaba del resto de los trabajadores. En particular reglamentó la carrera docente estableciendo normas referentes al ingreso, la estabilidad, el ascenso y los destinos de los docentes.

El Estatuto Docente regula las relaciones laborales entre los docentes y el sistema educativo estatal. Constituye la normativa de mayor influencia en la configuración de la capacitación docente (Serra, 2004). En este sentido "fijó la necesidad de contar con cursos de perfeccionamiento y se definieron criterios de remuneración salarial" (Schueler y Southwell, 2011). El hecho de que la certificación de la capacitación posea un valor respecto de las posibilidades pautadas en la normativa para la carrera docente 
promovió y consolidó la lógica del puntaje en la valorización de la capacitación, que configura una marca en la gramática de la escolaridad.

La gramática "resultó de los esfuerzos de grupos que se movilizaron para obtener apoyo a sus definiciones de los problemas y a sus soluciones propuestas. Cuanto más poderosos y prestigiosos fueron los grupos, más probablemente lograron apoyar sus reformas con leyes, regulaciones y requerimientos de acreditación." (Tyack y Cuban 1995: 169)

Cabe señalar que el estatuto constituye un elemento importante en la regulación de la actividad docente en el marco del programa institucional. Da cuenta de una fuerte presencia del Estado en la reglamentación de la tarea, es el resultado de luchas de los sectores docentes por consolidar un grado de legalidad, que al mismo tiempo refleja las tensiones entre el control del Estado y la autonomía docente ${ }^{14}$. Al respecto Southwell señala que "los dirigentes sindicales entendieron la sanción del Estatuto como un avance en materia de organización gremial para la defensa de los derechos" (2011: 171). De este modo, frente a la posición de un sector de los docentes que definía su identidad ligada a la idea del apostolado guiado por la vocación, otro sector lo asociaba con la apropiación de competencias técnicas para un desempeño laboral preciso y a los intentos de desarrollar una identidad ligada al maestro trabajador sindicalizado empezaron a forjar una "conciencia profesional más cercana al "profesional trabajador" que a la del "profesional liberal" (2011; 172).

El Estatuto sufrió diversas modificaciones a través del tiempo pero en lo que refiere a la consolidación de la lógica del puntaje aún permanece sin cambios. Se promueve la búsqueda de puntaje a través de capacitación, lo que conforma un rasgo permanente en la mirada docente sobre la elección de la oferta de capacitación.

\subsubsection{La capacitación y el surgimiento de los expertos}

En la década de 1950 irrumpen en la Argentina las corrientes educativas de corte desarrollista y tecnocrático. Desde esta perspectiva se interpreta que la función del sistema escolar es atender a los requerimientos del desarrollo económico, suponiendo que la elevación del nivel educativo de la población contribuiría con dicho desarrollo.

14 Esta noción de autonomía se encuentra reflejada en la estructura del sistema de capacitación al respecto haré alguna consideración más adelante. 
Los conceptos como eficacia, eficiencia, tecnificación, modernización, evaluación adquieren una relevancia particular en la retorica de la reformas impulsadas por los organismos internacionales, en especial la Comisión Económica para América Latina (CEPAL) creada en 1948. En este contexto se produce una serie de cambios que van a impactar en la conformación de la formación docente y la capacitación. En primer lugar, se producen cambios en la conformación de los campos del saber y la institucionalización de los mismos como lo demuestra el surgimiento de instituciones de profesorado de nivel universitario. Ligado a esto surge la figura del experto que implica la división del trabajo pedagógico entre quien planifica y quien ejecuta. A diferencia de la etapa anterior en la cual quienes se dedicaban a motorizar las capacitaciones eran los propios docentes, son los expertos quienes se ponen al frente de la prescripción del saber.

El docente pasa a ser considerado como un "práctico idóneo que aplicaba una serie de prescripciones que eran diseñadas por diferentes especialistas que trabajaban en la administración o el planeamiento educativo, diseñadores exteriores del curriculum, confeccionadores de material didáctico, reguladores y evaluadores externos" (Southwell, 1997: 133-134).

Esto coloca la autoridad del saber en los expertos devaluando el saber de los propios docentes. La legitimidad del saber experto expresado por un especialista y consagrado por determinadas instituciones adquiere un peso que va a conformar una mirada muy duradera en la elección de la capacitación.

Southwell advierte que se produce la combinación de dos posiciones, las corrientes espiritualistas y el tecnocratismo. Los primeros formaron parte de la constitución del sistema educativo argentino que abogaron por la idea que "nos enseñó esa posibilidad de entendernos ilimitados, la superación de las miserias estaba unida a trascender los valores espirituales, el desarrollismo conjugó estos elementos en la búsqueda del desarrollo sin límites y la búsqueda de superación de situaciones a partir de la previsión y la sistematización orientada hacia nuevos fines" (Southwell, 1997: 138)

\subsubsection{La profesionalización de la Educación Física en el nivel universitario}

Desde la creación del INEF la institucionalización de la formación docente sistemática, quedó constituida por circuitos tradicionales que incluyen los Institutos Nacionales y Provinciales de Educación Física y la oferta de los Institutos del ámbito privado (Villa, 1997). En el año 1953 se suma a estos circuitos el Profesorado Universitario de 
Educación Física (PUEF) que forma parte de la Facultad de Humanidades y Ciencias de la Educación de la $\mathrm{UNLP}^{15}$, que se crea a instancias del Prof. Alejandro Amavet. Además de formar para el trabajo en los distintos ámbitos, en particular desde sus inicios se ocupó de fortalecer la formación pedagógica para el trabajo en la escuela (Villa, 2011).

En las décadas de 1960 y 1970, con el desarrollismo, dos expresiones de la pedagogía cobran fuerza. Por un lado, las que buscaban la transformación del orden social con Freire como referente, y por el otro la que finalmente se profundizó en el contexto autoritario y de inestabilidad institucional, la del "control ideológico y la utilización de las nuevas tecnologías como garantía de la modernización que se articularon con una noción de "profesionalidad" entendida como eficiencia, vocación y eficacia técnica" (Southwell, 2011: 175). El abordaje del deporte escolar se ajusta a una perspectiva tecnicista acorde al modelo de la pedagogía por objetivos y a los movimientos estereotipados junto a los conceptos como eficacia, eficiencia y a una mirada de la evaluación en términos de resultados medibles y observables (Aisenstein, 2002). El enfoque biológico y estadístico de la materia "Evaluación" acentúa su peso en el curriculum de la formación docente (Aisenstein, 1999).

El inicio de la formación universitaria de profesorado coincide con una fuerte presencia del saber experto en las políticas de capacitación, lo cual va a legitimar un modelo de capacitación que incide en la construcción de sentido que adquiere la elección de la capacitación por parte de los docentes.

\subsection{Las desregulaciones del programa institucional en la reforma de la década de 1990: efectos y consecuencias}

La década de 1990 en la Argentina coincide con lo que Dubet (2004) define como la "declinación del programa institucional", señalando un sentimiento de crisis por parte de los docentes en el que "la legitimidad de la escuela y de su cultura se ha derrumbado porque la escuela perdió su carácter sagrado para convertirse en un servicio cuya utilidad se dispute en detalle y se mide progresivamente mediante estudios y encuestas nacionales e internacionales" (Dubet, 2004: 25).

15 La creación coincide con los cambios curriculares que se producen en la segunda mitad del siglo $\mathrm{XX}$ el campo disciplinar de la educación física, los métodos meticulosos y precisos de la sociedad disciplinaria, comienzan a ser reemplazados por formas más liberadas de educación corporal en las escuelas que priorizan al deporte en la escuela, media y a los juegos en el nivel primario (Scharagrodsky y Aisenstein 2006). 
El derrumbe de la legitimidad se debe tanto al aumento de la distancia entre la cultura de masas respecto de la cultura y gramática escolar, como a la introducción de la política y el discurso económico neoliberal, que condujo al quiebre de la idea de igualdad presente en la matriz homogeneizadora que caracteriza a la constitución del sistema educativo. Así, las cuatro grandes características que definen en su origen al programa institucional (a) Valores y principios fuera del mundo, b) La vocación, c) La escuela es un santuario $y$ d) La socialización también es una subjetivación) son fuertemente trastocadas por los cambios culturales y económicos.

Respecto a los cambios culturales, Dubet (2004) se refiere a aquellos que cuestionan la legitimidad de la autoridad escolar, advirtiendo la creciente distancia entre la cultura de masas basada en la rapidez y la satisfacción inmediata y la cultura escolar que demanda esfuerzo y postergación de resultados y beneficios culturales y sociales.

En nuestro país estos cambios culturales estuvieron acompañados por cambios en la política económica direccionados por las pautas de los organismos multilaterales de crédito. Al respecto Bonal (2002) advierte que los '90 fueron la expresión de las pautas del neoliberalismo para América Latina, y señala cómo estos organismos sólo otorgaban préstamos a los países que se comprometían a estabilizar sus economías y a llevar a cabo un plan de reformas estructurales ${ }^{16}$.

De acuerdo a los criterios y a las presiones de los prestamistas, para obtener el crédito los países que lo solicitaban debían ajustarse a sus lineamientos, sometiéndose al efecto perverso de sus recetas, las cuales "nos pondrían en el camino del desarrollo", pero que por el contrario solo condujeron al aumento de la deuda externa y recortes en los gastos sociales. Estas políticas de reforma estructural implicaron efectos directos e indirectos sobre las políticas educativas, que se expresan en una fragmentación del sistema educativo (Tiramonti, 2004) y en la consecuente hiper-responsabilización de la escuela y la actividad docente (Martinis, 2006), dado que mientras el Estado reducía gastos en otras políticas sociales, trasladaba esa responsabilidad al sistema educativo y por consiguiente a la actividad docente. Así al tiempo que se aumentaba la carga sobre la tarea docente, se impulsaba un discurso económico desde la política educativa que promovía la evaluación de la institución.

16 Las medidas de ajuste incluían: la apertura comercial la liberación de los tipos de cambio, la caída del precio de las materias primas en el mercado internacional, la privatización de las empresas estatales y la desregulación del mercado de trabajo (Bonal, 2002) 
Estos aspectos expresan una presión sobre el profesorado, con un continuo maltrato desde las políticas impulsadas por el Banco Mundial sobre el sector docente, que incluyen la reducción salarial, el deterioro de las condiciones laborales y el aumento de los sistemas de supervisión (Bonal, 2002).

Respecto al significado que reviste la profesionalización se expresan dos posiciones cruzadas entre los lineamientos de los organismos internacionales ${ }^{17}$ ligados a la "excelencia" a través de la formación permanente y a la evaluación para la mejora de la calidad, y la de los gremios docentes ligada a la "dignificación" del trabajo docente (Southwell, 2008).

Tanto los cambios culturales como el discurso y la política económica de la década de 1990, alimentaron una mirada nostálgica por parte de los docentes respecto a las bases del programa institucional. Sin embargo es preciso considerar, como advierte Dubet (2004), que las políticas neoliberales brindaron la posibilidad de pensar una crítica endógena de la escuela, algo que jamás se asoció con la crítica "anti-ultra-neoliberal".

\subsubsection{La estructura de la política de capacitación en la década de 1990, su} conformación, cambios y continuidades

La reforma de la década de 1990 implicó la descentralización educativa y la consecuente redistribución de las responsabilidades educativas entre el nivel nacional y subnacional del Estado (las provincias). La institucionalización de la formación continua se constituyó a partir de la Red Federal de Formación Docente Continua (en adelante RFFDC), lo que implicó una diferenciación entre la responsabilidad política y la oferta de las acciones de formación docente continua.

Es decir que se estableció una diferenciación entre responsables y oferentes en donde el Estado podría cumplir el rol de oferente pero además se encargaría de regular la oferta, acreditando a las instituciones oferentes, de modo que cada provincia reconocía los cursos de formación continua a través de un sistema de puntaje que se encuentra asociado a la carrera docente, en lo que respecta al acceso a los cargos y a la promoción escalafonaria. De manera que el modelo de formación continua quedaba estructuralmente configurado por regulaciones a la oferta, pero con flexibilidad a la demanda por sus contenidos, ya que permitía a los docentes elegir las opciones de

$17 \quad$ (OEI, UNESCO, BID) 
capacitación de acuerdo a la metodología y a la temática que abordan (Finocchio y Legarralde, 2006) ${ }^{18}$.

En este sentido Bonal señala que: "muchas de las reformas dirigidas a la descentralización de los sistemas de enseñanza no persiguen prioritariamente la mejora de la productividad sino mayor control sobre el trabajo docente y aliviar la responsabilidad financiera y de gestión de los gobiernos centrales" (2002; 13). En la estructura de la política de capacitación el Estado mantuvo la misma orientación que para el resto del "mercado educativo": descentralizó, como señalan Martínez, Villa y Seoane: "no cesó en su función reguladora y de control ante el aparente otorgamiento de mayor libertad para los individuos" (2009; 32).

La combinación de los conceptos de libertad y regulación que se construye con la descentralización, llevan a pensar la noción de autonomía docente desde su utilidad en el planteo de la política de capacitación. Esta noción de autonomía pudo ser aprovechada para que el Estado amplíe el mercado de la capacitación, delegando el costo de la tarea en los oferentes privados. Al pensar la reforma en la estructura de la capacitación, otro elemento importante asociado a la descentralización está en el peso de la acreditación de la institución oferente.

\subsubsection{La lógica de la acreditación vs la lógica del puntaje}

En esta política de capacitación, el peso de la acreditación de la institución oferente regulada por parte del Estado podría haber reordenado la oferta en base al prestigio de la institución, desplazando o empezando a desplazar la lógica del puntaje que se consolidó en la cultura docente a partir del establecimiento del Estatuto de 1958.

Sin embargo, el hecho de que la certificación de la capacitación posea un valor respecto de las posibilidades pautadas en la normativa para la carrera docente, promovió el desarrollo de una industria de la capacitación privada en la que el Estado, al parecer, delegó gran parte de sus funciones y el costo de la tarea (Serra, 2004). La oferta de

18 Así en nuestro país hay una regulación estatal de quiénes están habilitados a ofrecer capacitación, pero no se regulan "todos" los contenidos. Las líneas de capacitación donde el estado nacional o provincial es el oferente, están determinadas por una oferta centralizada. El resto de los oferentes participa de definiciones de distinto tipo, y generalmente las universidades, los gremios, los privados, entre otros, definen los temas a partir de la demanda.

En general los contenidos que ofrecen se ajustan a los saberes de los campos tradicionales que se disputan en la conformación de la asignatura (Ainsestein, 2003), pero se distingue además la oferta para formación en saberes para concursar en la carrera docente generada especialmente por los gremios y oferentes privados. 
capacitación estuvo moldeada entre otras cosas por la normativa respecto al valor de la acreditación en el marco de la carrera docente, y por los cambios que atañen a la política educativa, en lo que concierne a la implementación y el impacto de las reformas. En este sentido el discurso que acompañó a la oferta de capacitación en la década de 1990 encontró fuerte resistencia desde algunos espacios como los sindicatos, que defendían el valor del saber docente en medio del continuo descrédito. El término "profesionalización" se puso en el centro de la controversia.

Los aspectos vinculados a la cultura escolar que permiten a los docentes "sobrevivir a las reformas" se hicieron presentes para defender su lugar de trabajo docente y su autonomía. Al mismo tiempo aspectos relacionados a la valoración de la capacitación asociados al puntaje parecen haber estado muy consolidados en la gramática, al punto de no permitir que la acreditación del oferente pese sobre el puntaje en la elección.

Al parecer la intención de la reforma, en lo referente a la política de capacitación, pretendía orientar la elección valorando el peso de la acreditación del oferente, pero no logró imponerse en el corto plazo frente a la lógica del puntaje en la valoración de la oferta arraigada en la gramática. Al respecto, Tyack y Cuban señalan que "una razón por la que es dificil cambiar la gramática es que las reformas en el aula, una mini escuela o una escuela, o un distrito ocurren dentro de un sistema que en gran parte es interdependiente" (1995: 210). Es decir, que para que este tipo de reforma tuviese efecto, no bastaba solo con cambiar la estructura sino era acompañaba con una ampliación de la oferta, a través instituciones valoradas por el peso de su acreditación y al mismo tiempo con una regulación que las sobrevalúe por sobre el resto de la oferta.

A partir de la década de 1990 la morfología de la oferta de capacitación también cambió con la expansión del mercado de la educación superior. La creación de las carreras de posgrado sumó una variante a las posibles expectativas de formación continua de los docentes ya que permite elegir entre el formato "curso" tradicional o una carrera. Lo que lleva a preguntarse ¿cómo incide la expansión de las carreras de posgrado en la posible elección de capacitación?

\subsubsection{De la vocación a la profesión. La reinterpretación del concepto de vocación}

Otro aspecto importante a considerar es el pasaje de la vocación a la profesión. Dubet (2006) aborda el estudio del trabajo docente desde una mirada que reúne la sociología del trabajo con la sociología de la socialización, para comprender cómo los sujetos 
"construyen su experiencia de trabajo, cómo jerarquizan sus orientaciones y elecciones culturales, cómo se vinculan en el trabajo estas orientaciones a lazos sociales" (2006: $31)$.

Para Dubet (2004) el trabajo es concebido por quienes lo llevan a cabo como un proceso institucional denominado "programa institucional", y la "decadencia del programa institucional" es en sí una mutación. En correspondencia con esto señala: "El programa institucional designa una forma peculiar de llevar a cabo el trabajo sobre los otros, puede definirse como un proceso social que transforma valores y principios en acción y en subjetividad por el sesgo de un trabajo profesional específico y organizado" (2006: 32).

En la conformación y transformación de este trabajo profesional específico $\mathrm{y}$ organizado se sitúa el análisis de la vocación / profesión, como un elemento clave para comprender los cambios en la identidad laboral docente, que resultan útiles para intentar comprender los intereses de los docentes respecto a la oferta y la dinámica de capacitación.

De acuerdo con Dubet (2006), dentro del programa institucional primitivo, la vocación se imponía sobre el profesionalismo, que constituía la encarnación de la vocación y su desarrollo técnico. Este sentido se consolida en la gramática escolar. Sin embargo a través de los cambios en el trabajo docente, la vocación se aleja del "deber ser" y adquiere un sentido menos mítico, más heróico, más protestante. En la actualidad, el término "vocación" ya no tiene buena prensa, debido a que evoca una suerte de adhesión ciega, una forma de compromiso total que choca de lleno con los valores de reflexividad, profesionalismo y dominio de sí. De modo que la connotación del término se desplaza de lo sagrado a lo profano, abandonando su matriz clerical.

Otro componente del rechazo actual del concepto de "vocación" proviene de los propios sindicatos que consideran que la vocación se asocia a un compromiso "desinteresado" con el trabajo docente. Esto ubica al docente en el lugar de quien asume su tarea sin considerarla en el fondo como un trabajo asalariado. Si esto es así, es un cambio importante porque también explica por qué el rechazo de la "vocación" se da paralelamente al fortalecimiento del "puntaje", ya que el "puntaje" ofrece la vía para una recompensa salarial.

Este desplazamiento de la vocación al profesionalismo implica cambios en la definición del trabajo docente, en los cuales la gramática que sustenta la vocación es reinterpretada 
en la interacción con la cultura escolar que se redefine a través los cambios en el trabajo docente.

Así el desplazamiento del peso planteado en el par conceptual vocación / profesión refleja en el trabajo docente procesos readaptación, de interpretación de búsqueda de intereses personales o gremiales frente a los mandatos de las reformas y las innovaciones educativas impulsadas desde la política pública como también frente a los cambios sociales que inciden en el trabajo de enseñar. En este punto quiero señalar que en las entrevistas a los distintos referentes de la capacitación provincial ${ }^{19}$, todos acuerdan en que a fines de los años '90 y principios del 2000 , hubo un cambio de actitud en quienes asistían a las capacitaciones: "aparece la necesidad de compartir lo que estaba sucediendo, de entenderlo, la idea de venir a escuchar al experto empieza a cambiar ${ }^{20}$ (Referente III). De este modo, los cambios promovidos por las políticas educativas de los '90 que motivaron el declive del programa institucional, son reinterpretados desde la cultura y la gramática de la escolaridad que se visualiza en un cambio de actitud en quienes asisten a las actividades de capacitación.

\subsubsection{El "Congreso de Educación Física" como una particularidad en la oferta de capacitación platense}

Desde 1993, la Facultad de Humanidades y Ciencias de la Educación de la Universidad Nacional de La Plata, a través del Profesorado Universitario de Educación Física (PUEF) organiza el "Congreso Argentino de Educación Física y Ciencias". El evento se repite cada dos años y el último se llevó a cabo en el mes de septiembre del 2013. Este Congreso cobra importancia en el marco del campo de la formación docente en Educación Física por dos cuestiones principales:

1) Por la fuerza simbólica y la legitimidad de la institución que organiza asociado al poder de convocatoria.

2) Por su vinculación con los egresados que trabajan en las escuelas.

19 Entrevistas: al representante de cultura de SUTEBA, a la asesora pedagógica de la dirección de educación física, a la inspectora de media y capacitadora del CIE La Plata para el área, a la responsable de Extensión y capacitación de la FHCE de la UNLP.

20 Frente al formato curso que puede ser considerado como el dispositivo de la capacitación hegemónico vinculado la fragmentación del saber, los gremios docentes planteaban estrategias de capacitación situadas en defensa de una perspectiva de la profesionalización que valorice el saber docente. 
Respecto al primer punto cabe destacar que la mayoría de los profesores de Educación Física que trabajan en el distrito se formaron en el PUEF (UNLP) ${ }^{21}$, si bien el Instituto Educativo CESALP y las carreras de Licenciatura y Profesorado de la UCALP se constituyen como otra oferta de formación en Educación Física en el distrito, para muchos el PUEF (UNLP) constituye un referente identitario en la formación y un espacio legítimo de circulación de saber.

Con relación al segundo punto, el Congreso establece una clara vinculación con quienes trabajan en las escuelas a través de una fuerte estrategia de difusión, al mismo tiempo que prevé el no cómputo de inasistencias para los puestos en el sistema educativo, por lo cual se presenta como una capacitación en servicio, y a pesar de que no otorga puntaje se constituye como una opción que eligen la mayoría de los docentes entrevistados.

Estas cuestiones lo vuelven particular porque es un evento convocante que conjuga la justificación de las inasistencias para quienes trabajan en el sistema educativo provincial, con el hecho de que lo convoca el espacio de formación principal dentro del campo de la educación física en La Plata.

Desde este encuadre, el congreso presenta continuidades y reconfiguraciones a lo largo de su historia desde 1993 hasta 2013. Respecto de las continuidades se incluyen la presentación, reflexión y análisis de las problemáticas diversas vinculadas a tres campos de estudio: el académico y el escolar y el profesional. Las temáticas recurrentes en las mesas de trabajo de los últimos tres congresos (2009, 2011 y 2012) abordan la relación entre Educación Física y: los discursos y las prácticas corporales, la teoría y la investigación, la educación e inclusión social, la escuela, la prevención y promoción de la salud, el deporte, la gestión y la formación profesional, la organización de torneos, eventos y competencias.

Respecto de las reconfiguraciones, en cada oportunidad el acento está puesto en un enfoque particular. Así, por ejemplo, entre los objetivos del $8^{\circ}$ Congreso realizado en mayo del 2009 se propone "analizar las diferentes políticas de enseñanza e investigación sobre las prácticas corporales en Argentina y Latinoamérica y promover la reflexión sobre el papel que a la Educación Física le cabe en relación con la educación y con la ciencia, tanto en la actualidad como en el futuro". Mientras que en el último Congreso el acento estuvo puesto en las "Prácticas de la Educación Física Escolar, Académica y Profesional" con la intención de ampliar la participación de los profesores por sobre el 
debate de la disertación erudita. En este sentido es posible advertir una clara intención de romper las fronteras entre los "prácticos" y los "teóricos" propiciando un espacio de encuentro y participación. Con una dinámica de participación que incita a compartir el saber a partir de diferentes formatos.

Entre las formas de participación se incluyeron la posibilidad de presentar trabajos a través de ponencias y posters y de escuchar a los distintos invitados del exterior, nacionales y de la UNLP. En el año 2007 y 2009 se sumó la posibilidad de participar en "cursos de actualización y perfeccionamiento" a los cuales los docentes podían inscribirse en forma opcional. Estos últimos estuvieron destinados a abordar temáticas vinculadas a la enseñanza del "deporte escolar" en los diferentes niveles, por lo cual la opción que convocó a muchos de los docentes que trabajaban en el sistema educativo ya que se vincula directamente con las problemáticas de trabajo en las escuelas. Así el formato "curso" que constituye la opción con mayor presencia en el campo profesional de los profesores que trabajan en las escuelas, se sumó a las opciones de participación características del campo académico (poster, ponencias y paneles).

Esta modalidad dejo de estar presente en el $9^{\circ}$ congreso organizado en el 2011, y se acentuó la presencia de otras formas de participación como: las clases abiertas, las muestras corporales, los eventos corporales, y los registros multimedia, que habilitan otras formas de encuentro e intercambio. Estas implican una relación más horizontal, corporal y casual con el saber, entre los que, a modo de ejemplo, se ofrece a los asistentes la posibilidad de participar en propuestas como: corre caminatas, deportes no convencionales, futbol y vóley mixto entre otras.

Cabe destacar que la diversidad en las modalidades de participación propicia la interacción de profesores que trabajan en el sistema educativo con quienes trabajan en la universidad y con aquellos que lo hacen en el campo profesional, ya sea vinculados al deporte de alta competencia, a la prevención de la salud, etc. Lo que habilita un modo particular de circulación del saber, que se distancia de la división que se impone los circuitos especializados de capacitación en los en los que alrededor de una temática que se inscriben saberes y prácticas específicos.

En síntesis, la riqueza del evento conjuga un alto poder de convocatoria con el abordaje de múltiples temáticas desde una dinámica que permite el encuentro de profesores trayectorias de trabajo y formación, que rompe con la distinción entre los "teóricos" y los "prácticos". 


\subsection{La Ley de Educación Nacional y los cambios y continuidades en la capacitación}

La Ley de Educación Nacional $\mathrm{N}^{\circ} 26.206$ (2006) marca un conjunto de continuidades y rupturas en el terreno de la formación docente continua respecto de la Ley Federal de Educación de $1993^{22}$.

El artículo 76 define un nuevo marco institucional al crear en el ámbito del Ministerio de Educación Ciencia y Tecnología, el Instituto Nacional de Formación Docente (INFD). Entre sus funciones se destacan:

- Aplicar las regulaciones que rigen el sistema de formación docente en cuanto a evaluación, auto evaluación y acreditación de instituciones y carreras, validez nacional de títulos y certificaciones.

- Coordinar las acciones de seguimiento y evaluación del desarrollo de las políticas de formación docente inicial y continua.

Como señalan Diker y Serra, la normativa opera en dos ejes claves respecto de la política implementada en la década anterior. "En primer lugar, afirma y consolida la intervención y regulación por parte del Estado nacional de la política de formación docente y reafirma la necesidad de un sistema integrado de dicha formación"... "En segundo lugar, implica la eliminación de la propia RFFDC, lo que se puede inferir a partir de su omisión en la ley y su reemplazo por el Instituto Nacional de Formación Docente (INFOD)" (Diker y Serra, 2008: 67)

De esta forma la política de capacitación se apropia de los avances de la política de la década de 1990 en materia de experiencia en la regulación del sistema de formación y al mismo tiempo, se desprende de los emblemas de la "reforma educativa menemista" y jerarquiza la formación docente, ya que el INFD posee jurídicamente más autonomía y mayores posibilidades de generar políticas de Estado que su antecesora la RFFDC (Diker y Serra, 2008).

Además del marco institucional en otros artículos se advierten cambios que implican una nueva perspectiva de la capacitación:

$22 \quad$ El antecedente se encuentra en la resolución del CFCYE N ${ }^{\circ} 223$ del 11 de agosto de 2004 que delinea un proyecto alternativo para desactivar el existente que aprueba nuevos lineamientos en el terreno de la capacitación expresados en el documento Politicas para la formación y el desarrollo profesional docente. 
En el artículo 67 del primer capítulo establece el derecho de los docentes " $A$ la capacitación y actualización integral, gratuita y en servicio, a lo largo de toda su carrera", (inciso b); y la obligación "a capacitarse y actualizarse en forma permanente" (Inciso c)

En la Ley Federal de Educación el derecho a la capacitación se vinculaba directamente a "la adaptación a los cambios curriculares" mientras que la nueva Ley se refiere a una capacitación integral, de modo que incluye cuestiones que sobrepasan lo curricular (Diker y Serra, 2008), y que concuerdan con una perspectiva más situada desde donde es posible considerar las demandas y los intereses de los docentes y las particularidades de sus ámbitos laborales.

En este sentido, es posible advertir que la presencia de la división entre los modelos pensados desde la oferta respecto a los modelos surgidos desde la demanda (Finocchio y Legarralde, 2006), fue dejando lugar a modelos que combinan ambas posiciones ya que si bien los contenidos pueden estar originados desde la oferta, pueden al mismo tiempo atender al carácter situado de las demandas. Lo cual implicó un cambio hacia nuevos modos en la forma de definir los contenidos y los dispositivos de la formación continua a partir de la construcción de problemas y la identificación y priorización de las necesidades de docentes y escuelas.

Esto no implica cambios en el valor que el puntaje tiene para los docentes, pero sí relativiza la consideración sobre el mismo ya que implica la presencia de otros intereses vinculados a la profesión que adquieren relevancia para la formación profesional.

Otro aspecto importante de la nueva Ley es la mención a la gratuidad como constitutiva del derecho a capacitarse. En este aspecto la Ley de Educación Nacional marca una continuidad respecto de lo que plantea la Ley Federal pero suma un importante cambio a nivel provincial que vincula el valor de puntaje al oferente.

\subsubsection{La implicancia en la provincia de Buenos Aires}

La Ley Provincial de Educación 13.688 (2007) retoma las orientaciones de la Ley Nacional y establece un marco específico para garantizar el derecho y la obligación de la capacitación. Para esto la Dirección General de Cultura y Educación establece a través de la Resolución $\mathrm{N}^{\circ} 4730$ que a partir del año 2008 las acciones de capacitación 
generadas por el nivel central duplican el valor de puntaje de una oferta similar $^{23}$ generada por otro oferente. Tal como lo señalan las siguientes tablas:

\begin{tabular}{|c|c|c|c|c|c|}
\hline & \multicolumn{2}{|c|}{$\begin{array}{c}\text { Acciones de capacitación } \\
\text { a nivel central }\end{array}$} & \multicolumn{2}{|c|}{ Otras } \\
\hline & & $\begin{array}{c}\text { Acciones } \\
\text { presenciales }\end{array}$ & $\begin{array}{c}\text { Acciones } \\
\text { a } \\
\text { distancia } \\
\end{array}$ & $\begin{array}{c}\text { Acciones } \\
\text { presenciales }\end{array}$ & $\begin{array}{c}\text { Acciones a } \\
\text { distancia }\end{array}$ \\
\hline \multirow{4}{*}{ 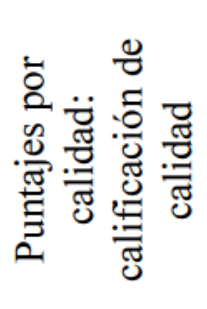 } & 70 a 78 & 0,12 & 0,06 & 0,06 & 0,03 \\
\hline & 79 a 87 & 0,18 & 0,09 & 0,09 & 0,04 \\
\hline & 88 a 95 & 0,24 & 0,12 & 0,12 & 0.06 \\
\hline & 96 a 100 & 0,36 & 0,18 & 0,18 & 0,09 \\
\hline \multirow{5}{*}{ 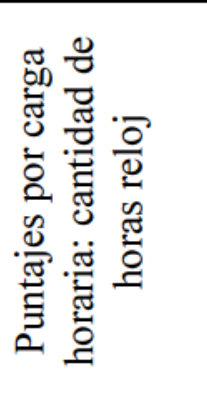 } & 20 a 36 & 0,08 & 0,04 & 0,04 & 0,02 \\
\hline & 37 a 53 & 0,12 & 0,06 & 0,06 & 0,03 \\
\hline & 54 a 70 & 0,16 & 0,08 & 0,08 & 0,04 \\
\hline & 71 a 87 & 0,20 & 0,10 & 0,10 & 0.05 \\
\hline & $\begin{array}{l}88 \text { a } 100 \text { o } \\
\text { más }\end{array}$ & 0.24 & 0,12 & 0,12 & 0,06 \\
\hline
\end{tabular}

Fuente: Resolución 4730/8

-Las "acciones de capacitación del nivel central" son aquellas que cuentan con el aval de la Subsecretaria de Educación de la DGCE y se implementan a través de instituciones de gestión estatal registradas en la Dirección de Capacitación.

-Las pautas para evaluar los proyectos se encuentran en la resolución $\mathrm{N}^{\circ} 3817 / 07$

Respecto a los objetivos de la política nacional de formación docente expuestos en el artículo 73, me interesa seleccionar alguno de ellos para comprender los cambios de perspectiva: en el inciso d) se establece "Ofrecer diversidad de propuestas y dispositivos de formación posterior a la formación inicial que fortalezcan el desarrollo profesional de los/as docentes en todos los niveles y modalidades de la enseñanza".

Esto implica la adecuación a los cambios en las políticas masivas de perfeccionamiento que estaban vinculadas casi exclusivamente a las reformas curriculares y estructurales que otorgaban escasa autonomía a la formación docente continua (Vezub, 2010). El

\footnotetext{
23 Similar hace referencia la cantidad de puntaje que se le asigna a una acción de capacitación respecto a la calidad y la carga horaria.
} 
nuevo paradigma aporta una perspectiva más integral del docente y del proceso de su formación, vinculada a una noción de carrera docente desplegada a lo largo de la vida profesional (Diker y Serra, 2008). Esta visión amplía la perspectiva de la relación con el saber (Charlot, 2000) que los docentes desarrollan en las distintas etapas del su formación y considerando las variaciones en los intereses que se advierten en el ciclo vital de los profesores (García, 1995) lo que implica la construcción de un saber docente que integra distintos tipos de saberes (Tardif, 2004).

2.4.2. Expansión, regulación y oficialización de la capacitación: su impacto en la formación en Educación Física.

Si bien a partir del 2008 hay un cambio a favor la oferta pública y gratuita, hay que advertir que se pondera la oferta oficial por sobre el resto de la oferta (Coria y Mezzadra, 2012) lo que constituye una "democratización jerarquizada" de la oferta. En este sentido la valoración de la oferta gratuita de capacitación, como una expresión de la retórica de la reforma incluye solo a la oferta del nivel central, fortalece la regulación y desconsidera otras opciones, otros contenidos, otros intereses.

La Resolución $\mathrm{N}^{\circ} 4730 / 08$, mencionada en el apartado anterior, no es por sí sola una medida que democratice el acceso a la capacitación. Al respecto los referentes de la capacitación provincial señalan:

"Esta revalorización efectuada a través de la recategorización de los cursos es un mecanismo que accionó la provincia para imponer un principio de igualdad frente a lo que es la oferta de capacitación, que sí tiene que ver con jerarquizar la capacitación pública pero más que eso tiene que ver con un derecho del docente a poder capacitarse y no tener que pagar para hacerlo, y este es un derecho establecido en el estatuto." (Referente I)

"Hubo una reevaluación de cursos que disminuyó significativamente el puntaje de los cursos que otros ofrecían. Esto cambia bastante la valoración respecto de la oferta que se genera desde aquí, que siempre fue valorada pero al haber un periodo de ausencia de otra oferta, en el mercado de cursos se acrecienta la demanda por la oferta estatal" (Referente IV) 
En ambos fragmentos se advierte optimismo respecto de la proyección de expansión de la oferta del nivel central. Respecto a la cobertura de la demanda de actividades de capacitación pensadas desde la perspectiva del desarrollo profesional uno de los referentes de la capacitación del distrito señala:

"Es un derecho pero todavía no hay una oferta amplia. Está el aparato, la logística, pero no está el recurso porque eso implica dinero. Pensá que en la provincia [hay] 25 regiones y en cada región hay un equipo técnico. Se llaman equipos técnicos regionales. Yo, por ejemplo, soy la capacitadora de la Región I del nivel secundario, tengo que darles a los 6 distritos de la Región I. Entonces es complejo, por ejemplo ya fui a Punta Indio ahora me toca ir a Magdalena, yo trato de rotar justamente para que la capacitación llegue. Lo ideal sería que haya mayor cantidad de capacitadores pero eso tiene un costo importante que no se puede cubrir" (Referente I)

\subsection{Conclusiones}

En este capítulo se abordó un análisis del desarrollo histórico de las políticas de capacitación en Educación Física y su relación con la historia de la asignatura, a partir de su surgimiento hasta principios del año 2000. Se destacaron las variaciones de mayor envergadura a través de los cuales la capacitación cobró diferentes sentidos asociados a las transformaciones en la identidad docente a través de las marcas presentes en la retórica de los conceptos de vocación, profesión, trabajador sindicalizado, trabajador profesional, formación docente universitaria, surgimiento de los expertos, saber docente, estructura de la capacitación, y mercado de la capacitación entre otros.

El aporte de esta revisión histórica no fue presentar una mirada evaluadora y clasificadora del pasado sino recuperar su riqueza con la certeza de que estos sentidos operan en la elección de la capacitación a partir de la cual se puede arribar a las siguientes conclusiones:

a. La historia de la capacitación docente y la historia de la consolidación de la Educación Física como asignatura escolar convergen en la gramática institucional de la segunda mitad del siglo XX.

b. En ese plano, la relativa especialización disciplinar, curricular y formativa de la educación física encontró reflejo en la capacitación docente de la década de 1990, en la concreción de cursos especializados en el marco de las nuevas políticas de capacitación. 
c. Esta oferta especializada se vio atravesada (como el resto de la oferta de capacitación) por una tensión entre dos lógicas: la lógica del puntaje y la lógica de la acreditación.

d. La lógica del puntaje quiere decir que la oferta de capacitación se asocia al otorgamiento de puntaje establecido en el marco del Estatuto de 1958. Esto hace que el puntaje sea defendido por los sindicatos docentes, en función de su defensa global del Estatuto. Pero también relaciona a la capacitación con un "derecho" de los docentes, en su condición de trabajadores, y se asocia a la posibilidad de acceder a una recompensa salarial.

e. La lógica de la acreditación fue establecida por la RFFDC. Se basa en el reconocimiento de la calidad de la institución oferente y supone que el Estado se posiciona como un regulador de una oferta de la que puede participar pero que no monopoliza.

f. La Ley de Educación Nacional junto con la Ley Provincial de Educación de 2007 y la decisión de la sobrevaloración del puntaje de la oferta estatal de 2008 confirman una "victoria" de la lógica del puntaje por sobre la de la acreditación.

g. Sin embargo, existen algunas excepciones. La más llamativa en el distrito de La Plata es el Congreso de Educación Física y Ciencias, ya que no ofrece puntaje pero es reconocido ampliamente por los docentes de Educación Física como una instancia de capacitación, cuya convocatoria se basa en el prestigio de la institución organizadora.

Queda por analizar cómo operan estas tensiones desde la perspectiva de los propios docentes.

\section{Bibliografía}

Aisenstein, A, (1999). "La Educación Física en la Escuela Primaria (1880 - 1930)”, en: Aisenstein, A. (1998). "Historia de la educación Física escolar en Argentina", en: Revista del Instituto de Investigaciones en Ciencias de la Educación, año VII, $\mathrm{n}^{\circ} 13$, p. $10-17$.

Aisenstein, A. (2003). "Epilogo", acápite "El modelo tecnológico y sus implicancias para la enseñanza”, en: Aisenstein, A. Ganz, N. Perczyck, J. La enseñanza del deporte en la escuela. Buenos Aires. Miño y Dávila.

Alliaud, A. (1993). Los maestros y su historia: un estudio socio-histórico sobre los orígenes del magisterio argentino. Buenos Aires: CEAL 
Ascolani, A. (Comp.) La Educación en Argentina. Rosario: Del Arca, p. 145 - 161.

Béjar, M. D. (1992). “Altares y banderas en una educación popular. La propuesta del gobierno de Manuel Fresco en la provincia de Buenos Aires, 1936 - 1940", en: Mitos altares y fantasmas. Aspectos ideológicos en la historia del nacionalismo argentino, $\mathrm{n}^{\circ}$ 12 , p. $83-130$.

Birgin A. (1999). "El empleo docente una mirada hacia un Estado que cambia", en: Birgin, A. El trabajo de enseñar. Entre la vocación y el mercado: las nuevas reglas del juego. Buenos Aires: Editorial Troquel S. A., p. 39 - 54.

Bonal, X. (2002). "Globalización y política educativa: un análisis crítico de la agenda del Banco Mundial para América Latina", en: Revista Mexicana de Investigación Educativa, v. 64, no .3 , p. 3 - 35, julio-septiembre.

Charlot, B. (2000). Da relação com o saber: elementos para uma teoria. Porto Alegre: Artes Médicas Sul.

Diker, G. y Serra, J. C. (2008). La cuestión docente. Argentina: las políticas de capacitación docente. Buenos Aires: Fundación Laboratorio de Políticas Públicas.

Dubet, F. (2004). “¿Mutaciones institucionales y/o neoliberalismo?”, en: Tenti Fanfani, E. (Org.) Gobernabilidad de los sistemas educativos en América Latina, IIPE, Buenos Aires, p. 15 - 44.

Dubet, F. (2006). El declive de la institución. Profesiones, sujetos e individuos en la Modernidad. Barcelona: Gedisa.

Dussel, I. (1995). "Pedagogía y burocracia. Notas sobre la historia de los inspectores", en: Revista Argentina de Educación. Año XIII, nº 23, p. 55 - 80.

Finocchio, S. Legarralde, M. (2006). Modelos de formación en América Latina. Buenos Aires: Centro de Estudios en Políticas Públicas.

Garcia, M. (1995) Formação de Professores- Para uma mudança educativa. Portugal: Porto Editora.

Martinez, M. E.; Villa A. y Seoane, V. (2009). "Manteniendo las distancias: mercado escolar y desigualdad social". En: Martinez, M. E.; Villa A. y Seoane V. (Coord.) Jóvenes, elección escolar y distinción social. Buenos Aires: Prometeo, p. 29 - 47.

Martinis, P. (2006). "Educación, pobreza e igualdad: del "niño carente" al "sujeto de la educación”. En: Redondo, P. y Martinis, P. (Comps.) Igualdad y Educación: Escrituras entre (dos) orillas. Buenos Aires: Del Estante Editorial, p. 13 - 31. 
Pineau, P. (2012). "Docente "se hace" notas sobre la historia de la formación en ejercicio", en A. Birgin (Comp.) Más allá de la capacitación: debates acerca de la formación de los docentes en ejercicio. Buenos Aires: Paidós, p. 29 - 47.

Saraví Riviere, J. (1999). Historia de la Educación Física Argentina. Buenos aires: Siglo XIX.

Scharagrodsky, P. (2011). “Curriculum y Educación Física Escolar (1884-1940) Educando a los cuerpos y "ejercitando" los sentidos de la diferencia sexual", en: Rozengrdt, R. y Acosta, F. (Comp.) Historia de la Educación Física y sus instituciones. Buenos Aires: Miño y Dávila, p. $43-68$.

Scharagrodsky, P. y Aisenstein, A. (2006). Tras las huellas de la Educación Física escolar. Cuerpo género y pedagogía (1880-1950). Buenos Aires: Prometeo Libros.

Schueler, A. y Southwell, M. (2011). "Profesionalización del magisterio en Brasil y Argentina en perspectiva comparada (1820-2000)", en: Vidal, D. y Ascolani, A. (Orgs). Reformas educativas en Brasil y en Argentina ensayos de historia comparada de la educación 1820-2000. Buenos Aires: Biblos, p. 147 - 188.

Serra, J. C. (2004). El campo de la capitación docente. Políticas y tensiones en el desarrollo profesional. Buenos Aires: Miño y Davila.

Southwell, M. (1997). “Algunas características de la formación docente en la historia educativa reciente. El legado del tecnocratismo", en Puiggrós A. (Dir.) Historia de la Educación Argentina, tomo VIII. Buenos Aires: Galerna, p. 105 - 156.

Southwell, M. (2008). "Política y educación: ensayos sobre la fijación del significado", en: Cruz Pineda, O. y Echevarría, C. L. (Coord.) Investigación educativa. Herramientas teóricas y análisis político del discurso. México: Casa editorial Juan Pablos - PAPDI.

Southwell, M. (2009). "Docencia, tradiciones y nuevos desafios en el escenario contemporáneo", en: Yuni, J. (Comp.) La formación docente. Complejidad y ausencias. Córdoba: Encuentro Grupo Editor.

Tardif, M. (2004). Los saberes del docente y su desarrollo profesional. Madrid: Narcea. Tiramonti, G. (2009). Una aproximación a la dinámica de la fragmentación del sistema educativo. Especificaciones teóricas y empíricas, en: Tiramonti, G.; Montes, N. (Comp.) La escuela media en debate. Problemas actuales y perspectivas desde la investigación. Buenos Aires: Editorial Manantial - FLACSO, p. 25 - 38.

Tyack, D. y Tobin J. (1995). En busca de la utopía. Un siglo de reformas de las escuelas públicas. México: Fondo de Cultura Económica. 
Vezub, L. F. (2010). El desarrollo profesional docente centrado en la escuela: concepciones, políticas y experiencias. - $1^{\mathrm{a}}$ ed- Buenos Aires: IIPE - Unesco.

Villa, A. I. (1997) Lógicas y discursos en la formación docente: en el caso del Profesorado Universitario de Educación Física de la Universidad Nacional de La Plata, en: Actas de las II Jornadas La Universidad como objeto de investigación. Buenos Aires: Centro de Altos Estudios - UBA.

Villa, A. I. (2011) “Curriculum de Educación Física y formación del profesorado. El caso del Profesorado de Educación Física de la Universidad Nacional de La Plata”, Argentina, en: Ágora para la Educación Física y el Deporte, v. 3, n¹3, p. 321-340, septiembre - diciembre.

Viñao, A. (2002). Sistemas educativos, culturas escolares y reformas. Continuidades y cambios. Madrid: Morata. 


\section{CAPítulo III}

\section{La elección de la oferta: múltiples intereses, posibilidades y condicionantes}

\subsection{Introducción}

En este capítulo se retoman elementos teóricos presentados en el capítulo I, y elementos históricos contextuales, referidos a la conformación de la disciplina Educación Física, al desarrollo de la formación docente y a la estructura de capacitación nacional y provincial abordados en los capítulos II, los cuales serán empleados en el análisis de la elección de la capacitación a partir de las entrevistas.

Cabe recordar que para el trabajo de campo se plantearon dos momentos en la estrategia metodológica, en principio se realizaron las entrevistas a los referentes de la capacitación en el distrito de La Plata, y luego se llevaron a cabo las entrevistas a los docentes. El análisis que aquí se plantea se centra en los relatos de los docentes, pero integra elementos de ambas entrevistas.

Desde perspectiva que esta tesis plantea cobran relevancia para el análisis de la elección: el momento particular de la carrera docente, la biografía del docente, las características de su formación inicial, las particularidades de su socialización laboral y las características del marco que plantea la política pública de capacitación de donde se elige.

\subsection{La elección frente a la tensión entre la necesidad de puntaje y la profesionalización}

Diferentes estudios señalan que desde la perspectiva laboral de los docentes, el puntaje se encuentra aun hoy entre los principales incentivos para la realización de cursos de capacitación (IIPE, 2000; Serra, 2004; Diker y Serra, 2008). Desde esta mirada la búsqueda de puntaje se presenta como el motivo que orienta la elección y que regula la relación ilusio - capital - campo en la dinámica del campo de la capacitación. Sin embargo es posible advertir distintos elementos que se suman y combinan los cuales adquieren diferente relevancia en cada uno de los sujetos. Al respecto un referente de la capacitación señala: 
"Existen dos bloques de profesores para poder pensar cuáles son los aspectos que inciden en la elección de la capacitación. Así: existe un grupo de profesores grandes de varios años de antigüedad que están tranquilos en el puesto de trabajo a los que no les interesa hacer un curso, que lo dicen que no les interesa. Dentro de este grupo están también a los que les interesa capacitarse pero es porque quieren acceder a otro tipo de cargos dentro del sistema educativo, en este caso la capacitación está vinculada a un intento de ascenso de jerarquía, y eso implica una lectura distinta de esta cuestión.

Y después está el que empieza en la docencia; ese es el gran grueso, que en principio van por el puntaje y lo expresan pero no es lo único por lo que van, e incluso a veces uno desde el lugar de capacitadora tiene el prejuicio de que van por el puntaje." (Referente I)

Es posible advertir variaciones a los distintos momentos de la carrera docente. Las entrevistas marcan que la relación entre capacitación y puntaje es más directa al inicio de la carrera, y que si bien el puntaje incide en la mirada docente respecto a la capacitación, hay otros elementos relativos al interés de cada docente, a sus orientaciones particulares y a su propia subjetividad que delinean trayectorias en la relación personal que cada uno establece con el saber. Estos ejercen una fuerte influencia, la cual aumenta a medida que se avanza en la carrera docente a favor de la profesionalización y la especialización en diferentes campos.

Si bien vamos a advertir cambios en la búsqueda de puntaje a lo largo de la carrera docente, los distintos intereses por la elección de la capacitación coexisten. Un mismo docente elige un curso por la búsqueda de puntaje, al mismo tiempo que cursa una carrera universitaria. Las expectativas que los sujetos tienen implican una relación particular con el saber (Charlot, 2000) que incide en la elección.

Respecto de la relación entre la capacitación y el trabajo docente en los primeros años de la carrera los docentes señalan:

"Al principio cuando empezás, necesitas puntaje y te anotás en lo que sea que te sume, pero ya con los años sé qué cosas me sirven más, para lo que me gusta." (Profesor B) 
"En esta oportunidad, no sé ni lo miré igual con mi antigüedad ya estoy tranquila con el tema del puntaje.

En otro momento de mi vida si era importante cuando buscaba acceder al cargo importaba, cuando recién me recibí estaba soltera hice una especialización en rehabilitación en la Facultad de Medicina, ese me dio puntaje" (Profesor C)

"Entrevistador: Considerando esta situación hoy ¿por qué estás dispuesto a pagar? ¿Si estás dispuesto?

Entrevistado: No hoy por hoy, si estoy dispuesto a capacitarme, más que por pagar o no pagar, más que por el puntaje, voy a elegir algo que.... me beneficie a nivel profesional." (Profesor B)

En quienes tienen mayor estabilidad en sus cargos, es posible advertir la presencia de otros intereses más allá del puntaje. Igualmente marcan el peso que el mismo tuvo al principio de su carrera laboral. Mientras que quienes están al inicio de su carrera, señalan la necesidad del puntaje con más fuerza para mejorar su posición en el campo laboral, asociada a la inversión de capital económico para conseguirlo:

"Bueno, lo que te comentaba lo hice ahora hace un mes, pero ya me arrepentí, lo que pasa es que después de los actos públicos de titularizaciones empezaron a titularizar y yo no llegué entonces los compré ahora para así me entran para el año que viene. $Y$ es caro pero todo suma aunque sea algunas centésimas, pero no es mi prioridad." (Profesor A)

La necesidad de invertir capital económico en capacitación, aparece como una regla injusta del campo de la capacitación (Serra 2004), porque aunque en la provincia de Buenos Aires se produjeron importantes avances en la jerarquización de la oferta oficial gratuita a partir del 2008, y ésta brinde una oferta amplia en cuanto a contenidos y formatos de capacitación, desde el punto de vista de los entrevistados no alcanza a cubrir la demanda. Además no se reconoce puntaje o algún otro tipo de crédito, a otras carreras o actividades, donde circulan saberes que están asociados a los intereses particulares de los docentes, por lo cual todavía es difícil pensar en una real "visión integral de la capacitación” como se señala en la Ley Nacional de Educación (2006). 
Aunque en la Ley se explicita un movimiento conceptual a favor de la perspectiva del "desarrollo profesional" y haya medidas fuertes para regular la incidencia del mercado en el campo de la capacitación, la lógica que asocia la capacitación al puntaje es en el inicio de la carrera una marca muy fuerte. En este sentido la efectividad del saber no se vincula directamente a las posibilidades de desarrollo profesional.

Otro aspecto a señalar, es que el acceso y la permanencia en el cargo específico de Profesor de Educación Física en la escuela secundaria implican en muchos casos pasar por otros puestos de trabajo del sistema de enseñanza pública. Así que el hecho de que la cantidad de puestos de trabajo sea menor a la cantidad de profesores que buscan ingresar al sistema, motivó el desarrollo de otras estrategias laborales vinculadas al desempeño en otros puestos de trabajo de las instituciones de enseñanza media, como el trabajo de preceptor o la posibilidad de tomar módulos de la materia Construcción de Ciudadanía. En algunos casos, esta última opción va acompañada de la toma de capacitaciones que no están asociadas a la formación inicial ni a las expectativas laborales de quienes pretenden trabajar de aquello para lo que fueron formados.

“...tengo 10 módulos de educación física y el resto de construcción ciudadana. Porque me gusta la estabilidad que te da este tipo de cargo ya que no tiene movimiento (...) En todas tengo dos módulos a todas voy dos veces por semana una hora cada vez"

"Hice un curso de Construcción Ciudadana en el CIIE, lo pude hacer porque pedi permiso, en ese momento trabajaba de preceptor y tenía otra relación." (Profesor A)

El caso contrario, el de los profesores que empezaron su actividad en la docencia del sector público en momentos donde la cantidad de puestos de trabajo era mayor que la cantidad de profesores, la preocupación por el puntaje no apareció en su carrera. Al indagar si para su ingreso a la escuela secundaria el puntaje fue una preocupación, se advierte la siguiente respuesta:

"No no, no era un problema, no es como ahora, éramos pocos profesores era otro momento la carrera acá en La Plata recién comenzaba." (Profesor F) 
El hecho de que el puntaje no representara un problema, implicó la posibilidad de insertarse en un lugar de trabajo, de concentrar las horas allí, lo que favoreció un mayor grado de implicación con la institución en la cual trabajan (Devincenzi, 2002), y la posibilidad de poner en juego antes los saberes específicos de la formación inicial. Aunque también es posible advertir en este caso, que el hecho de que no existiera "la carrera por el puntaje" implicó una baja participación en las actividades de formación permanente sistematizadas.

Como advierte Gvirtz: "más allá de regulaciones que vinculan las condiciones de la carrera con la capacitación, los estatutos no avanzan en la explicitación de lineamientos que ordenen u orienten de alguna manera la formación docente continua de los docentes. En efecto en general no promueven, por ejemplo una tendencia a la profundización o especialización en ciertas temáticas o ciclos, por lo que los docentes pueden realizar un conjunto de cursos sin conexión alguna o alejados de su propia práctica laboral. Asimismo si los docentes ya son titulares y no aspiran a ascender, pueden permanecer en su cargo toda su carrera hasta la jubilación sin realizar ninguna actividad de capacitación." (Gvirtz, 1994, en Diker y Serra 2010: 25)

En vínculo con lo que expresa esta autora, en las entrevistas a los referentes de la capacitación del distrito, se advierte la falta de conexión entre ellos. El hecho de que ninguno sepa qué acciones está llevando a cabo el otro oferente, podría pensarse como una falta de orientación en la en la posibilidad de construir un sistema integrado de capacitación, como fue la intención de la RFFDC que se continua a través del INFD. Al mismo tiempo si bien la política pública provincial establece áreas prioritarias para la validación de cursos, no hay ninguna regulación que ubique a los docentes frente a la necesidad de realizar esas capacitaciones.

Diker y Serra advierten que "estas características imprimen un rasgo particular al perfeccionamiento docente. Básicamente es individual, no contempla el trabajo conjunto de los docentes, ni la dimensión institucional”.

Por otro lado cabe destacar que el trabajo docente en escuelas secundarias representa para algunos una posibilidad laboral circunstancial, que puede estar asociada a la necesidad de subsistencia y a un interés particular por trabajar en este nivel de enseñanza, como así también es importante advertir que el trabajo en la docencia facilita 
proyectar otras posibilidades de formación debido al régimen de licencias que marca el Estatuto $^{24}$.

Sea cual fuere el motivo por el cual los docentes hacen su trabajo hay sucesos particulares que operaron para que ciertos saberes y no otros, fuesen los buscados en la capacitación, es decir que aunque el interés por el puntaje en un principio tiene un peso considerable en la elección, no es el único que cobra fuerza en las estrategias que construyen los agentes en el campo de la capacitación.

A medida que se alcanza mayor experiencia en el trabajo docente y que se accede a los puestos de trabajo con mayor estabilidad en el cargo, es posible empezar a visualizar la presencia de intereses distintos al puntaje que inciden en la elección. Las entrevistas tuvieron como objetivo ver qué otros elementos además de la necesidad de puntaje se ponen en consideración en las elecciones que realizan los docentes y qué presencia tienen.

De todos modos no hay que ignorar el peso objetivo que el puntaje tiene para el acceso a los cargos en cualquier momento de la carrera. Diker y Serra (2008) advierten que después de lograr la titularización en el cargo la "carrera por el puntaje continúa" ya que determina el orden de merito a partir del cual el docente tiene prioridad para elegir tanto si desea trasladar su cargo, si desea realizar suplencias tomando otro cargo, o si por alguna circunstancia se cierra alguna sección en su escuela y se pierde el cargo y el docente queda en disponibilidad. El mayor puntaje le otorga prioridad para elegir un destino. De modo que el puntaje otorga mayor seguridad laboral al docente.

"Entrevistador: ¿Hoy por hoy estás en una situación cómoda respecto al puntaje, no? es decir que no necesitas sumar puntos.

Entrevistado: Siempre viene bien sumar puntos, pero no, es verdad, estoy cómodo con eso. (Profesor B)

\footnotetext{
$24 \quad$ El Artículo 114 inciso LL del Estatuto del Docente de la provincia de Buenos Aires indica las licencias por examen y pre-examen, posibilita un importante beneficio para quienes estudian:

11.1.1. Cuando se cursen carreras universitarias o terciarias, de grado o de postgrado, o se realicen cursos en los Institutos Superiores de Formación docente, se concederá al personal titular, licencia - con goce de haberes - hasta un total de doce (12) días hábiles por año calendario para la preparación de exámenes. No podrá ser utilizada en bloques de más de tres (3) días por examen y deberán ser acordados en los días inmediatos anteriores a la fecha fijada para los mismos.

Además se le concederá un (1) día de licencia por cada día de examen, la que será prorrogada automáticamente cuando la mesa examinadora no se reúna o postergue su cometido.

Estas licencias aplican para el Personal titular y provisional. En el caso del Personal suplente se acordará el día de examen.
} 
En el fragmento de entrevista se advierte comodidad respecto a la estabilidad en el cargo. Corresponde a un docente ubicado en un momento de su ciclo vital donde la necesidad de puntaje también se asocia a la energía y la ambición de este momento particular (Sikes, 1985 en García, 1995).

Otro aspecto a considerar es que el puntaje también es necesario para el ascenso en la carrera docente y esto es algo a lo que aspira una proporción importante de docentes, para lo que es necesario concursar ya que para el acceso a un cargo de mayor jerarquía se requiere capacitación.

La tensión entre el puntaje y la formación profesional que advierte Serra (2004) como un rasgo distintivo del campo de la capacitación coloca a los docentes ante la disyuntiva de maximizar la obtención de puntaje o de formación (Diker y Serra, 2008). Pero aunque la política de capacitación provincial refleja la tensión en entre puntaje o formación, los intereses en las elecciones de la oferta de capacitación no están solo direccionados por la necesidad de obtener puntaje.

A continuación voy a avanzar sobre algunas dimensiones que permiten analizar la relación de los sujetos con el saber. Para esto considero que los sujetos trazan estrategias de capacitación en las que ponen en juego múltiples intereses en los que inciden la formación inicial, la experiencia sociocorporal, el formato de la capacitación, la difusión de la oferta de capacitación y las instituciones escolares respecto a los espacios y equipos de trabajo.

\subsection{Las instituciones de formación de profesorado en La Plata y la selección de los docentes entrevistados}

En el distrito de La Plata existen tres instituciones de formación de profesorado en Educación Física, la FaHCE de la UNLP, la UCALP, y el Instituto Educativo CESALP. La mayoría de los docentes que trabaja en escuelas secundarias estatales fue formado en el Profesorado de la FaHCE. Esta institución se inscribe en el área como una institución de prestigio a nivel nacional de carácter gratuito, mientras que las otras dos opciones de formación corresponden al ámbito privado ${ }^{25}$. La mayoría de las entrevistas

\footnotetext{
25 Para el caso profesorado del CESALP se advierte una formación orientada hacia el ámbito la salud, toma el curriculum de formación que prescribe la provincia pero acentúa y profundiza los saberes de determinadas disciplinas.
} 
fueron realizadas a docentes que se graduaron de la $\mathrm{UNLP}^{26}$ en distintos momentos. En la selección de los entrevistados se tomaron en cuenta dos criterios centrales: el año de graduación y la antigüedad en la docencia.

Cada una de estas instituciones desarrolla su propia oferta de capacitación que incluye cursos, encuentros, congresos, jornadas y carreras de posgrado. A la oferta que ellas generan se suma la de la que brinda la provincia a través de la Dirección General de Cultura y Educación, además de la que generan los gremios docentes y la que proponen el resto de los oferentes privados.

\subsection{El rango del saber en el curriculum de la formación de profesorado, la vinculación con la práctica y la elección de la capacitación.}

Para visualizar la presencia de los saberes de la formación inicial en la práctica docente y su incidencia en la elección de la capacitación, adopto la perspectiva del saber docente y el desarrollo profesional sostenida por Tardif (2004), quien plantea que el saber docente puede ser entendido como "una amalgama, más o menos coherente" (p. 29) de cuatro fuentes:

a) Los saberes de la formación profesional (de las ciencias de la educación y de la ideología pedagógica) estas ciencias no se limitan a producir cocimiento, también procuran incorporarse a la práctica del profesor

b) Los saberes disciplinares. Son los saberes que corresponden a los diversos campos del conocimiento, son los saberes de las disciplinas que emergen de la tradición cultural de los grupos sociales productores de saberes

c) Los saberes curriculares corresponden a los discursos, objetivos, contenidos y métodos a partir de los cuales la institución escolar categoriza y presenta los saberes sociales que la escuela selecciona para ser transmitidos a las futuras generaciones (Tardif, 2004; Ferreira Borges, 1998)

d) Los saberes de la experiencia adquiridos por el profesor en el ejercicio de su profesión.

Cabe aclarar que si bien voy a dividir el análisis de las entrevistas de acuerdo a las categorías que plantea Tardif (2004), la amalgama de saberes que conforman el saber

\footnotetext{
26 No porque desconsidere el lugar de formación inicial como un criterio de selección, sino por la dificultad que tuve para encontrar docentes que se encuentren trabajando en el distrito en escuela media que hayan sido formados en otra institución
} 
docente no se organiza ni presenta de modo fragmentado, sino que los saberes se integran en la práctica, y es a través de la práctica que se seleccionan estratégicamente los contenidos necesarios para el desarrollo de la profesión docente (Tardif, 2004). Se valorizan y recobran saberes de la formación inicial al mismo tiempo que permite identificar los saberes que necesitan fortalecerse.

\section{a) Respecto de los saberes de la formación profesional:}

Un aspecto que marca Villa (1997) es que en el caso del Profesorado de Educación Física de la UNLP el bloque pedagógico, es decir las asignaturas que provienen de las ciencias de la educación y de la ideología pedagógica (Tardif, 2004) quedaron en manos del carrera de Ciencias de la Educación sin intersección con los contenidos de la Educación Física.

Los cambios en los programas de las asignaturas ${ }^{27}$ y la creación de equipos interdisciplinarios en estas cátedras implicaron un acercamiento progresivo.

Estos saberes adquieren mayor relevancia en la práctica docente y no tanto durante la formación inicial:

"Pero yo creo que con la formación de profesorado de acá de La Plata para escuela estás muy bien preparado, lo digo por la cantidad de materias pedagógicas que tenés, hay muchas materias que abren la cabeza, que en su momento cuando yo estaba cursando las criticaba, y decía por qué tenemos que cursar esto, pero después te das cuenta que te sirve un montón, que en relación al laburo en las escuelas son muy útiles."

No sé, historia de la educación, politica y legislación, todas materias que no me gustaban, pero que después te das cuenta que te sirven un montón." (Profesor A)

Así, la orientación pedagógica y la preparación para el trabajo docente en las escuelas, se señalan como uno de los ejes centrales de la formación de profesorado de la UNLP. Es posible advertir en las entrevistas que la elección de la capacitación que se orienta hacia estos saberes, busca adecuarse y comprender los momentos y contextos de trabajo.

$27 \quad$ Plan de estudios año 2000. 
En correspondencia los docentes entrevistados buscaban elementos que los ayuden para realizar su trabajo en contextos de violencia. Quienes eligen capacitarse en cuestiones vinculadas a las ciencias de la educación y a la ideología pedagógica ${ }^{28}$ lo hacen explícitamente para entender a los alumnos con quienes trabajan.

"Entrevistado: Hice un curso de Mediación. Lo hice a través de Santillana. Esos cursos a distancia...

Entrevistador: ¿Cuál fue tu por interés hacer ese curso?

Entrevistado: Por interés, con respecto a la gran violencia que hay en las escuelas, por una preocupación. Yo en esa época tenía hijos adolescentes, y eso me movía mucho." (Profesor D)

Cabe advertir que las experiencias de la vida de los docentes tienen incidencia en la formación continua, más allá de que en el campo de la capacitación la acumulación de puntaje marca una dinámica particular. Se suman factores individuales que orientan las elecciones e inciden en la formación profesional y en la construcción un saber docente particular.

Otro aspecto importante a considerar es que la búsqueda de estos saberes refleja las mutaciones en el programa institucional moderno que señala Dubet (2010), que marca un cambio en la mirada de los docentes sobre los alumnos, que coincide con lo que señalan los referentes de la capacitación, tendiendo hacia una perspectiva que no culpabiliza a los alumnos e intenta crear una mirada más justa del trabajo en las instituciones.

\section{b) Respecto de la incidencia de los saberes disciplinares:}

En el discurso de la educación física confluyen saberes de distintas disciplinas (Villa, 1997) que marcan paradigmas e ideologías respecto a los objetivos de la educación física, los cuales contribuyen a construir y consolidar distintas posiciones respecto al valor de la asignatura que los docentes pretenden trasmitir a través de sus clases:

\footnotetext{
28 "Los saberes pedagógicos se presentan como doctrinas o concepciones provenientes de reflexiones sobre la práctica educativa, en el sentido amplio del término, reflexiones racionales y normativas que conducen a sistemas más o menos coherentes de representación y orientación de la actividad educativa. Es el caso, por ejemplo, de las doctrinas en la ideología de la "escuela nueva". Estas doctrinas (o mejor las dominantes) se incorporan a la formación profesional de los maestros, proporcionando, por una parte un armazón ideológico, y por otra, algunas técnicas y formas de saber hacer" (Tardif , 2004: 29)
} 
"cuando yo empecé a estudiar educación física, lo que más me gustaba eran la parte de cuerpo humano, la parte de anatomía, fisiología y entrenamiento, entonces me empecé a interesar por el lado de la kinesiología, la medicina. (...) el tema es que se cumpla el objetivo de la educación física en este caso en la escuela, que en la mayoría de los casos me parece que se cumple, ¿Cuál es el objetivo? el movimiento para la salud, ese es el objetivo, después podés tener sub objetivos

La educación física para mi tiene ese objetivo. Eso considero yo, incluso si vos agarrás los contenidos básicos comunes y te lo ponés a leer, está puesta para eso, después también, está fundamentada que esté separada en dos veces por semana por eso mismo."

"Pero el objetivo es ese, creo que está un poco confundido, no sé, la sociedad o los mismos profes, llega un momento que no analizan por qué estamos dando educación física.

Es una visión personal, pero creo que igual es objetiva." (Profesor A)

Entrevistador: Ahora volviendo a la formación de profe en la facultad ¿hubo algo, una materia, un deporte que te intereso más que otra cosa? ¿Qué cambió tu visión sobre determinado deporte?

Entrevistado: Si, la natación.

Entrevistador: ¿Por qué?

Entrevistado: No, respecto a la natación me cambié el panorama porque hasta la facultad lo veía como un hobby... lo sigo viendo como un hobby, lo veía como algo para el tiempo libre o como un pasatiempo de verano, y partir de la universidad la empecé a ver como una necesidad para que muchos chicos aprendan a manejarse en el agua. Me encanta enseñar natación, me encanta que los chicos aprendan a nadar." (Profesor B)

Es posible advertir que el gusto por determinado saber no solo condiciona las prácticas y la formación permanente. En ambos casos los saberes médicos o los de los vinculados a la natación orientan y definen el valor de la asignatura y están presentes estrategias de formación profesional que construyen estos docentes. 
En estos casos los saberes disciplinares de la formación inicial incidieron en las elecciones de formación permanente. Estas opciones que en principio no son tomadas para el trabajo en la escuela, están presentes en la práctica en las clases de los profesores y al mismo tiempo son un insumo para ampliar y fortalecer las posibilidades de acceso al trabajo:

"la clase que viene vamos a hacer teórico, por ejemplo de cuerpo humano" y a la clase siguiente todos trajeron afiches..." (Profesor A)

“...no es algo que en principio hacés para trabajar en la escuela, pero después te ayuda, te sirve para trabajar, por ejemplo en el distrito de Berisso para horas como canotaje y natación te piden el titulo de guardavidas para que puedas tomar las horas.

Al mismo tiempo son dos posibilidades de trabajo porque podés ser profe y guardavidas a la vez." (Profesor B)

El hecho de que estos saberes disciplinares estén presentes en la identidad laboral de estos docentes, en cómo piensan sus prácticas y en la definición de sus estrategias de elección de capacitación, implica volver sobre el carácter identitario, epistemológico y social que señala Charlot (2000). Las diferencias en características epistemológicas de los saberes, son valorados de manera muy distinta por los profesores, lo que se pone de manifiesto en la manera en la que hacen circular ese saber.

\section{c) Respecto de la incidencia de los saberes curriculares:}

La presencia de cambios importantes en el abordaje situado de estos saberes, que remiten a los discursos, objetivos, contenidos y métodos (Tardif, 2004) que el Estado prescribe, implica que se consideren los intereses y las situaciones particulares de los contextos laborales de quienes eligen estas temáticas en las capacitaciones, desde una mirada reflexiva, que otorga distinto significado a las planificaciones y a la manera de ordenar los contenidos que los docentes desarrollan:

“Entrevistado: Este último tiempo sacando la maestría ¿no?, lo que hice fueron capacitaciones de actualización, por ejemplo cuando vino la reforma de la ESB del polimodal, que me daban la posibilidad de pensar la organización de los 
contenidos de una manera diferente pensando las distintas etapas del año y variantes que implican pensar si me organizo por contenidos o por bloques, aunque los temas que damos son los mismos, vóley, handball entrada en calor, me daba otras posibilidades de organizarlos.

Entrevistador: ¿Esas capacitaciones quien las daba?

Entrevistado: Esas son capacitaciones que daba la Dirección General de Escuelas a través de los inspectores de educación física. Esas fueron capacitaciones que se dieron en el 2007, 2008 que nos mandaban comunicados que se hacían en el CEF (Centro de Educación Física), que daban puntaje y eran gratuitas."

Entrevistador: ¿El tema era siempre la planificación curricular o había otros temas relacionados a la enseñanza de determinados contenidos?

Entrevistado: Las que yo hice si eran todas de curriculum, pero la última que yo no la hice este año era sobre enseñanza de deporte pero yo no la hice porque si bien yo estaba interesada no había más lugar." (Profesor C)

Las capacitaciones que se abocan a difundir orientaciones curriculares que el Estado prescribe se conjugan de otros aspectos vinculados al resto de los saberes que hacen al desarrollo profesional, lo que implica una adecuación en las políticas masivas de perfeccionamiento que estaban vinculadas casi exclusivamente a las reformas curriculares y estructurales que otorgaban escasa autonomía a la formación docente continua (Vezub, 2010). Así, respecto a las temáticas y a su definición, una referente de la capacitación provincial señala:

"no son totalmente elegidas por nosotros. Hay un equipo de coordinación pedagógica en la Dirección de Educación Física que depende en la Dirección de Capacitación que media, que decide las temáticas. Así, de un tiempo a esta parte estuvimos metidos con los diseños curriculares, así cada vez que salía un diseño curricular se hizo una capacitación de ese diseño, de primero, segundo, tercero, ahora estuve dando la de cuarto. Después también se dio este año y el año pasado un curso sobre evaluación que tuvo muy buena receptividad de los docentes. Despertó interés, el hecho de cómo evaluar en el área en media. Y después otra temática es sobre otro curso que di sobre el abordaje del deporte escolar" (Referente I) 
Las reformas educativas llevaron a que una parte importante de la oferta de capacitación gratuita se aboque a la actualización de los diseños curriculares, específicamente aplicados a la planificación. Hay que advertir que la misma se orientó a considerar las características situadas del contexto laboral, se trató poner los diseños curriculares en el marco de cada realidad de trabajo. Al mismo tiempo no fue la única temática abordada, otras contenidos como la evaluación y sobre todo el abordaje del deporte escolar fueron muy elegidas por los docentes ya que rápidamente se agotaron los cupos y varios de los docentes entrevistados se quedaron sin poder asistir.

En esta línea a través de sus actividades de extensión, la FaHCE (UNLP) generó actividades de capacitación vinculadas a la didáctica del deporte escolar ${ }^{29}$, lo que se corresponde con el interés que los docentes muestran por estas temáticas.

La elección de estas temáticas se relacionan con la posibilidad de conocer nuevos enfoques didácticos a partir de escuchar a un experto o desde una metodología que suele estar muy presente en las capacitaciones en Educación Física ${ }^{30}$, que implica la oportunidad de compartir la manera de enseñar de cada profesor a través de la selección del contenido que convoca, para "dar la clase a sus compañeros". La valoración de esas actividades tiene que ver con lo "aplicable".

“...teníamos que plantear una clase de Educación Física y exponerla ante el grupo, un grupo de 4 o 5 compañeros y había varios grupos, cada uno tenía un contenido diferente... por ahí era iniciación al deporte, o el deporte en sí, la técnica especial del deporte; de esa mesa se elegía, se votaba la clase que a todos les gustaba más y después la hacíamos con todos los profes" (Profesor D)

El hecho de que la competencia y los encuentros deportivos formen parte de la curricula de Educación Física en la escuela secundaria, motiva la elección de este tipo de capacitaciones en dos sentidos: 1) porque implica la posibilidad de contactarse con otros docentes para organizar encuentros deportivos más allá de los que plantea el municipio y la Dirección de Deportes de la provincia, 2) porque permite actualizarse respecto de las variaciones en los reglamentos de cada deporte.

29 Cabe destacar que estas capacitaciones no se orientaron solo a abordar temáticas vinculadas a los deportes instalados en las escuelas ya que sumaron la difusión y el desarrollo de deportes alternativos. 30 Por las características epistemológicas del contenido que involucran el hacer motriz. 
Así, es posible establecer una relación entre el trabajo de Profesor de Educación Física y la necesidad de capacitación, que se refleja en la convocatoria del área a las actividades de formación docente continua:

\begin{abstract}
“Comparando el acercamiento de los profesores a la capacitación en relación a otras áreas, desde lo personal y en las charlas con el resto de los capacitadores, los profesores de otras áreas siempre son muy selectivos frente a la oferta, en cambio en el profesor de educación física y la maestra de primaria e inicial esto es distinto. Es más de ir a capacitarse. Por ejemplo en áreas como en geografía, la posibilidad de convocar a los profesores es muy dificil, por esta selectividad respecto de la actividad de capacitación a la que adhieren. Este es uno de los problemas del nivel Un ejemplo de esto es que en un distrito grande como La Plata, si se plantea un curso en geografia hay pocos inscriptos, en educación fisica esto no es así. Hoy hay muchos inscriptos y lista de espera para las actividades pautadas, el crecimiento fue exponencial." (Referente I)
\end{abstract}

\title{
d) Respecto de la incidencia de los saberes de la experiencia:
}

Tanto Tardif (2004) como Charlot (2000) aportan elementos para analizar la elección de la capacitación. Los profesores en el ejercicio de su práctica profesional desarrollan saberes específicos, basados en su trabajo cotidiano y en el conocimiento de su medio. Esos saberes brotan de la experiencia y son validados por ella. Se incorporan a la experiencia individual y colectiva en la forma de habitus y habilidades de saber hacer y saber ser.

"cuando uno sale de la universidad o del profesorado, sale con lo que la universidad te da y la experiencia te va enseñando, porque vos transitás 4, 5 años por una misma universidad, pero la experiencia laboral después se transita por 25, 30 años. Entonces los diversos contextos en que vos vas a trabajar te van dando, digamos, la madurez como para poder vos acomodarte a los distintos lugares de trabajo. Cuando vos salís, querés enseñar lo mismo en todos lados, querés enseñar el atletismo igual en todas las escuelas y después te vas dando cuenta que vos no podes enseñar de la misma manera en todas las escuelas, en todos los lugares y ahí es donde empezás a hacer una revisión, y a entender que el profesor lo que tiene que entender que está en función del 
alumno y no en función de él y eso es uno de los grandes errores que tenemos los profesores cuando empezamos, queremos enseñar lo que nosotros queremos y no lo que el chico necesita." (Profesor E)

La práctica no es un saber en sí mismo, sino que la misma moviliza información, conocimientos y saberes (Charlot; 2000). En este sentido, "Quem "tem prática" vive em um mundo onde os percebe indícios que outros não veriam, dispõe de pontos de referência e de um leque de respostas dos quais outros estariam desprovidos" (Charlot, 2000: 63).

La socialización profesional implica una serie de transformaciones ligadas a la práctica que producen la incorporación implícita y explicita de formas de pensamiento valoración y actuación (Davini, 1995). En este proceso visualizar las necesidades de los alumnos, así identificar y definir las necesidades ligadas a la construcción de una estrategia de formación permanente para mejorar la enseñanza en determinados espacios o acceder a otros espacios laborales implica tiempo y una serie de acciones ligadas a la construcción de la identidad laboral.

"Lo que nosotros trabajamos es que el profesor desde su contexto laboral, desde su análisis propio, pueda aplicar los contenidos que uno da en el curso. No son lineamientos como antes que eran lineamientos fijos y estandarizados. Hoy lo único que uno hace es un abanico de didácticas para que el profesor que, por ejemplo, trabaja en una escuela privada, donde tiene gimnasio cerrado con cancha, material didáctico, que tiene toda la infraestructura necesaria pueda aplicar los conocimientos en función del contenido didáctico, y que el profesor que a lo mejor trabaja en un contexto en una villa de emergencia, que tenga que trabajar en piso de tierra, pueda contextualizar tomando esos contenidos que uno le da, acomodarlo a su contexto y bajar una didáctica específica para esos grupos" (Profesor E)

El fragmento de la entrevista coincide con una perspectiva que toma las necesidades de los alumnos, que retoma el contexto desde una mirada situada de la enseñanza, que coincide con los cambios en las políticas de capacitación (Vezub, 2010) donde la construcción de la formación y de la profesionalización se asocia a una reflexión sobre las propias prácticas. En general las capacitaciones que tienen una vinculación directa 
con la práctica son muy valoradas por los docentes, como se advierte en el siguiente fragmento:

"para los que trabajamos en media, tenés un grupo que por ejemplo a mi me pasó, tiene un nivel de vóley muy alto, maneja el deporte y no te alcanza con lo que tenés. $O$ momentos en los que estás dirigiendo un partido, te perdés y decís ¿Ay, qué estoy cobrando? Con algunos grupos sentís que te faltan apuntalamientos tácticos. Ahí que las capacitaciones de deportes te sirven, que son muy útiles" (Profesor C)

“...las deportes ayudan mucho con lo que es el trabajo con el deporte por eso atraen, porque están a cargo de gente que está en el tema específicamente en un deporte determinado, además hay modificaciones continuamente de los reglamentos, por ejemplo a mi me paso llevar grupos con otra profe a un torneo de handball jugando con la defensa sin posibilidad de tomar al contrario como era antes sin saber que eso se había modificado y enfrentar a otro grupo que juega con esa regla y es un motivo de discordia." (Profesor C)

Tardif (2004) advierte que los profesores producen o intentan producir saberes mediante los cuales comprendan y dominen su práctica, los saberes de la experiencia permiten a los profesores distanciarse de aquellos adquiridos fuera de esa práctica, los profesores priorizan los saberes que califican como prácticos o de la experiencia. Es decir que la práctica permite una evaluación y un reordenamiento del resto de los saberes que resultan útiles para definir perspectivas de formación.

\subsubsection{La valoración de la formación inicial respecto a las necesidades de capacitación}

Es importante advertir que la valoración de la formación inicial sufre cambios en las distintas etapas del ciclo vital. Así, al principio de la carrera docente el manejo de los contenidos y la disciplina de los alumnos constituyen las principales preocupaciones (Sikes, 1985 citado en García, 1995).

"vos salís de la facultad con el titulo y después en la práctica no es lo mismo. Y lo que te dicen todos y lo que me pasó a mi es que aprendés después en la 
práctica, y es así por más que vos hagas práctica previa. Yo creo que no es lo mismo porque tenés menos carga horaria.

El tema es en los deportes que no practicaste. Por ejemplo, cuando doy hándbol los pibes saben más las reglas que yo, y como yo me estoy capacitando en otras áreas no me pongo a leer el reglamento de hándbol, por ahí es un error mío, pero lo que pasa es que si no, no te da el tiempo para capacitarte." (Profesor A)

Que manejo del contenido y la preocupación disciplina de los alumnos sean cuestiones valoradas al principio de la socialización laboral (Garcia, 1995), incide en que los docentes pretendan fortalecer los saberes que dan en sus clases pero no son único aspecto que orienta la formación. En la relación entre el momento en que se cursó la formación inicial y la cantidad de clases del deporte específico, se advierten cambios que impactan en la necesidad de capacitación:

...nosotros cursábamos Hándbol, por ejemplo, todos los deportes los cursábamos dos años, teníamos Hándbol I y Hándbol II, Vóley I y Vóley II. Tenías dos años por deporte y tenías promedio de 20, 25 clases al año de cada deporte, o sea tenías entre 50 y 60 clases, en total para Vóley, y hoy tienen 14, veían con más profundidad al deporte. Hoy el profesor que dicta Hándbol en la universidad tiene que hacer malabares para en 14 clases desarrollar el deporte, eso en cuanto a la especificidad del deporte. (Profesor E).

Además de la cantidad de clases del deporte específico en la formación inicial es importante considerar la necesidad de actualizar la formación. Algo que exige la práctica docente.

Existe una transición de los perfiles de formación dominantes a los emergentes (Gómez, 2006) marcada por dos aspectos. En primer lugar por la ampliación de la una agenda de temas y problemas característicos de los nuevos tiempos, cuya atención permite la evolución y el mejoramiento de las relaciones sociales y culturales y la superación de la disciplina; se incluyen la promoción del disfrute lúdico, el interés activo por el medio ambiente, la relación entre género y educación, multiculturalismo entre otros. En segundo lugar, por cambios en los modos abordaje de estas temáticas que incluyen el dialogo reflexivo, crítico y democrático, consideran que las técnicas y metodologías así 
como el saber acerca de los contenidos disciplinares se implementan en función de la significatividad local.

El aumento y consecuente diversificación de los saberes disciplinares en el curriculum de la formación de Profesorado de Educación Física redujo el tiempo destinado al desarrollo de contenidos específicos, lo que impacta en las necesidades de formación de quienes se inician.

Los docentes con más antigüedad, egresados en las décadas de 1970 y 1980, que tuvieron una experiencia de formación inicial cercana a los modelos de gestión curricular centrados en la enseñanza curricular y a modelos de gestión pedagógica con un marcado componente tecnológico comportamental, valorizan la seguridad que ese tipo de saber proveniente de esos modelos le otorgaron al inicio de la carrera.

Así se pueden distinguir dos momentos respecto de la necesidad de formación: el que se da al inicio que coincide con el "shock de realidad" (Veeman 1988 citado en Serra 2004) donde se marca que la formación recibida en el profesorado no les alcanzó para enfrentar la realidad; y otro que tiene que ver con que los conocimientos que recibieron que se volvieron insuficientes o habían quedado obsoletos.

\subsubsection{El vínculo entre vivencias deportivas y la elección de los contenidos para especializarse.}

Considerar la relación de los sujetos con el saber, implica advertir que las vivencias socio-corporales pueden incidir para que algunos saberes se prioricen y otros se resignifiquen. Es decir, que aportan sentido a la elección en distintos momentos y contextos. En este sentido, la formación no se construye por acumulación (de cursos, de conocimientos o técnicas, sino a través de un trabajo reflexivo y crítico sobre la base de prácticas de reconstrucción permanente de una identidad personal. Para ello, es importante encontrar espacios de interacción entre las dimensiones personales y profesionales, permitiendo a los profesores apropiarse de sus procesos de formación y darles un sentido acorde a sus historias de vida (Figueiredo, 2004).

Al indagar si las experiencias sociocorporales de los docentes orientan en la elección de la oferta de capacitación, y si es así cómo lo hacen, se pueden advertir múltiples respuestas:

"Dentro de lo que es la especialidad deportiva me orienté por el hándbol, de hecho, yo juego desde que era chico, después segui jugando hasta los 22 años, 
después hice un curso de entrenador nacional, de árbitro de la Federación Metropolitana, y estuve como técnico de Estudiantes durante 10 años. Paralelamente a eso yo siempre me capacité en educación para el sistema educativo, al trabajar en el sistema educativo siempre recurrí a los perfeccionamientos, que se hicieran a través del Centro de Investigación Educativa, después las capacitaciones que se hacían en las escuelas.

En las escuelas doy hándbol como iniciación deportiva, ya en $4^{\circ}$ grado de la primaria, hasta $6^{\circ}$ grado, de iniciación al deporte, donde los juegos deportivos los tomamos como estrategia didáctica, y a partir del secundario arrancamos con el deporte propiamente dicho" (Profesor E)

“...de chica viví mucho la colonia, los juegos, y eso me marcó. Mi padre estaba enfermo y algunos veranos no podíamos salir así que me mandaban a la colonia. Ahí viví el deporte más asociado al juego, y después mi primeras experiencias laborales estuvieron en la colonia" (Profesor C)

Estos docentes marcan la preferencia por un determinado deporte o por el juego desde sus vivencias personales mas allá de la formación inicial, vale decir que en algunos casos estas vivencias condicionan la valoración de los contenidos en la carrera, y aportan sentido a las elecciones que los docentes realizan para capacitarse en el desarrollo de su profesionalidad.

Para otros profesores el hecho de poseer determinadas vivencias deportivas no implica una especialización para la práctica, sino incluso todo lo contrario, una desjerarquización de la materia respecto al valor del saber curricular, al sentido del saber tiene para las futuras generaciones (Tardif, 2004)

"de chico yo practiqué fútbol, y hoy por hoy es algo que trato de evitar cuando doy clases, que es algo que todos chicos te piden, por el hecho de que es algo que pueden practicar en cualquier lugar: en la plaza, en muchos clubes. Me parece que la escuela no es el ámbito para jugar al fútbol, porque creo que se desvaloriza la materia." (Profesor B)

Los sentidos que imprimen las experiencias corporales pueden incidir en la elección de la oferta de capacitación, pero hay que advertir que esto no responde a un proceso 
lineal. Existen múltiples condicionantes que pueden cambiar la valoración que los docentes tienen de sus prácticas motrices, la interacción con factores asociados al saber docente, los saberes de la formación profesional, disciplinares, curriculares y de la experiencia (Tardif, 2004) pueden ejercer cambios en los sentidos del saber con los cuales los docentes se identifican (Charlot, 2000).

\subsection{La incidencia del formato de la oferta en la elección de la capacitación}

En la valoración de formatos inciden: aspectos objetivos vinculados a las posibilidades temporales y materiales; y aspectos subjetivos, asociados al carácter situado de las propuestas, y al carácter epistemológico del contenido en relación con el formato.

La oferta de capacitación se constituye principalmente por los siguientes formatos:

Curso: Es el dispositivo de capacitación preponderante en el marco de las reformas educativas. Su función es comunicar cambios y/o actualizaciones respecto de un tipo de saber. En general solían tener un marcado carácter instrumental alejado de las características de los contextos particulares de trabajo. Diker y Serra (2008) señalan que dada la dificultad que el sistema educativo tiene para otorgar puntos a otras modalidades formativas se sigue sosteniendo esta modalidad pese a su baja eficacia, ya que permite a los docentes cumplir con el requisito formal de la capacitación. Aunque hay que advertir que en los últimos años se produjeron modificaciones dentro del formato que lo acercan a una perspectiva situada vinculada al trabajo colaborativo en la escuela.

Taller y/o clínica deportiva: son las actividades centradas en la puesta en común o discusión de la práctica realizada por los cursantes, donde los docentes participan activamente exponiendo sus experiencias. Ejemplo: ateneos, presentación de situaciones de aprendizaje.

Orden técnico: es una instancia de capacitación vinculada a la carrera docente en el sistema educativo de la provincia de Buenos Aires, tiene por objeto garantizar el acceso a la información vinculada a los concursos docentes para acceder a cargos de mayor jerarquía. Básicamente informa sobre la dinámica de evaluación que se lleva adelante en los concursos para los distintos cargos a los que forman parte del escalafón docente ejemplo secretario, vice director y director de un servicio educativo, inspector, secretario de inspección.

Seminario: Es una opción muy presente en la formación que brindan las carreras de posgrado. Son las actividades referidas a una temática puntual, cuyo objetivo es discutir sobre avances de una disciplina o aportes de resultados de investigaciones. 
Carreras de grado: son las carreras que permiten la obtención del "titulo de grado" en la Argentina tienen una duración de entre 4 y 5 años. La titulación permite acreditar un puntaje de base para la carrera docente, el promedio de calificaciones de titulo también suma. Hacer una segunda carrera de grado vinculada a la docencia suma puntaje, pero es una opción a largo plazo frente a la posibilidad que brindan los cursos que en menos tiempo permiten acumular puntos.

Carreras de posgrado: son los estudios universitarios posteriores al título de grado, abarcan especializaciones, maestrías y doctorados. En la mayoría de los casos no otorgan puntaje y se adaptan más a la gente que trabaja en la universidad, lo que marcaría una diferencia entre circuitos de formación docente continua.

\subsubsection{Los formatos y las posibilidades de capacitación}

El formato de la capacitación ya sea como curso, seminario, carrera u otra modalidad incide en la elección, ya que se vincula el momento particular de la vida de los docentes, a los tiempos disponibles, y en ocasiones a los costos. El hecho de que la mayoría de la capacitación no sea en servicio implica un esfuerzo de los agentes para acomodarse a la oferta y al mismo tiempo una adecuación de la oferta a las posibilidades reales de capacitación. Así respecto al tiempo disponible para la capacitación una docente señala:

"En algún punto las actividades semi presenciales de la provincia fueron un poco básicas y redundantes respecto a las actividades ya que se podía realizar planificaciones y es algo que realizo en el año, lo bueno era que eran tiempos cortos 3 hs en interacción con otros colegas.

La maestría tiene un punto a favor que se cursa una vez al mes pero muchas horas juntas, lo que hace que te pierdas un poco con los temas y en la interacción con los compañeros a los que ves solo una vez al mes. Pero por otro lado te permite organizarte en relación a la dinámica familiar." (Profesor $\mathrm{C}$ )

En relación al carácter presencial, semipresencial o a distancia de la capacitación y la elección, si bien entre el 2007 y 2009 la mayoría de la oferta generada por los oferentes $\operatorname{consultados}^{31}$ era presencial y semi presencial, mientras que la oferta a distancia se

31 La responsable de Cultura del SUTEBA La Plata, la responsable de Cultura del SUTEBA La Plata, la responsable de Extensión y Capacitación de la FHCE de la UNLP., la responsable de la Dirección de Educación Física de la Provincia de Buenos Aires., capacitadora del área en CIE La Plata e 
concentraba principalmente en los oferentes privados, es preciso aclarar que la mayoría de los oferentes estaba llevando a cabo acciones para incluir actividades a distancia.

Aunque los docentes entrevistados llevaron adelante acciones de capacitación semi presenciales y algunos a distancia, la valoración más positiva se manifiesta para las opciones presenciales:

"a mí las que más me gustan son las presenciales, que es donde uno más aprende. Además nosotros elegimos la profesión porque nos gusta jugar también. Por ahí a través de Internet hacer un curso es totalmente diferente porque es puramente intelectual. Cuando vos lo practicás tenés otro recuerdo motor de lo que estás haciendo" (Profesor D)

En este punto es preciso hacer una reflexión sobre el carácter epistemológico del contenido, los saberes prácticos que refieren a la didáctica de la enseñanza del juego, la gimnasia y los deportes, de modo que como advierte Charlot:

"existen relaciones epistémicas con el saber (las cuales son antes relaciones epistémicas con el aprender)." (2000: 69) En este sentido "aprender" puede ser dominar una actividad, y ese domino se inscribe en el cuerpo (Charlot, 2000)

Así la vivencia corporal de algunos saberes, se presenta como la mejor vía para aprenderlos, mientras que otros saberes con distinto carácter epistemológico (saberes propios del ámbito de la teoría del entrenamiento deportivo, de la reflexión pedagógica, de la relación con los contextos de enseñanza) no son solo abordados por los formatos presenciales sino que se constituyen como una opción factible de ser tratada a través de formatos semi presenciales y distancia.

“...las capacitaciones a distancias están más orientadas hacia una temática... obviamente que es teórico, la convivencia, la violencia en la escuela, el lenguaje expresivo del docente con el alumno, son otras temáticas que bueno prácticas no podes tener." (Profesor D)

inspectora de Educación física en el distrito, el Director del Instituto Educativo CESALP, el cual constituye un referente de la oferta privada de capacitación en el distrito. 
La relación que se plantea con este tipo de saberes es distinta por las características epistemológicas del contenido, pero en la elección se constituyen como una posibilidad que se adecua a los tiempos disponibles y necesidades de formación.

De modo que respecto de algunos saberes ligados a la vivencia de prácticas corporales y deportivas, el carácter de la capacitación (presencial, semi presencial o a distancia) condiciona el abordaje del contenido y la elección de la capacitación.

\subsubsection{Los cambios en los formatos de capacitación y las demandas de los docentes}

Las reformas de la década de 1990 buscaron acrecentar el control sobre el trabajo docente. Se incluyó a los docentes como meros destinatarios receptores, sin participación en ninguna de las etapas de la formulación del proyecto. La selección de los temas y contenidos de la capacitación se efectuó a nivel de la cabecera nacional, sobre la base de definición de diversos especialistas de cada área, lo que marcó un papel subordinado para los docentes (Diker y Serra, 2008; Feldfeber, 2000; Diaz Barriga e Inclán Espinosa, 2001)

El formato "curso" se consolidó como el hegemónico (Serra, 2004), lo que fortaleció el carácter individual de la capacitación y dejó poco espacio para el desarrollo de formatos centrados en el trabajo colaborativo de los docentes en la escuela (Diker y Serra, 2008) A partir de los cambios que plantea la Ley Nacional de Educación que incluyen una "visión integral de la capacitación" y la perspectiva del "desarrollo profesional" se puede observar que los distintos oferentes adecuaron los formatos de capacitación al carácter situado de las demandas. Lo cual implicó un cambio hacia nuevos modos en la forma de definir los contenidos y los dispositivos de la formación continua, a partir de la construcción de problemas y la identificación y priorización de las necesidades de los profesores y las escuelas.

"en la capacitación en el 2000 había una demanda de receta. Era como que el profe estaba muy estructurado. Estaba esa demanda de esperar que vos le dieras la cátedra", hoy esto no es así, ni desde la demanda ni tampoco desde la metodología, desde donde lo que se trata es de borrar esa noción, por ejemplo en la capacitación para deporte escolar se partió de cuáles son los problemas que se presentan a la hora de enseñar el deporte en la escuela"... "se trata de barrer con la idea del experto que imparte los conocimientos a los asistentes" (Referente I) 
"Hay una evolución en las demandas de los docentes. Antes hasta mediados de los noventa el pedido clásico era la búsqueda de recetas, de metodologías para abordar los contenidos. Esto no es así, hay un vuelco sobre las categorías de análisis de los contenidos. Sobre conocer el contenido para desarrollar formas particulares de enseñarlo, no se plantea una búsqueda de recetas, está la idea de reflexionar sobre los contenidos incluso si el contenido es una metodología.

Por lo cual hoy ya no dice “¿qué querés?, mirá los alumnos que tengo”, sino que hay una preocupación, un interés que hace que el planteo de la demanda pase por entender a sus alumnos y colocar la responsabilidad sobre ellos mismos. " (Referente III)

Los fragmentos de las entrevistas a los referentes de la capacitación, marcan que generan propuestas cuyas temáticas están directamente asociadas a problemáticas del trabajo en la escuela. Es posible advertir que el carácter participativo y situado de la capacitación está en relación a la efectividad de la misma, aumentando el consenso de quienes asisten. El acento está puesto en la vinculación de la teoría con la práctica.

Para atender a la valoración de la capacitación respecto al carácter variado de los contenidos y metodologías, cabe detenerse en las características del Congreso de Educación Física y Ciencias que la UNLP organiza a través de la $\mathrm{FaHCE}^{32}$. Aunque no son gratuitos, estos eventos constituyen una oferta de capacitación en servicio, que no otorga puntaje, a la cual asisten muchos de los docentes que trabajan en el sistema educativo. Es una actividad que marca el vínculo de la universidad, más particularmente del Profesorado de Educación Física, con la comunidad educativa. Además que cuenta con una valoración positiva de los docentes por el carácter variado de la propuesta que permite elegir capacitarse entre diversas temáticas vinculadas con la práctica docente:

"A mí me gustó, por ejemplo, en el congreso de Educación Física (en referencia al Congreso del año 2009, organizado por la UNLP) que te daban tanto la parte

32 Estos eventos se organizan cada dos años, de acuerdo al periodo abordado en esta tesis se consideran: el VII Congreso Argentino y II Latinoamericano de Educación Física y Ciencias en agosto de 2007 y el VIII Congreso Argentino y III Latinoamericano de Educación Física y Ciencias en mayo de 2009. 
teórica como la parte práctica. Ahí vos elegís de qué participar, había varias opciones y vos podías optar por algunas, y suponete, yo elegi la parte de handball, entonces viene un árbitro de handball y te explica la reglamentación teórica y una vez que termina te mandan con Mara Torres, un profesor que es técnico de una selección nacional que tiene mucha experiencia y eso que te dieron te lo pasa en una parte práctica, y efectiva, que lo veas, que lo hagas, y eso me parece muy completo." (Profesor B)

Al mismo tiempo brinda la posibilidad de conocer otras perspectivas para la formación continua:

"en las distintas exposiciones en la oferta del Congreso vi que estaba presentada el área de investigación en distintas temáticas que no había solo cuestiones referidas a la enseñanza práctica, sino que se podía empezar a conocer, a saber de los temas desde otra óptica más profunda como es la investigación. Entonces pensé en la maestría y por otra parte con esto de trabajar en tantas escuelas me hacía el tiempo para trabajar, planificar y pensar la práctica, pero no para actualizarme, pensar la parte teórica y revisar otros conceptos, ver las modificaciones que había tenido lo que yo había estudiado en mi formación inicial, tener una mirada más profunda de tener la oportunidad de poder pensar las cosas de otra manera. Yo estoy en ejercicio, no voy a cambiar la realidad pero por lo menos voy a pensar la realidad de otra manera. Tomarme este tiempo para pensar, para leer, para debatir, por lo menos es la intención que yo tengo al hacerla. (Profesor C)

El Congreso permite a los docentes visualizar otras perspectivas para su formación, que acompañan el tránsito de los perfiles dominantes a los perfiles emergentes tanto respecto en los modelos de gestión curricular (Gómez, 2006, 2007) de las instituciones formadoras, como respecto de la organización y el dictado de cada asignatura con la presencia de un modelo de gestión curricular centrado en la investigación.

El carácter participativo y situado de los formatos de capacitación facilita otros modos de circulación del saber: "uno siempre aprende cosas nuevas...no solamente aprendés 
con el que da el curso, sino con el propio compañero en una charla casual hay muchas veces un intercambio..." (Profesor $\mathrm{D})$

Además del carácter situado e integral de los formatos, de los costos económicos, y del tiempo disponible destinado a la capacitación, otro aspecto importante a considerar en la elección es el nivel de exigencia que los profesores están dispuestos a sobrellevar.

"La de la provincia para mí, es muy personal lo que voy a decir, para mi tendría que exigir un poco más, es más llevadera, los tiempos de la entrega se acuerdan con flexibilidad, en cambio yo en la facultad me tengo que volver a sentar a estudiar y a me parece, ya te digo es muy personal lo que digo. Creo que lo que brinda la provincia esta bueno y que si exigiría un poco mas daría mejores resultados y la posibilidad de generar cambios en el trabajo.

Y lo de la universidad es otra óptica. La provincia se centra en la práctica y sugiere la lectura del sustento teórico que fundamenta esa práctica pero no te lo exige." (Profesor C)

Aunque la lógica de la acreditación parece indicar cuánta exigencia está dispuesto un docente a sobrellevar, hay que advertir que los oferentes con mayor legitimación simbólica, diversifican su oferta y desarrollan distintos formatos acorde a las distintas posibilidades de elección en términos de tiempo y costos.

Delinear una estrategia de capacitación desde la lógica de la profesionalización implica que tenga algún impacto en la práctica. No sucede lo mismo cuando se analiza la elección solo desde la lógica puntaje, porque si bien puede tener una vinculación con la práctica, el hecho de que se adecue a las reglas del campo de la capacitación, pone a la profesionalización en un lugar difuso.

Que triunfe la lógica del puntaje en la política pública de capacitación provincial, no implica que se desconsidere la profesionalización que es algo muy valorado en las elecciones de los docentes, pero no ocupa un lugar central. Los cambios en los formatos que presentan una perspectiva más situada buscan fortalecer el impacto en la práctica, al adecuar los niveles de exigencia ajustándolos a la disposición de tiempo los capitales disponibles. 
3.4.3. La vinculación entre la capacitación y la carrera docente ¿desde qué oferentes?

Quienes deciden concursar para acceder a cargos jerárquicos trazan distintas estrategias que pueden incluir la preparación individual o en grupo con colegas, la búsqueda de capacitación a través del gremio y la preparación mediante de los cursos que suelen ofrecer en forma privada quienes ya desempeñaron esos cargos.

Es preciso destacar que la Ley Nacional de Educación (2006) y la Ley Provincial de Educación (2007) explicitan el vínculo entre capacitación y carrera docente, lo cual constituye una novedad respecto a su antecedente, la Ley Federal (1993). Esto implicó que para el caso del distrito de La Plata, antes de cada concurso se lleve a cabo una jornada de capacitación brindando consulta e información para los aspirantes a cargo desde la Dirección General de Cultura y Educación.

Una de las opciones de quienes deciden presentarse a concurso es la preparación individual o en grupo con colegas:

"Entrevistado: En su momento rendí una vez para vice-director de una escuela Entrevistador: ¿Y para ese concurso hiciste o tuviste alguna capacitación? Entrevistado: No. Estudie, me preparé con unos compañeros" (Profesor D)

"Entrevistado: yo ya concurse para inspectora hace un par de años...

Entrevistador: ¿Recibiste o hiciste alguna capacitación para prepararte para el concurso?

Entrevistado: No estudie con otros dos profes que también se presentaron" (Profesor C)

Respecto a la opción que constituyen los gremios, cabe destacar que si bien se abocan a tratar distintos temáticas, son un referente de la capacitación en las cuestiones vinculadas a los cambios en el trabajo y la carrera docente. En este sentido la posibilidad de avanzar en carrera docente implica estatutariamente concursar por los cargos. Para poder hacerlo se requieren por lo menos 5 años de antigüedad. Otro aspecto importante vinculado al trabajo y la carrera docente, es el momento del ciclo vital en el que se encuentran los profesores. Estos aspectos aparecen reflejados en lo que señala la entrevistada: 
"En media muchos docentes de educación fisica particularmente buscan actividades de capacitación vinculadas a los concursos para los cargos jerárquicos. Es gente con varios años de antigüedad. Es gente que tiene en general más de 40 años. " (Referente II)

Acorde con lo que expone la referente del gremio, de los docentes entrevistados quienes se presentan a concurso poseen más de quince años de antigüedad. En esta línea se puede advertir en las entrevistas que los docentes con menos de 15 años de antigüedad ven a futuro la opción de concursar:

-“¿crees que vas a querer seguir estando siempre frente a grupo o en algún momento crees que vas a querer cambiar de función?

- No, yo creo que por lo menos concursar para otra función seguro..." (Profesor B)

-“ ¿te verías en el futuro ocupando otros puestos dentro del sistema?

- Estoy esperando llegar a los 5 años de antigüedad para poder concursar como secretario o algún otro cargo dentro del sistema." (Profesor A)

Por último existe otra opción que está representada por oferentes privados individuales (personas que ya concursaron y ejercen o ejercieron cargos jerárquicos) que ofrecen sus saberes:

“...al poco tiempo" (año 2007) "una profe me llama y me dice ¿no querés venir?, vamos a hacer un curso a Monte Grande, un curso de capacitación para inspectores..."

- ¿y el curso lo daba la provincia?

-No, lo daba una inspectora de esa región

- ¿era privado el curso?

-Sí, era privado. Eran unos cursos que preparaban al futuro inspector ... estaba muy bueno en el sentido de que la persona que lo daba no se guardaba nada" (Profesor D) 
La posibilidad de concursar se visualiza en la mayoría de las entrevistas, es una opción que está asociada a los tiempos que marca el Estatuto Docente y también a la edad, aunque no todos los profesores tienen esta proyección.

Capacitarse para competir en los concursos, implica organizarse individualmente o con otros colegas y elegir la capacitación de un determinado circuito que incluye como oferentes a los gremios y los cursos privados que brindan quienes ejercieron el cargo. Las acciones de capacitación para concursar no dan puntaje, aunque si el docente que concursa, aprueba, la posibilidad de elegir entre las vacantes para cargo se organiza a partir de la calificación en el concurso, el puntaje y la antigüedad, por lo cual indirectamente la lógica del puntaje no desaparece.

\subsection{La incidencia del contenido y los oferentes}

"los contenidos que elegís para capacitarte, tienen que ver con lo que hablamos respecto de lo que te mueve a hacer los cursos... en distintas épocas y en distintos contextos con lo que uno fue viviendo desde que empecé a trabajar a ahora." (Profesor D)

Los cambios en el interés, van acompañados de distintas las estrategias de búsqueda acorde al oferente adecuado, ya sea al que se constituye como un referente de determinada temática y/o al que brinda el puntaje.

En este punto cabe hacer una distinción entre los cursos que brindan los oferentes privados, la provincia, los gremios y los que brinda la universidad y la oferta de las carreras de grado y posgrado.

Si bien muchas de las opciones de capacitación en los distintos niveles pueden ser elegidas en vinculación directa al trabajo en la escuela, otras opciones que requieren más inversión de tiempo y esfuerzo estarían asociadas a la posibilidad de desarrollo laboral en otros ámbitos (Curso de guardavidas, Posgrado en rehabilitación, Maestría, otras carreras de grado).

Estos cursos y carreras cuya elección no está asociada principalmente al puntaje se constituyen como una posibilidad de diversificar las posibilidades laborales. En los docentes entrevistados que eligen o eligieron estas opciones, se advierte que si bien permiten una proyección hacia otros contextos laborales, en su práctica vinculan los saberes de esa formación indirectamente con el trabajo en la escuela, pero están en 
desventaja respecto de la oferta forjada bajo la lógica del puntaje, de la cual todos los entrevistados señalan que la profundidad en términos de exigencia y de tratamiento de los contenidos es menor.

Otro aspecto a considerar es el hecho de que la política educativa a través de la Dirección General de Cultura y Educación prescribe cuales son las áreas prioritarias del saber que le interesa promover. La resolución 3817/07 establece que: "resulta necesario dar a conocer los problemas y núcleos temáticos que servirán de base para orientar las diferentes propuestas de capacitación de las instituciones oferentes". La evaluación de las propuestas que realiza la Dirección de Capacitación de la Provincia, teniendo en cuenta estas orientaciones para el otorgamiento de puntaje. Así de la presencia de determinados contenidos se deriva la asignación de puntaje que condiciona la elección. $\mathrm{Al}$ respecto uno de los referentes de la capacitación del distrito señala:

"hasta el 2004 nuestra oferta tenia puntaje pero a partir de ese año la provincia nos sacó el puntaje, considerando que la salud y los deportes no son áreas prioritarias"... "el hecho de haber perdido el puntaje incidió en la matrícula los cursos pasaron de tener 30 personas a 15, además vienen preguntan por los cursos, tienen interés por las temáticas pero cuando se aclara que no dan puntaje se retiran" (Referente V)

Cabe señalar que la oferta que el CESALP ofreció entre el 2007 y 2009 incluyó cursos de: entrenador personal, instructor de natación, rehabilitación por el ejercicio, colonia de vacaciones y actividad física adaptada, la cual no se constituye como un contenido directamente orientado a la escuela pero que encuentra puntos de encuentro y utilidad. Es importante advertir que igualmente esta institución sigue ofreciendo cursos y aunque los mismos no otorguen puntaje, continúan sosteniendo la oferta porque tienen demanda, aunque no se constituye como una oferta pensada para el trabajo en la escuela, el acento esta puesto en la salud y en la recreación para ámbitos distintos al escolar, cabe destacar que una parte del cuerpo docente de esta institución está vinculado al profesorado de la UNLP, en especial en las disciplinas vinculadas al saber médico. 
Así, aunque algunos oferentes tienen una oferta diversa de contenidos, éstos se constituyen como referentes de determinadas temáticas que direccionan las estrategias de búsqueda y elección de la capacitación.

\subsubsection{El prestigio del oferente y su incidencia en la elección}

El prestigio del oferente constituye un aspecto importante en la elección. Si bien existe una amplia oferta de cursos que otorgan puntaje que en su mayoría es privada, la valoración que los sujetos hacen en la elección está asociada inicialmente al acceso al trabajo, pero no son el único interés que motiva la capacitación. Sucede que los sujetos suelen combinar la adquisición de estos cursos con otro tipo de formación de la cual rescatan el respaldo del oferente y la contribución de la formación permanente para la profesionalización. Así en algunas elecciones, asociadas a la proyección laboral en otros campos se marcan el prestigio del oferente en la estrategia de formación (por ejemplo Medicina UBA, Posgrado en rehabilitación UCA, Curso de Guardavidas Cruz Roja, Maestría en Educación Corporal UNLP).

"hice un solo curso de esos arancelados, que se ofrecen en las escuelas y en secretaria de inspección. Pero que era un chiste porque tenía que poner si- no, si-no en el examen, después el trabajo práctico me lo pasaron las respuestas, no solamente a mí sino que se lo pasaban todos" (Profesor A)

A partir de la Ley Nacional de Educación (2006), el puntaje fue un recurso para ponderar las acciones de capacitación que el Estado genera por sobre el resto de la oferta. Esto garantiza el derecho a la capacitación, pero continúa sin jerarquizar la oferta en base al prestigio del oferente.

Los cambios que plantea la normativa son justos, pero continúan atados a la lógica del puntaje. No se adecuan a las transformaciones en la oferta de la formación continua marcados por la ampliación de la oferta de posgrado, donde la elección se asocia al prestigio del oferente, a su legitimidad respecto de los saberes que trasmite.

\subsubsection{La difusión de la oferta, las fuentes de información}

Los comunicados de las capacitaciones que organiza la provincia a través CIIE, llegan a los docentes y escuelas por medio de cadenas de e-mail que difunden los inspectores, además en el cuaderno de comunicados de cada institución se notifica a los docentes de 
estas capacitaciones y de las que organiza la universidad a través de las actividades de extensión, como así también los congresos de educación física. Otro aspecto a considerar es la incidencia del grupo de pares mediante el "boca a boca". En el caso de los oferentes privados, difunden su oferta en los espacios estratégicos, principalmente en los lugares donde se realiza la designación de cargo y en la puerta de las escuelas. Allí se ubican quienes promueven esta oferta para repartir sus folletos o exhibir sus carteles. Estas se presentan como las fuentes de información más recurrentes que los docentes tienen para elegir.

"Pero también pasa que los cursos se hacen por los comentarios o porque alguno va y te comenta, el boca en boca de los cursos" (Profesor A)

"Los de vocación docente son los primeros que hice hace unos cuantos años ya, y ahora en los últimos 2, 3 años los de educap que son los que primero se cruzaron, vino el flaco a la escuela a ofrecerlos y el puntaje que ofrecían era bueno y me pareció interesante." (Profesor B)

Cabe señalar que no hay un calendario de la oferta que llegue a las escuelas con anticipación. La difusión no está centralizada, no hay una fuente de información que concentre los datos, y que facilite a los docentes organizar los tiempos destinados a la capacitación. Lo que deriva en situaciones como la que se advierte en el relato de esta docente:

"Me quedé con ganas... me entere tarde. Viste que ahora están dando uno de educación física para media, pero cuando pasé por el CIIE para averiguar ya estaba cerrado, después ya era tarde." (Profesor C)

Sin dudas uno de los eventos con mayor difusión es el Congreso de Educación Física organizado por la FaHCE de la UNLP, el cual que representa un evento académico con gran poder de convocatoria. De hecho en la mayoría de los entrevistados lo consideran como un espacio enriquecedor que se ajusta a sus demandas y a los diversos intereses de los docentes. Otro factor importante a considerar es que se ajusta al régimen de licencias para capacitación prevista en el Estatuto del Docente de la provincia de Buenos Aires. 
En este caso, el prestigio del oferente incide en la difusión de este evento, como el hecho de estar convocado por la institución formadora más representativa del distrito, en la cual cursaron su carrera la mayoría de los profesores que trabajan en la región. Lo cual representa para muchos la posibilidad de volver a la institución de formación inicial, como un elemento identitario de la relación con el saber.

"tiene mucha difusión, siempre que lo hacen te enterás. Igual la mayoría de los que lo hacen, lo hacen para poder faltar una semana a la escuela ... La verdad lo digo por lo que hablo, porque además está bastante salado, no sé cuanto esté este año. Pero este año por ahí lo hago, porque me acuerdo que la última vez que estuvo yo no lo hice, por la guita más que nada, y esa semana no fue nadie a la escuela, después me puse a sacar cuentas de lo que gasto yendo de una escuela a la otra y esa guita me la gastaba en nafta, pero igual no lo voy a hacer solamente por eso, porque me llegó varios mail de la facultad, con mesas sobre rehabilitación de salud de lo que me gusta a mí y voy a elegir las que más me interese así que capaz que lo hago este año." (Profesor A)

Más allá del prestigio del oferente, el hecho de que el congreso implique el no cómputo de inasistencias para los docentes que trabajan en la provincia, colabora con la difusión. Al mismo tiempo hay que destacar que este evento consolida el vínculo entre la universidad y la comunidad educativa, y se constituye como un espacio de encuentro entre los profesores por fuera de la estructura de la Dirección General de Cultura y Educación. .

\subsection{Las instituciones y el grupo de pares}

3.6.1. La institución escolar. El vínculo entre las instituciones y las posibilidades de capacitación de los docentes

Se puede advertir que algunos deportes parecen estar instalados en la escuela, de modo que algunas instituciones se identifican con determinadas prácticas:

En este sentido es posible suponer la incidencia de diversos factores:

-El gusto particular y la intención de los profesores que orienta la enseñanza, hacia las prácticas de determinados deportes y no otros. Los docentes entrevistados que se 
especializaron en algún deporte en particular los llevan a las escuelas desde sus prácticas de enseñanza, la compra de materiales y la conformación de equipos de trabajo -El hecho de que la formación inicial y capacitación en general remita a determinadas prácticas y no a otras.

-El peso de la responsabilidad civil sobre los profesores y directivos de las escuelas que orienta las prácticas hacia determinadas actividades en las que se evita el contacto físico y se reducen las posibilidades de accidentes en clase.

"siempre todos los cursos que he hecho relacionados con deporte, por cuestiones también de violencia y por los accidentes el voley está bueno porque vos tenías una red y no había contacto con el otro" (Profesor D)

-Las características del espacio disponible para las clases de educación física, la disponibilidad de los espacios también ejerce influencia sobre lo que los docentes pretenden enseñar y sobre lo que deciden capacitarse

"Suponete en la técnica " $X$ ", que tiene un patiecito muy chico, los chicos ya están acostumbrados a que de primero a quinto o sexto a que terminan es vóley, porque no hay otra cosa, es cemento, es un cuadrado justo, donde lo que entra es una cancha de vóley pared, pared, no hay otra cosa, entonces es vóley, vóley y vóley, y ahí no podes elegir otra cosa, es como que esta impuesto."

"vos llegás a una escuela, como suplente, como provisional, como titular lo que sea, y ya tienen impuesto que ahí se da vóley. Entonces está bien aceptás no tenés problema porque ahí se practica vóley porque les gusta o por el espacio. Pero eso de jugar vóley todo el año también te implica capacitarte en vóley, porque ¿Qué vas a hacer? ¿le vas a hacer, partidito todo el año? Eso es lo mismo que jugar a la pelota de futbol, es exactamente lo mismo. Entonces si el chico empieza primer año y sale en sexto sabiendo exactamente lo mismo es porque no le diste un carajo, en seis años no le diste nada.

Entonces viene primer año empieza, segundo año va mejorando, tercero va mejorando, llega un cuarto año donde ya tenés que darle más fundamentos técnicos, o jugadas de ataque jugadas de defensa, ya te metes más profundo. Te obliga a capacitarte en el deporte que tenés que darle." (Profesor B) 
Otro aspecto a considerar es la mirada las instituciones tienen respecto de las posibilidades de formación de los docentes:

"no soy de faltar, pero por ahí falto porque tengo un examen, pero y lo tengo justificado, y me hicieron la cruz ya de entrada mal, y el otro día con la secretaria casi me peleo. Le digo mira la semana que viene no voy a venir y me empieza a criticar porque no voy, pero mal, asi que le dije mira yo te estoy justificando aparte te estoy avisando con tiempo, le digo sacá las horas a acto público, si no voy a venir una semana pueden salir a acto público. Viste tenes que entrar en el roce, está bien tengo once escuelas me pasa en una o en dos, en las otras no te hacen problemas pero esa parte no me gusta, me gustaría no tener problemas con nadie."

$O$ sea que te quiero decir con esto, vos te querés seguir capacitando y se te complica." (Profesor A)

Que los docentes asistan o participen de la capacitación, así como que hagan uso de las licencias por pre examen y examen cuando cursan una carrera o rinden examen en un concurso, son acciones reguladas por el Estatuto del Docente. Pero hay que advertir que aunque la capacitación legitima la tarea docente no siempre se lo entiende de esta forma, porque estas licencias suelen alterar la dinámica de las instituciones e implican un trabajo extra de cobertura de cargos que en ocasiones implican roces.

\subsubsection{El grupo de pares y su incidencia en la elección.}

Los docentes entrevistados comparten en su mayoría, el tiempo y espacio laboral con otros colegas en las instituciones que trabajan. Son pocas las oportunidades en que disponen para su clase de todo el espacio y el material de la escuela destinado al área de educación física. Esta situación motiva instancias de trabajo compartido en la que se llevan a cabo torneos internos y actividades gimnásticas compartidas, las cuales conforman un importante espacio de circulación de información que implica la difusión de la oferta de capacitación, al mismo tiempo pueden constituirse como un espacio para pensar el trabajo en equipo dentro de las instituciones.

A esta situación hay que sumar la fragmentación del trabajo y el tipo de designación que llevan al docente a trabajar en varias instituciones ya que si es suplente o provisional no tiene una continuidad asegurada en el cargo, lo que atenta contra la implicación del 
docente en la institución y reduce las posibilidades de proyectar el trabajo en forma colectiva (Devincenzi, 2002), y de pensar una estrategia de capacitación colectiva por lo cual se refuerza el carácter individual de la capacitación.

\subsection{Conclusiones}

De acuerdo al análisis de las entrevistas es posible advertir que en principio las estrategias en la elección de la oferta de capacitación responden a:

1) Aspectos vinculados la lógica del puntaje, la cual se impone desde las reglas que regulan el campo de la capacitación en la relación "ilusio, capital, campo" (Serra 2004). 2) Los intereses individuales asociados al carácter identitario individual del saber, que inciden en la valoración de determinado tipo de saberes, que su vez ubican a los sujetos con distintas competencias y en distintas posiciones en el campo laboral.

Además se advierten una serie de particularidades en elección de la oferta de capacitación en los profesores de educación física, vinculadas a:

a) Las características epistemológicas del saber: las capacitaciones que revisten un mayor interés para los docentes son los que permiten la vivencia corporal del saber y se asocian de manera directa a la práctica, es decir a la participación en juegos y actividades vinculadas a la enseñanza de la gimnasia y deporte. Las características de este tipo de propuestas de formación continua marcan el carácter social de saber, se distancian de las del rasgo individual que poseen otros formatos de capacitación (Diker y Serra, 2008).

b) Los saberes instalados en las instituciones: el gusto por individual o la preferencia hacia la enseñanza determinados deportes por parte los profesores es un rasgo del vínculo identitario con el saber que se traslada hacia los espacios de trabajo, implica que se instale en las instituciones una dinámica de trabajo alrededor de ese deporte que deriva en la compra de material, el acondicionamiento de los espacios de trabajo.

Una vez que la práctica de un deporte específico está instalada en la institución, existen mayores posibilidades de que traccione a que los profesores que se incorporan a trabajar en la escuela a organizar sus clases en torno de los mismos saberes, lo que podría derivar en la organización equipos de trabajo para la participación en torneos o encuentros deportivos, y a la necesidad de un tipo de capacitación específica que permita proyectar en función de los distintos niveles de complejidad que se aborden en las clases. 
c) La incidencia de las características de los espacios de trabajo: los patios y gimnasios que tiene las escuelas secundarias no son un espacio estándar ni uniforme, presentan muchas variaciones respecto de las dimensiones y de las condiciones de seguridad que ofrecen, esto genera las condiciones para que puedan practicarse algunos deportes y otros no. De modo que actúan como otra variable que permite instalar determinados saberes en las instituciones.

\section{Bibliografía}

Charlot, B. (2000). Da relação com o saber: elementos para uma teoria. Porto Alegre: Artes Médicas Sul.

Davini M. C. (1995). La formación docente en cuestión: política y pedagogía. Buenos Aires. Paidós.

Devincenzi, D. (2002). "Ser maestro en una escuela pública: una mirada institucional". En De Cristóforis, M. (Comp.) Historias de inicios y desafios. El primer trabajo docente. Buenos Aires: Paidós, p. $45-59$.

Díaz Barriga, A. e Inclán Espinosa C. (2001). "El docente en las reformas educativas: sujeto ejecutor de proyectos ajenos", en Revista Iberoamericana de Educación, n ${ }^{\circ} 25$, p. 17 - 41, enero- abril.

Diker, G. y Serra, J. C. (2008). La cuestión docente. Argentina: las políticas de capacitación docente. Buenos Aires: Fundación Laboratorio de Políticas Públicas.

Dubet, F. (2010). "Crisis de la transmisión y declive de la institución", en Revista Política y Sociedad, v. 47, nº. 2, p. $15-25$.

Feldfeber, M. (2000). "Una transformación sin consenso: apuntes sobre la política educativa del gobierno de Menem”, en Versiones, $\mathrm{n}^{\circ} 11$, p. 8 - 20.

Ferreira Borges C. M. (1998). O professor de Educação Física e a construção do saber. Campinas: Papirus Editora.

Figueiredo, Z. C. C. (2004). "Experiencia docente en Educación Física experiencias sociales y la relación con el saber", en: Movimento, Revista da escuela de Educación Física Porto Alegre, v.10, nº 1, p. 89 - 111, janeiro/abril.

Garcia M. (1995). Formação de Professores. Para uma mudança educativa. Portugal: Porto Editora. 
Gómez R. H. (2006). “¿Cómo se enseña a los que enseñan? Perfil dominante y perfil emergente en la formación docente en la Educación fisica Hispanoamericana", en: Actas del Congreso Repensar la Educación Física. Córdoba: IPEF.

Gomez, R. H. (2007). Perfil dominante y perfil emergente en la formación docente en Educación Física, en: Actas del Congreso Internacional de Educación Física - IPEF. Córdoba: UNC.

IIPE (2000). Los docentes y los desafios de la profesionalización. Informe Final. Buenos Aires.

Tardif, M. (2004). Los saberes del docente y su desarrollo profesional. Madrid: Narcea.

Vezub, L. F. (2010). El desarrollo profesional docente centrado en la escuela: concepciones, políticas y experiencias. - $1^{\mathrm{a}}$ ed- Buenos Aires, IIPE- Unesco.

Villa, A. I. (1997). Lógicas y discursos en la formación docente: en el caso del Profesorado Universitario de Educación Física de la Universidad Nacional de La Plata, en: Actas de las II Jornadas La Universidad como objeto de investigación. Buenos Aires: Centro de Altos Estudios - UBA. 


\section{CONCLUSIONES}

El objetivo de esta tesis es analizar la elección de la oferta de capacitación pública y privada en los docentes de Educación Física que se desempeñan en escuelas secundarias del distrito de La Plata, durante los años 2007 a 2009. Para ello, las siguientes preguntas guiaron el análisis del trabajo de investigación:

¿Qué lugar ocupan los saberes de los docentes dentro de las políticas de capacitación? Y ¿Qué sentido/s tiene una acción de capacitación para quien la realiza? ¿Cuáles son los aspectos que inciden en la elección?

¿En qué medida el cambio en el puntaje impulsado por la provincia en el 2008 incide en la elección de los docentes? ¿Cómo impacta este cambio en las relaciones de los docentes con el saber?

El abordaje recobra la incidencia de la antigüedad docente, el ciclo vital de los profesores, la normativa sobre la carrera docente y el trabajo docente, la estructura de capacitación provincial y la valoración de los oferentes, las características de la formación inicial y la práctica recurrente de determinados deportes en instituciones de enseñanza secundaria.

En este marco, la intención de este capítulo de conclusiones es dar cuenta de en qué medida se pudo dar respuesta a estas preguntas, presentar reflexiones y tensiones e interrogantes que se desprenden del proceso de investigación.

\section{La valorización del saber docente en las políticas de capacitación}

Es posible advertir variaciones en la valoración del saber docente que se expresan en las transformaciones de las políticas de formación docente continua. Al respecto, Tardif advierte que el saber docente es un saber desvalorizado, frente al campo intelectual y de recontextualización oficial" : "los saberes de la formación profesional y los saberes curriculares de los profesores parecen siempre ser más o menos de segunda mano”. En este sentido, continúa "la función docente se define en relación a los saberes, pero

\footnotetext{
33 Serra (2004) define al campo de la capacitación como un subcampo dentro de la recontextualización oficial, dado que los discursos y las prácticas que se asocian a la capacitación articulan producciones del campo intelectual de la educación, nacional e internacional, con sus respectivas recontextualizaciones nacionales e internacionales, que constituyen una forma particular de entender la capacitación en la Argentina.
} 
parece incapaz de definir un saber producido y controlado por los que la ejercen" (40; 2002)

Esta afirmación se sostiene, desde la concepción del saber de los docentes que se instala a partir de la conformación del programa institucional moderno, que advierte que la necesidad de un saber técnico en la formación docente y en la capacitación fue moldeando una gramática de la escolaridad, que vincula la capacitación con la obtención de "recetas" de enseñanza provenientes del saber experto.

La aparición de los expertos y el surgimiento de la formación universitaria en 1953 a través de la creación del Profesorado de Educación Física en la UNLP se dan en el marco de la división de los campos de la educación, lo que acompaña y consolida la separación entre los productores de conocimiento y quienes lo aplican.

Las reformas de los años '60 en el marco del desarrollismo y de los '90 en el contexto neoliberal acentuaron estas características, y se basaron casi exclusivamente en las necesidades de las administraciones educativas, limitando la autonomía de la formación docente continua que vinculó la oferta casi íntegramente a las reformas curriculares y estructurales.

Se advierte que además del campo de recontextualización oficial existe el campo de recontextualización pedagógica, con relativa autonomía respecto a la autoridad política y del control del Estado (Serra, 2004), donde entran en juego las decisiones del hacer pedagógico de los profesores que pueden o no alinearse con los lineamientos. ${ }^{34}$ Frente a estas políticas es posible pensar que la cultura escolar posibilitó la reinterpretación de los contenidos de la capacitación por parte de los docentes, es decir la adecuación de los mismos a los contextos particulares que le permiten diseñar estrategias de enseñanza desde su propia relación con el saber. En este marco la presencia del saber docente en el campo de recontextualizacion pedagógica empieza a ser reconocida y pasa de tener un lugar devaluado a un lugar preponderante, a través de las políticas de formación docente continua que atienden a la profesionalización y a una visión integral de la formación permanente.

En este sentido hay que señalar un cambio en la evolución los modelos y la agenda de las políticas de capacitación en Latinoamérica que son la contracara de lo que plantea Tardif. En lugar de centrarse casi íntegramente en las necesidades de las

\footnotetext{
$34 \quad$ Hay que advertir que no toda la oferta de capacitación que generan los gremios, universidades y oferentes privados se ajusta a las normativas incluso hay una parte de la oferta que no posee valor de puntaje
} 
administraciones educativas, buscan "impulsar una serie de iniciativas diversas arraigadas en la escala de lo local, en las situaciones especificas que viven los docentes, en los problemas de enseñanza reales, en las prácticas cotidianas y en los modos particulares de hacer escuela" $(10 ; 2009)$ lo cual implica un acercamiento en la relación entre los distintos campos de la educación (intelectual, pedagógico, de recontextualización oficial).

En las elecciones que los docentes realizan sobre la oferta de capacitación, el vínculo con la práctica es un aspecto muy valorado por los docentes, los cambios recientes en las políticas de capacitación que instalan una perspectiva situada en la relación con el saber vuelven la percepción de la oferta más atractiva, que al mismo tiempo brindan la posibilidad de generar una mayor implicación en quienes la eligen.

\section{El triunfo de la lógica del puntaje sobre la lógica de la acreditación}

Aunque la política de capacitación provincial se sostenga en conceptos como "desarrollo profesional" y "educación integral" expresados en la Ley de Educación Nacional (2006), es posible reconocer que la lógica del puntaje estaría definiendo las elecciones de capacitación de los profesionales.

En este sentido, las lógicas de formación se reconstruyen desde dos planos. Por un lado, en el plano de las representaciones, los agentes del campo de la capacitación (tanto referentes como docentes), perciben que los cambios que ha impulsado la provincia en el 2008 son justos y ya que conciben la formación continua como un derecho y reposicionan a los docentes en la construcción de las distintas estrategias individuales de capacitación.

Por otro lado, en el plano de las características de las elecciones y acciones de los profesionales en Educación Física, respecto de su formación, la "carrera por el puntaje" constituye una marca en la gramática de la escolaridad que se estableció y consolidó a través del vínculo entre capacitación y carrera docente previsto por el Estatuto el cual implicó una lógica de "credencialismo meritocrático" para el acceso y permanencia en los puestos de trabajo, que no se estaría relacionando necesariamente con la idea de formación "como derecho". En general, se observa una preponderancia de la participación en el circuito organizado principalmente alrededor del formato de curso que satisface la necesidad de puntaje en el corto plazo, mientras que otras opciones de formación que incluyen otros formatos no son inicialmente consideradas por los 
docentes como una fuente formación rápidamente acreditable y que redunde en mejores posicionamiento en el corto plazo.

Más bien, los profesores reconocen que la formación en otros formatos demanda un esfuerzo muy grande en términos de inversión de capital y ligan la posibilidad de obtener el puntaje después de un tiempo prolongado. No obstante, ambas ofertas conviven, aunque en diferente medida, y son elegidas; en algunos casos, por un mismo docente.

De esta manera, con una mirada en ambos planos, es posible inferir que los cambios que plantea la normativa son justos, pero continúa existiendo distancia entre ambas lógicas forjada por la separación entre los distintos campos del saber académico, profesional, escolar, al cual contribuyó al desarrollo de un mercado de la capacitación que se consolidó través de la implementación de la RFFDC que empieza a perder fuerza a partir de los cambios suscitados en el 2008.

\section{La capacitación y las particularidades del saber en Educación Física}

Diker y Serra (2010) señalan que la capacitación es individual, que no contempla el trabajo en conjunto de los docentes ni la dimensión institucional. Es preciso advertir un rasgo diferencial respecto de lo que señalan estos autores en referencia a los saberes curriculares de la materia Educación Física. El hecho de que la competencia y los encuentros deportivos formen parte de la curricula de materia en la escuela secundaria, motiva la elección de capacitaciones en deporte como contenido en dos sentidos: por un lado, porque implica la posibilidad de contactarse con otros docentes para organizar encuentros deportivos más allá de los que plantea el municipio y la Dirección de Deportes de la provincia. Por otro lado, porque permite actualizarse respecto de las variaciones en los reglamentos de cada deporte.

Así es posible establecer una relación entre el trabajo de profesor de educación física y la necesidad de capacitación, que explica la elevada asistencia a actividades de capacitación de los docentes del área que marcan los referentes de capacitación provincial entrevistados.

Otro aspecto a resaltar refiere a las características del contenido y la valoración de la metodología de las capacitaciones vinculadas a la práctica. En este sentido la vivencia corporal de algunos saberes se presenta como la mejor vía para aprenderlos porque implica un recuerdo motor, en algunos casos la posibilidad de vivenciar y compartir los saberes, de comparar distintas formas de enseñarlo que exceden la metodología clásica: 
escuchar al experto que también se reconoce como necesaria y valiosa siempre y cuando se vincule con la práctica.

En este sentido mas allá del campo particular de la capacitación en educación física los referentes de la capacitación del distrito señalan un cambio respecto a la política de capacitación hegemónica de los '90 que en un marco de descredito del saber docente, apuntalaban la actualización curricular y se abocaban a la didáctica del contenido. La política actual pone acento en la vinculación con la práctica y la perspectiva del desarrollo profesional, las propuestas que se generan desde esta perspectiva señalan que se trata de "borrar con la idea del experto que viene a dar cátedra" al mismo tiempo marcan que las demandas de los docentes están puestas en la necesidad de entender a los alumnos con quienes trabajan colocando la responsabilidad sobre sí mismos alejándose de la postura que culpabiliza a los alumnos. Estos cambios acompañan las mutaciones en el programa institucional (Dubet, 2004) distanciándose de la percepción de un sujeto pedagógico rígido. La elección de la capacitación sigue estos cambios que resignifican los saberes desde los propios espacios de trabajo.

\section{Los formatos, los circuitos y los destinatarios}

Las propuestas de formación docente se asientan en circuitos socio - formativos y estos circuitos están definidos por determinados perfiles y determinadas trayectorias de los profesionales en educación física.

Entre lo académico y lo práctico, si bien la oferta que genera la universidad con el Congreso de Educación Física tiene una amplia difusión y aunque no otorgue puntaje, se presenta como capacitación en servicio por lo que prevé el no computo de inasistencias, además del carácter identitario de la institución para quienes cursaron la formación inicial allí y de la legitimidad de la misma para el abordaje de distintas temáticas, hacen que este evento reúna una amplia convocatoria como se advierte en las entrevistas. Más allá de esto se constituye como una oferta de formación continua que difunde otros formatos como las maestrías que se dictan en la misma UNLP. En este sentido vale aclarar que son formatos diferentes respecto de la adecuación a los destinatarios, uno se adecua fuertemente a las características y necesidades de los docentes que trabajan en las escuelas, el otro si bien concentra las horas hace adecuación débil porque son los docentes que eligen estas opciones quienes deben adecuarse a las características del formato académico que es el que poseen las ofertas de posgrado. 
Más allá que la Universidad tenga a través del Congreso en Educación Física y de las actividades de extensión un vinculo estrecho con quienes trabajan en las escuelas, la división entre el campo académico y el campo profesional marca una tensión, de hecho es posible pensar que las maestrías conservan características excluyentes que restringen su oferta adecuándola a determinados perfiles y trayectorias académicas. Con lo cual, el campo de la formación docente de los profesionales en Educación Física se constituye de dos lógicas diferenciadas, por un lado, una lógica académica ofrecida por la Universidad y por otro, una lógica mercantil, acumulativa y condicionante para el ingreso al campo profesional. Se trata de una constitución del campo de la capacitación donde la formación continua aún no encuentra un espacio institucional.

Para finalizar, es preciso reconocer que esta tesis aborda un campo dinámico que está en permanente cambio a partir de las definiciones de la política educativa. Por eso, haber abordado un periodo acotado como el de 2007 - 2009 permite analizar un momento del campo en el que la interacción entre elecciones y política presentó una configuración particular. Los cambios en las políticas son importantes, pero también es importante su interacción con el resto de los factores considerados en esta tesis.

\section{Bibliografía}

Diker, G. y Serra, J. C. (2008). La cuestión docente. Argentina: las políticas de capacitación docente. Buenos Aires: Fundación Laboratorio de Políticas Públicas.

Dubet, F. (2004). “'Mutaciones institucionales y/o neoliberalismo?” En: Tenti Fanfani, E. (Org.) Gobernabilidad de los sistemas educativos en América Latina. Buenos Aires: IIPE, pp. 15-44.

Serra, J. C. (2004). El campo de la capacitación docente. Políticas y tensiones en el desarrollo profesional. Buenos Aires: FLACSO - Miño y Dávila.

Tardif, M. (2002). Los saberes del docente y su desarrollo profesional. Madrid: Narcea. 